\title{
New and Novel Fracture Stimulation Technologies for the Revitalization of Existing Gas Storage Wells:
}

\author{
Final Report
}

An R\&D Demonstration Program Sponsored By:

U.S. Department of Energy, National Energy Technology Laboratory

Contract No. DE-AC21-94MC31112

and co-funded by:

Gas Research Institute

Contract No. 5097-270-4057

Performed By:

Advanced Resources International, Inc.

with Cooperative Research Partners:

CNG Transmission Corporation

Columbia Gas Transmission Corporation

Consumers Energy Company

East Ohio Gas Company (a CNG company)

KN Energy Incorporated (now Kinder Morgan, Inc.)

MichCon Gas Company

National Fuel Gas Supply Corporation

Natural Gas Pipeline Company (now Kinder Morgan, Inc.)

December 1999 


\section{CONTRACTOR DISCLAIMER}

The material in this Report is intended for general information only. Any use of this material in relation to any specific application should be based on independent examination and verification of its unrestricted applicability for such use and on a determination of suitability for the application by professionally qualified personnel. No license under any Advanced Resources International, Inc., patents or other proprietary interest is implied by the publication of this Report. Those making use of or relying upon the material assume all risks and liability arising from such use or reliance. 


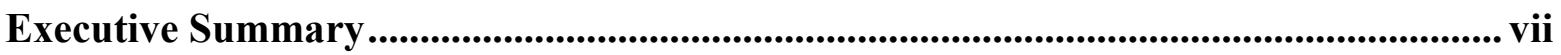

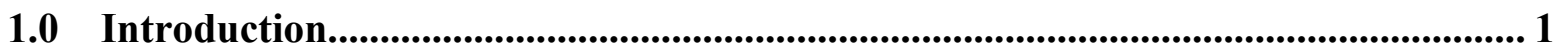

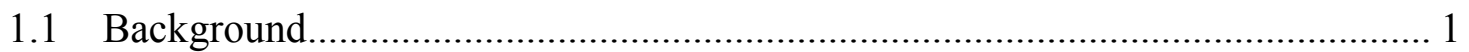

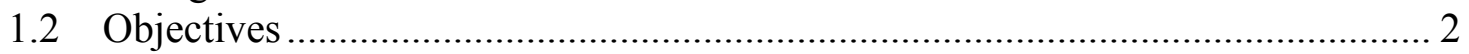

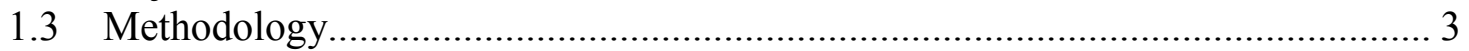

2.0 Description of New and Novel Fracture Stimulation Technologies ........................ 5

2.1 Considerations for Fracture Stimulation in Gas Storage Wells............................ 5

2.2 Classifications of Various Fracturing Processes ......................................... 6

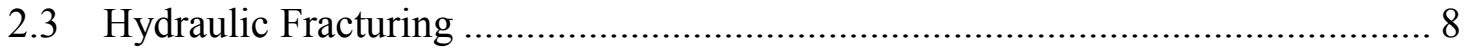

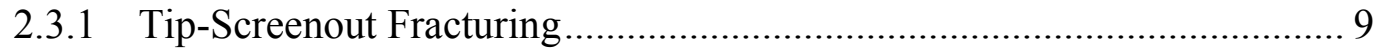

2.3.2 Liquid $\mathrm{CO}_{2}$ with Proppant Fracturing......................................... 10

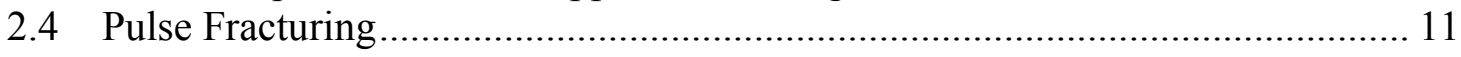

2.4.1 Extreme Overbalance Fracturing ....................................................... 11

2.4.2 High-Energy Gas Fracturing............................................................ 12

3.0 Test Site Results ........................................................................................ 14

3.1 Deliverability and Pressure Transient Testing Program.................................... 14

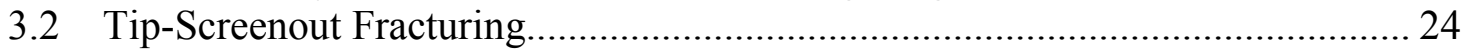

3.3 Liquid $\mathrm{CO}_{2}$ with Proppant Fracturing ........................................................ 28

3.4 Pulse Fracturing ..................................................................................... 35

4.0 Economic Assessment of Deliverability Enhancement............................................ 43

4.1 Current Evaluation Approaches and Limitations ........................................ 43

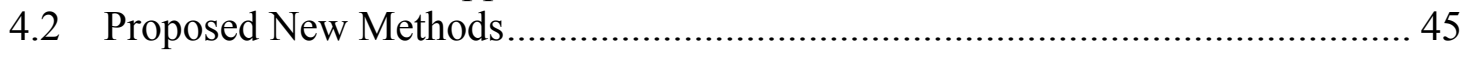

4.2.1 Cost/Benefit Analysis for Deliverability Maintenance.......................... 46

4.2.2 Economic Evaluation of Storage Asset Upgrading .............................. 47

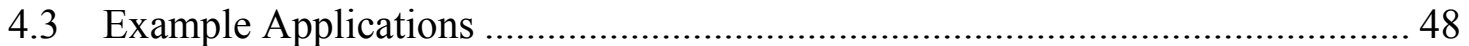

4.3.1 Tip-Screenout Fracturing vs. Wellbore Cleanouts ............................... 48

4.3.2 Liquid $\mathrm{CO}_{2}$ with Proppant Fracturing vs. Conventional Gelled-Water

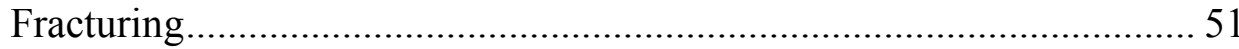

4.3.3 Economic Assessment of a Storage Facility Upgrade .......................... 54

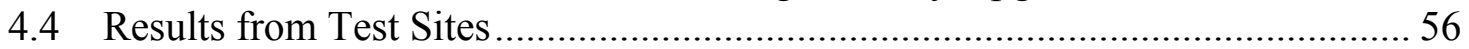

5.0 Guidelines for the Practical Application of New and Novel Fracture Stimulation

Technologies ............................................................................................................................... 58

5.1 Fracturing as a Stimulation Option.............................................................. 58

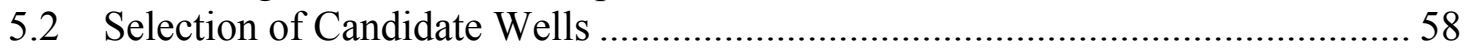

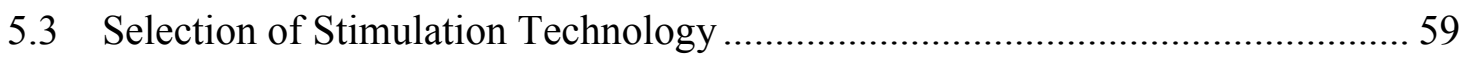

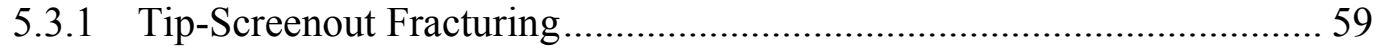

5.3.2 Liquid $\mathrm{CO}_{2}$ with Proppant Fracturing.............................................. 59

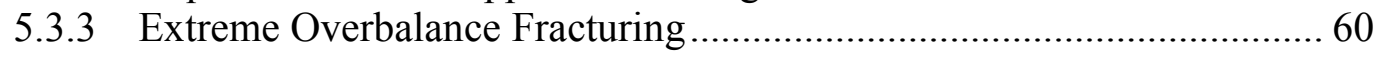

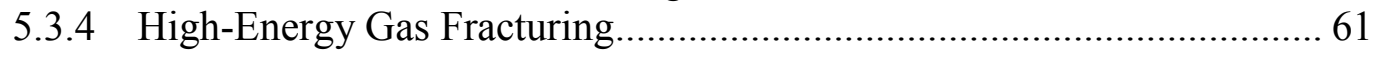


6.0 Technology Transfer and Fracturing Activity Surveys .......................................... 62

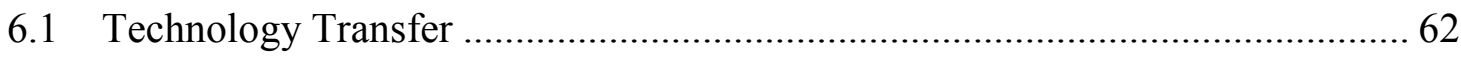

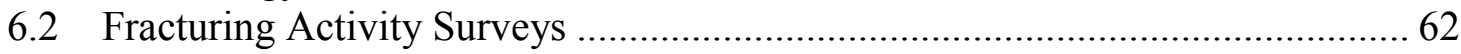

7.0 Conclusions and Recommendations....................................................................66

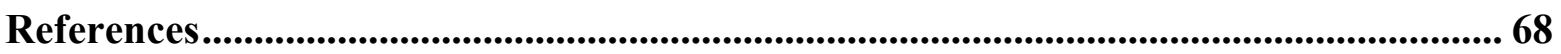




\section{List of Figures}

Figure 1-1: Key Elements of Project Technical Approach................................................ 4

Figure 2-1: Comparative Illustration of Energy Application Rates for Various Fracture Stimulation Methods ...................................................................... 7

Figure 2-2: Comparative Illustration of Resulting Fracture Patterns for Various

Fracture Stimulation Methods .................................................................... 7

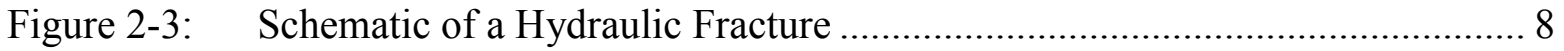

Figure 2-4: Top View of a Tip-Screenout …………….............................................. 9

Figure 2-5: Sequence of a Tip-Screenout Fracture Treatment ......................................... 10

Figure 2-6: Hydraulic vs. EOB Fracture Initiation Profiles ............................................. 12

Figure 3-1: Location of Test Sites ........................................................................ 14

Figure 3-2: $\quad$ Example Pressure and Flow Rate Response from a Deliverability and

Pressure Transient Test............................................................................... 19

Figure 3-3: Example Logarithmic Plot for the Final Shut-In Period................................. 20

Figure 3-4: Example Semi-Log Plot for the Final Shut-In Period ..................................... 21

Figure 3-5: Example Deliverability Curve ………….............................................. 22

Figure 3-6: Example Non-Darcy Flow Analysis Plot ..................................................... 23

Figure 3-7: Deliverability Results, Tip-Screenout Treatments ......................................... 25

Figure 3-8: Permeability Results, Tip-Screenout Treatments .......................................... 25

Figure 3-9: Total Skin Results, Tip-Screenout Treatments ................................................ 26

Figure 3-10: Mechanical Skin Results, Tip-Screenout Treatments.................................... 27

Figure 3-11: Non-Darcy Skin Results, Tip-Screenout Treatments ................................... 27

Figure 3-12: Post-Frac Multiple-Isotope Tracer Log, Huntsman 23 .................................. 28

Figure 3-13: Deliverability Results, Liquid $\mathrm{CO}_{2}$ Treatments ............................................ 29

Figure 3-14: Permeability Results, Liquid $\mathrm{CO}_{2}$ Treatments........................................... 30

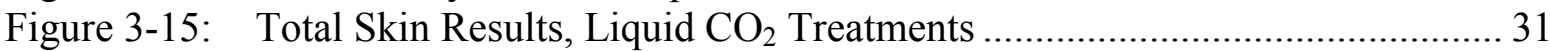

Figure 3-16: Mechanical Skin Results, Liquid $\mathrm{CO}_{2}$ Treatments ...................................... 32

Figure 3-17: Non-Darcy Skin Results, Liquid $\mathrm{CO}_{2}$ Treatments....................................... 32

Figure 3-18: Pre-stimulation Non-Darcy Skin Coefficients, Stark-Summit/

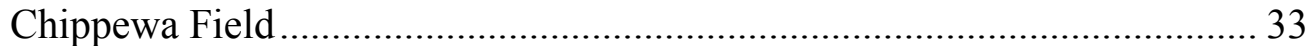

Figure 3-19: East Ohio Gas \#C-1874 Liquid $\mathrm{CO}_{2}$ Frac, Bottomhole Pressure/

Temperature Record ................................................................................... 33

Figure 3-20: $\quad \mathrm{CO}_{2}$ Phase Diagram, Stark-Summit/Chippewa Well \#C-1874........................ 34

Figure 3-21: $\quad \mathrm{CO}_{2}$ Content of Flowback Gas, Galbraith Test Site ..................................... 34

Figure 3-22: Deliverability Results, EOB and HEGF Fracturing Treatments .................... 35

Figure 3-23: Permeability Results, EOB and HEGF Treatments ...................................... 36

Figure 3-24: Total Skin Results, EOB and HEGF Treatments........................................... 37

Figure 3-25: Mechanical Skin Results, EOB and HEGF Treatments ................................ 37

Figure 3-26: Non-Darcy Skin Results, EOB and HEGF Treatments ................................ 38

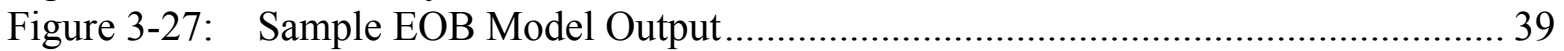


Figure 3-28: EOB Optimization Process ................................................................... 39

Figure 3-29: Downhole Pressure Record of EOB Treatment, Oakford \#103 .................. 40

Figure 3-30: Downhole Pressure Record of HEGF Treatment, Six Lakes \#15 ................ 41

Figure 3-31: $\quad$ Surface Pressure Record of HEGF Treatment, Six Lakes .......................... 41

Figure 4-1: Hypothetical Deliverability History Following a Stimulation Treatment ..... 44

Figure 4-2: $\quad$ Hypothetical Revenue Generation Potential of a Storage Asset vs.

Service Type (fixed working gas volume)............................................... 45

Figure 4-3: Conceptual Illustration of Cost/Benefit Analysis Approach ....................... 46

Figure 4-4: $\quad$ Deliverability Forecasts, Huntsman Field, Nebraska ................................. 50

Figure 4-5: $\quad$ Cost/Benefit Analysis Results, Huntsman Field........................................ 50

Figure 4-6: $\quad$ Deliverability Forecasts, Galbraith Field..................................................... 52

Figure 4-7: $\quad$ Cost/Benefit Analysis Results, Galbraith Field ........................................ 53

Figure 4-8: $\quad$ Deliverability Forecasts with Idealized Conditions, Galbraith Field ........... 54

Figure 4-9: $\quad$ Breakeven Capital Budget to Upgrade a 10 Bcf, 135-day Baseload

Facility to Shorter-Term Service ........................................................... 56

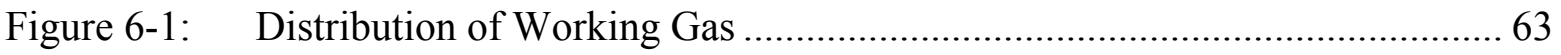

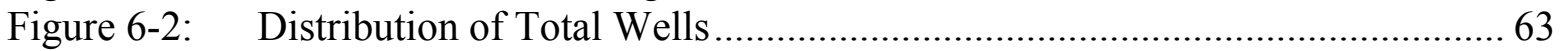




\section{List of Tables}

Table 1-1: $\quad$ Cost/Benefit Ranking of Various Gas Storage Well Deliverability Enhancement Methods (Modified from Reference 2) .................................. 2

Table 1-2: $\quad$ Mix of Reservoir Types and Test Sites........................................................ 3

Table 3-1: $\quad$ Test Site Descriptive Data .................................................................. 15

Table 3-2: $\quad$ Mix of Reservoir Types, Stimulation Technologies and Test Sites ............. 16

Table 3-3: $\quad$ Summary of Field Activities Performed .................................................... 17

Table 4-1: $\quad$ Economic Parameters for Huntsman Field ................................................ 49

Table 4-2: $\quad$ Economic Parameters for Galbraith Field ................................................ 52

Table 4-3: $\quad$ Storage Asset Upgrading Example, Input Parameters................................ 55

Table 4-4: $\quad$ Cost/Benefit Analysis Results for Each Test Site...................................... 57

Table 6-1: $\quad$ Storage Operators that Possess Assets in the Top 20\% of Both

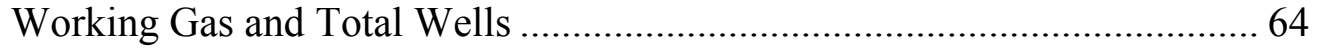

Table 6-2: $\quad$ Storage Operators that Possess Assets in the Top 20\% of Either

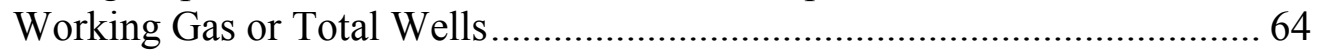

Table 6-3: $\quad$ Summary of Project Technical Articles, Reports and Presentations ............. 65 


\section{Executive Summary}

Gas storage wells are prone to continued deliverability loss at a reported average rate of 5\% per annum (in the U.S.). This is a result of formation damage due to the introduction of foreign materials during gas injection, scale deposition and/or fines mobilization during gas withdrawal, and even the formation and growth of bacteria. As a means to bypass this damage and sustain/enhance well deliverability, several new and novel fracture stimulation technologies were tested in gas storage fields across the U.S. as part of a joint U.S. Department of Energy and Gas Research Institute R\&D program. These new technologies include tip-screenout fracturing, hydraulic fracturing with liquid $\mathrm{CO}_{2}$ and proppant, extreme overbalance fracturing, and high-energy gas fracturing. Each of these technologies in some way address concerns with fracturing on the part of gas storage operators, such as fracture height growth, high permeability formations, and fluid sensitivity.

The project methodology relied predominately on field testing to accomplish the research objectives. Specifically, eleven technology tests were performed (multiple wells each at eight physical test sites), distributed among the storage reservoir types in approximate proportion as their relative share of total storage capacity. Each field test investigated one fracture stimulation technology and consisted of up to four test wells, three in which the new and novel technique was utilized and one control well in which a conventional well enhancement method was implemented as a performance benchmark. The eight sites are located in Illinois, Pennsylvania, Ohio, Michigan, and Nebraska. Tipscreenout fracturing was tested at five sites, liquid $\mathrm{CO}_{2}$ with proppant fracturing at two sites, extreme overbalance fracturing at three sites, and propellant fracturing at one site. In total, 29 new and novel fracture treatments were performed as part of this project, 152 deliverability and pressure transient tests, 28 fracture diagnostics tests (e.g., mini-fracs, steprate tests, bottomhole treating pressure measurements etc.), and 23 fracture height surveys (e.g., radioactive tracer, temperature, downhole camera surveys), among other tests and diagnostics.

Based on the results derived from the project, the following conclusions have been drawn:

- $\quad$ New and novel fracture stimulation technologies can provide attractive deliverability enhancement results while at the same time addressing the special requirements of gas storage wells (e.g., fracture height growth, high permeability formations, fluid sensitivity). Even though fracture stimulation was very successful at several test sites and led to significant improvements in deliverability, not every stimulation treatment was effective. The most consistently effective stimulation technology was tip-screenout hydraulic fracturing. While TSO fracturing was a huge success at the Huntsman Storage Field and while at least one well at every test site had an increase in deliverability, the overall improvements in deliverability at Stark-Summit, Overisel and Donegal Storage Fields were small compared to the expectations for fracture stimulation (real or not). Liquid carbon dioxide with proppant stimulation was very effective at the Galbraith test site but very little improvement was seen at 
the Chippewa test site where there was still evidence of linear flow and slightly negative skin factors from previous fracture stimulations.

- $\quad$ The liquid carbon dioxide with proppant stimulations at the Galbraith Storage Field led to the largest increases in well deliverability, almost seven fold for two of three test wells. Those sites demonstrating extreme overbalanced stimulations experienced a reduction in post-stimulation well deliverability; high-energy gas fracturing was ineffective.

- Gas storage formations appear to be highly sensitive to even small amounts of liquids, which appear to temporarily reduce permeability to gas. Non-aqueous stimulation fluids, such as liquid $\mathrm{CO}_{2}$, seem to provide more immediate stimulation benefits without the prolonged fluid cleanup time typical of aqueous methods.

- Lack of satisfactory understanding of certain stimulation processes, most notably liquid $\mathrm{CO}_{2}$ fracturing and extreme overbalance fracturing, is likely to lead to inconsistent results with these methods in the short run. However, this should not be considered as a problem with the stimulation concept, but rather viewed as a technology need to be met.

- Methods commonly used by industry today to measure and monitor well deliverabilities can frequently be misleading and/or incorrect. More advanced (yet cost-effective) methods are needed such that storage operators can better understand well performance and the impact of various well intervention activities on deliverability and for candidate selection.

- $\quad$ Being able to distinguish between permeability, true skin and non-Darcy skin is critical for candidate selection. It is equally important for treatment selection, as the stimulation requirements for high/low permeability wells and the type of damage (true or non-Darcy) can each be very different.

- A new approach to analyzing the economic benefits of various stimulation technologies is required such that gas storage operators can select the most costeffective deliverability enhancement technique for a given situation.

Significant accomplishments with regard to the research objectives have been achieved, as summarized below:

- The potential application of the various new and novel fracture stimulation technologies to gas storage wells has been demonstrated, and guidelines developed for their selection and design.

- The first liquid $\mathrm{CO}_{2}$ with proppant treatments in gas storage wells were pumped, with deliverability improvements of up to seven-fold. Deliverability improvements achieved for tip-screenouts were as high as 50 MMcfd at mid-season operating conditions. 
- A lack of analytical design tools has been identified for some of the fracture stimulation technologies being investigated. In response, a first-of-a-kind simulator has been developed to model the extreme overbalance fracturing process, and for the first time in the gas storage industry downhole pressure records have been collected for analysis. In addition, the first publicly available bottomhole pressure records for a liquid $\mathrm{CO}_{2}$ with proppant treatment were collected that answered long-standing technical questions about this process.

- A comprehensive dataset of multi-point deliverability and pressure transient tests, a rarity in the gas storage industry, has been assembled. This has provided a unique insight into the impact of stimulation on gas storage well deliverability, particularly with respect to the elimination of important non-Darcy flow effects, deliverability profiles, and how these change over time.

- $\quad$ Two new methods for evaluating the economics of deliverability enhancement in gas storage wells have been developed. The first method can be used to estimate the cost of deliverability maintenance, accounting for the variable deliverability profile of a well. The second can be used to evaluate the economic value added of a storage asset by upgrading it to a shorter term, higher value service (peaking vs. baseload).

The outcomes from this project represent a significant step forward in gas storage well deliverability enhancement technology. Further R\&D is still required, however, in several of the key areas outlined above. 


\subsection{Introduction}

\subsection{Background}

Since the introduction of Federal Energy Regulatory Commission Order 636 in $1992,{ }^{1}$ the fundamental role of the interstate gas transportation business has changed from that of intermediary between producer and consumer, to that of a service provider. Further, because these services are now unbundled and cannot be lumped into the supplier rate base, pipeline companies must now provide each of their services individually and at increasingly competitive prices. Some of these services include gas transportation, market center hub services (e.g., balancing, compression, loaning, parking, peaking, trading, etc.), and gas storage. Gas storage is used for two primary purposes: to meet seasonal winter demands for natural gas (base load storage) and to meet short-term peaks in demand (peaking storage), which can range from a few hours to a few days. For purely peak demand, cavern storage has become increasingly popular because of the extremely high deliverability that can be achieved, albeit only for short periods of time. Baseload storage facilities, for which depleted oil/gas fields are frequently used, can store larger volumes of gas but usually have lesser overall deliverability capacities. Nevertheless, minimum deliverability requirements still exist for baseload storage facilities.

One of the keys to providing baseload gas storage services on a commercially competitive basis today is to minimize the cost of maintaining minimum deliverability requirements for a given storage asset. In a study performed in 1993, the Gas Research Institute (GRI) determined that on average the storage industry loses over 5\% of its deliverability capacity annually from baseload fields ${ }^{2}$. Although the reasons behind the deliverability loss have been the subject of R\&D by GRI and the U.S. Department of Energy (DOE), they traditionally have been attributed to the introduction of foreign materials during gas injection periods (e.g., compressor oils, rust, scale, etc.), and to the deposition of scales and/or fines mobilization during periods of high rate withdrawal, both of which can contribute to near-well damage. More recent R\&D suggests that bacteria plugging may also be important formation damage mechanism in gas storage wells ${ }^{3}$. To counteract the deliverability decline, it has been estimated that industry spends more than U.S. \$100 million annually, two-thirds of which is used to drill new infill wells to supplement older wells that have experienced substantial deliverability decline. While new wells can be used to increase the overall storage capacity of a field if sited appropriately, the stimulation (or restimulation) of existing wells is a considerably more cost-effective approach to maintain deliverability.

Gas storage operators realize this. However, the traditional approaches to deliverability enhancement, namely blowing, washing or mechanically cleaning the wellbore, reperforating, and acidizing, which combined account for over $80 \%$ of all storage well enhancement activity, generally provide only limited and short-term results, not substantial, long-term well stimulation ${ }^{4}$. The previously-cited GRI study identified fracturing as a promising deliverability enhancement technique for gas storage applications, as shown in Table 1-1. However, storage operators have historically avoided such methods due in part to concerns about reservoir seal integrity. Nevertheless, as a result of 
competitive pressures, fracturing in gas storage wells is of increasing interest to storage operators. In response, the DOE (and subsequently GRI) sponsored a joint program with industry to demonstrate the application of new and novel fracture stimulation technologies in gas storage fields across the U.S. The objective of this program was to advance deliverability enhancement technology in the gas storage community to provide more efficient utilization of the country's gas storage assets in response to the growing demand for a widespread, reliable natural gas supply.

\section{Table 1-1: Cost/Benefit Ranking of Various Gas Storage Well Deliverability Enhancement Methods (Modified from Reference 2)}

\begin{tabular}{|c|c|c|c|}
\hline & $\begin{array}{c}\text { Deliverabil } \\
\text { ity } \\
\text { Increase } \\
\left(\frac{\circ}{\circ}\right) \\
\end{array}$ & $\begin{array}{c}\text { Treatment } \\
\text { Cost } \\
(\$ 1,000 \text { 's/we } \\
11) \\
\end{array}$ & $\begin{array}{l}\text { Benefit-to- } \\
\text { Cost Ratio } \\
(\% / \$ 1,000 \text { 's } \\
\text { ) }\end{array}$ \\
\hline Deltapressuring & $70 \%$ & 3.0 & 23.3 \\
\hline Fracturing & $175 \%$ & 27.5 & 6.4 \\
\hline Reperforating & $33 \%$ & 7.0 & 4.7 \\
\hline Blowing & $10 \%$ & 3.0 & 3.3 \\
\hline Mechanical Cleaning & $15 \%$ & 7.5 & 2.0 \\
\hline Acidizing & $20 \%$ & 12.0 & 1.7 \\
\hline Washing & $10 \%$ & 10.5 & 1.0 \\
\hline Horizontal Drilling & $400 \%$ & 434.5 & 0.9 \\
\hline $\begin{array}{l}\text { Tubing/Packer } \\
\text { Replacement }\end{array}$ & $15 \%$ & 37.5 & 0.4 \\
\hline Infill Drilling & $100 \%$ & 293.5 & 0.3 \\
\hline Gravel Pack & $25 \%$ & 100.0 & 0.3 \\
\hline
\end{tabular}

\subsection{Objectives}

Given the historical operator concerns over hydraulic fracturing in gas storage wells, plus the many other unique characteristics and resulting stimulation requirements of gas storage reservoirs (which are described later), the specific objective of this project was to identify new and novel fracture stimulation technologies that directly address these concerns and requirements, and to demonstrate/test their potential application in gas storage wells in various reservoir settings across the country. To compare these new methods to current industry deliverability enhancement norms in a consistent manner, their application was evaluated on a cost per unit of added deliverability basis, using typical non-fracturing well remediation methods as the benchmark and considering both short-term and long-term deliverability enhancement results. Based on the success (or lack thereof) of the various 
fracture stimulation technologies investigated, guidelines for their application, design and implementation have been developed. A final research objective was to effectively deploy the knowledge and experience gained from the project to the gas storage industry at-large.

\subsection{Methodology}

Given the nature of the project, namely that it is a field demonstration project, the methodology was to rely predominately on field testing to accomplish the research objectives. As such, after having first identified those fracturing technologies which appeared to hold promise for application to gas storage wells, a series of field tests were performed for demonstration purposes in various reservoir settings. Specifically, eleven field tests, consisting of multiple wells each, were performed at eight sites, distributed among the storage reservoir types in approximate proportion as their relative share of total storage capacity (Table 1-2). Each test site was used to investigate fracture stimulation technology and consisted of up to four test wells, three in which the new and novel technique was utilized and one control well in which the operators' conventional well enhancement method was implemented as a performance benchmark.

Table 1-1: Mix of Reservoir Types and Test Sites

\begin{tabular}{|c|c|}
\hline $\begin{array}{c}\text { Reservoir Lithology } \\
\text { (\% of working gas) }\end{array}$ & $\begin{array}{c}\text { Number of } \\
\text { Test Sites }\end{array}$ \\
\hline \hline Sandstone (77\%) & 7 \\
\hline Carbonate (23\%) & 1 \\
\hline
\end{tabular}

Each field demonstration project consisted of four key elements: 1) deliverability enhancement evaluation; 2) treatment design and analysis; 3) maintaining caprock integrity; and 4) technology transfer (Figure 1-1). These are each described below.

First, to assess the deliverability enhancement performance of the new versus currently used well treatment methods, pre- and post-treatment deliverability and pressure transient well testing was performed in all test wells, and again one year later to evaluate the sustainability of deliverability enhancement achieved with each approach.

Second, state-of-the-art design tools, such as hydraulic fracturing and pulsefracturing models, were utilized to design the different fracturing treatments to maximize success as well as understanding. 
Figure 1-1: Key Elements of Project Technical Approach

\begin{tabular}{|c|c|c|c|c|}
\hline Element & $\begin{array}{c}\text { Pre- } \\
\text { Fracturing }\end{array}$ & $\begin{array}{l}\text { During } \\
\text { Treatment } \\
\end{array}$ & $\begin{array}{c}\text { Post- } \\
\text { Fracturing }\end{array}$ & Long-Term \\
\hline \multirow{2}{*}{$\begin{array}{c}\text { Deliverability } \\
\text { Enhancement } \\
\text { Evaluation }\end{array}$} & $\begin{array}{c}\text { Deliverability } \\
\text { and Pressure } \\
\text { Transient } \\
\text { Testing }\end{array}$ & & $\begin{array}{c}\text { Deliverability } \\
\text { and Pressure } \\
\text { Transient } \\
\text { Testing }\end{array}$ & $\begin{array}{c}\text { Deliverability } \\
\text { and Pressure } \\
\text { Transient } \\
\text { Testing }\end{array}$ \\
\hline & $\begin{array}{l}\text { Control Well } \\
\text { Benchmarking }\end{array}$ & & $\begin{array}{l}\text { Control Well } \\
\text { Benchmarking }\end{array}$ & \begin{tabular}{|l} 
Control Well \\
Benchmarking
\end{tabular} \\
\hline \multirow{2}{*}{$\begin{array}{l}\text { Treatment } \\
\text { Design and } \\
\text { Analysis }\end{array}$} & $\begin{array}{c}\text { Stress and } \\
\text { Rock Property } \\
\text { Profiling }\end{array}$ & \multirow{2}{*}{$\begin{array}{c}\text { BHTP } \\
\text { Monitoring }\end{array}$} & \multirow{2}{*}{$\begin{array}{l}\text { Fracture } \\
\text { Modeling }\end{array}$} & \\
\hline & $\begin{array}{l}\text { Fracture } \\
\text { Modeling }\end{array}$ & & & \\
\hline \multirow{2}{*}{$\begin{array}{l}\text { Maintain } \\
\text { Caprock } \\
\text { Integrity }\end{array}$} & $\begin{array}{l}\text { Cement } \\
\text { Evaluation } \\
\text { Logging }\end{array}$ & \multirow{2}{*}{$\begin{array}{c}\text { BHTP } \\
\text { Monitoring, } \\
\text { Contingency } \\
\text { Planning }\end{array}$} & $\begin{array}{l}\text { Fracture } \\
\text { Height } \\
\text { Logging }\end{array}$ & \\
\hline & $\begin{array}{l}\text { Fracture } \\
\text { Modeling }\end{array}$ & & $\begin{array}{l}\text { Fracture } \\
\text { Modeling }\end{array}$ & \\
\hline \multirow[t]{2}{*}{$\begin{array}{c}\text { Technology } \\
\text { Transfer }\end{array}$} & $\begin{array}{c}\text { Operator/ARI/ } \\
\text { DOE/GRI Working } \\
\text { Partnerships }\end{array}$ & $\begin{array}{c}\text { Operator/ARI/ } \\
\text { DOE/GRI Working } \\
\text { Partnerships }\end{array}$ & $\begin{array}{c}\text { Operator/ARI/ } \\
\text { DOE/GRI } \\
\text { Working } \\
\text { Partnerships }\end{array}$ & $\begin{array}{c}\text { Operator/ARI/ } \\
\text { DOE/GRI } \\
\text { Working } \\
\text { Partnerships }\end{array}$ \\
\hline & $\begin{array}{l}\text { Technical } \\
\text { Publications } \\
\text { and Reports }\end{array}$ & $\begin{array}{c}\text { Technical } \\
\text { Publications } \\
\text { and Reports }\end{array}$ & $\begin{array}{l}\text { Technical } \\
\text { Publications } \\
\text { and Reports }\end{array}$ & $\begin{array}{l}\text { Technical } \\
\text { Publications } \\
\text { and Reports }\end{array}$ \\
\hline
\end{tabular}

KAO99330.PPT (1)

Third, the project directly addressed operator concern over caprock damage. Utilizing rock property and in-situ stress evaluations to guide fracture modeling at each field test site (when available), an increased understanding of what conditions may lead to caprock damage were obtained. Accordingly, the procedures to minimize or eliminate the potential for damage were prepared for each site. Post-stimulation fracture height measurements were also used in some cases to further verify final fracture geometry.

Finally, the project brought a strong commitment to rapidly transfer the project results to the gas storage industry. This was accomplished through a) intensive operator involvement in the project, from initial planning through final documentation of the results; b) the presentation and publication of results at various symposia, professional meetings and industry publications; and c) the publication of various technical reports. 


\subsection{Description of New and Novel Fracture Stimulation Technologies}

\subsection{Considerations for Fracture Stimulation in Gas Storage Wells}

Gas storage wells have a number of unique characteristics which require attention when considering fracture stimulation. While taken individually, none of these characteristics are necessarily new to the oil and gas producing community, but together they represent an interesting blend of special requirements and associated challenges.

Fracture Height Growth. First and foremost is fracture height growth. Frequently, only limited barriers exist between the storage formation and potential problem zones above and below it. Here, the concern is that the reservoir seal might be compromised by upward or downward fracture height growth, resulting in gas loss. The potential to penetrate waterbearing zones also exists; significant amounts of water influx can reduce or eliminate the potential of a well to contribute to field deliverability and can increase well operating costs. Hence, application of fracturing to gas storage wells should be limited to those approaches, geologic settings or reservoir conditions where fracture height growth can be controlled, or where the practical extent of height growth is not of concern. In most cases, this means limiting the size of the treatment, and performing treatments when the reservoirs are depleted in the summer months (i.e., when a greater stress contrast exists between the storage horizon and the bounding layers to help contain height growth).

High-Permeability Formations. Another important consideration for fracturing gas storage wells is the final fracture properties needed for effective stimulation. Because of high deliverability, one of the principal requirements for a gas storage field, storage reservoir permeabilities are frequently quite high compared with those of the normal domain of (hydraulic) fracturing. A 1993 survey of storage operators suggested that storage field permeabilities ranged from 20 to $>800$ millidarcies (md), ${ }^{2}$ with an average of nearly $300 \mathrm{md}$. The benefit in massively fracturing formations with permeabilities this high is debatable; instead, the use of short, high conductivity fractures to bypass near-well formation damage is more appropriate. This is not unlike the stimulation requirements in the Gulf of Mexico, for example; therefore, techniques applicable to that environment should also be suitable for many gas storage fields. In addition, recent R\&D by GRI and DOE has suggested that formation damage may only extend inches into the formation from the wellbore. ${ }^{3}$ While significantly deeper penetration of formation damage would be expected in naturally fractured formations, fracture lengths of "tens" of feet (rather than "hundreds") should be adequate to bypass damage in most storage reservoirs.

Fluid Sensitivity. A final consideration for storage reservoirs is their susceptibility to formation damage from stimulation (or other) fluids. The process of cycling dry, pipeline-quality gas into and out of storage wells can reduce the near-well area to a very low (or non-existent) water saturation. The re-introduction of fluids into the system can in and of itself be "damaging" because a fluid saturation is re-established, reducing the relative

permeability to gas. This situation can be exacerbated if the injected fluids contain potentially damaging chemicals and/or particulate matter, which might mix and react with already in-place compressor oils, rust, scale, fines, and other such materials, significantly compromising any stimulation benefit of a fracture treatment. Frequently, storage well 
deliverabilities actually decline following a traditional hydraulic fracture treatment, and can take several years to cleanup to the point of meeting or exceeding pre-fracturing deliverability levels, not to mention achieving the deliverability expectations from an undamaged hydraulic fracture. This suggests that gas storage reservoirs can be extremely sensitive to aqueous stimulation fluids, and therefore fracturing treatments must be designed to account for and minimize the impact of this sensitivity.

\subsection{Classifications of Various Fracturing Processes}

Fracture stimulation technologies for enhancing well deliverability can generally be categorized according to the rate at which energy is applied to the target horizon to induce fracturing. As shown in Figures 2-1 and 2-2(a), at one extreme, hydraulic fracturing involves a relatively low rate of loading, resulting in a two-winged vertical fracture extending outward from a well, theoretically $180^{\circ}$ apart and oriented perpendicular to the least principal rock stress. Generally, maximum fracturing pressures will only slightly exceed the minimum in-situ rock stress. Because of the creation of a single (bi-winged) fracture, and the ability to pump large volumes of fluids at relatively low rates, the potential penetration of the fracture lengthwise into the formation can be large, hundreds of feet in many cases.

On the other extreme, Figures 2-1 and 2-2(d), explosive fracturing involves a very rapid loading of the target formation resulting in a highly fractured zone around the wellbore, but usually to a radius not exceeding 10 feet. Because the peak pressures exceed both the minimum and maximum in-situ stresses, fractures in all three dimensions are created, which can be an advantageous fracture geometry when near-wellbore stimulation is the primary objective. Unfortunately, the peak pressures can also exceed the rock yield strength which, when coupled with the high induced compressive stresses in the vicinity of the wellbore, can cause compaction to such a degree that permeability is actually decreased in the near-wellbore region, resulting in a damaged zone.

Between these two extremes is pulse fracturing, Figures 2-1, 2-2(b) and 2-2(c), encompassing both high-energy gas fracturing with propellants (HEGF) and extreme overbalance fracturing (EOB). HEGF is characterized by peak pressures exceeding both the maximum and minimum in-situ stresses (creating a radial fracture pattern), but not to a level that exceeds the rock yield strength, hence avoiding the damage associated with the explosive fracturing approach. This technique results in multiple vertical fractures extending radially from the wellbore, with penetrations on the order of 5 to 20 feet. This technique captures the radial stimulation attribute of an explosive approach, but without the associated damage. The EOB technique strives for a similar end result but, due to the mechanics of the process, the rate of pressurization and the magnitude of pressures achieved are less, and hence the extent of radial fracturing is less. In some cases radial fracturing may not be achieved and only bi-winged fractures created. 
Figure 2-1: Comparative Illustration of Energy Application Rates for Various Fracture Stimulation Methods

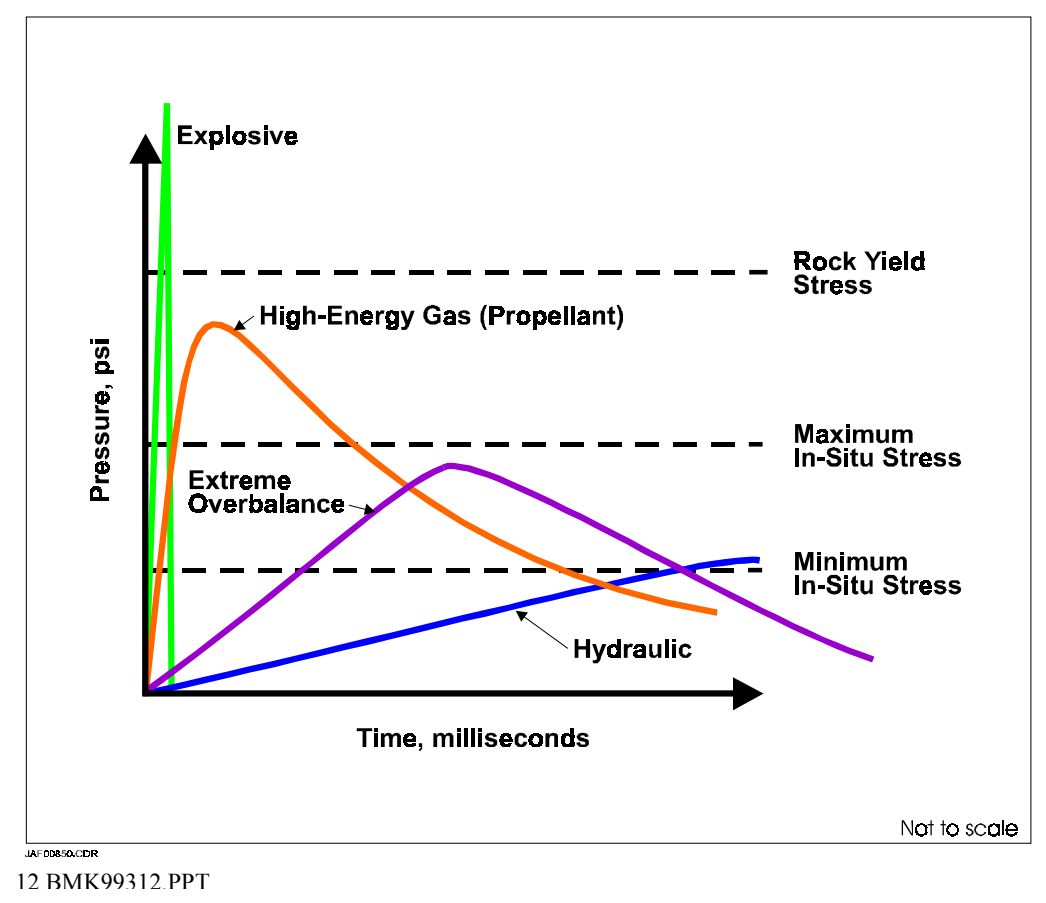

Figure 2-2 : Comparative Illustration of Resulting Fracture Patterns for Various Fracture Stimulation Methods

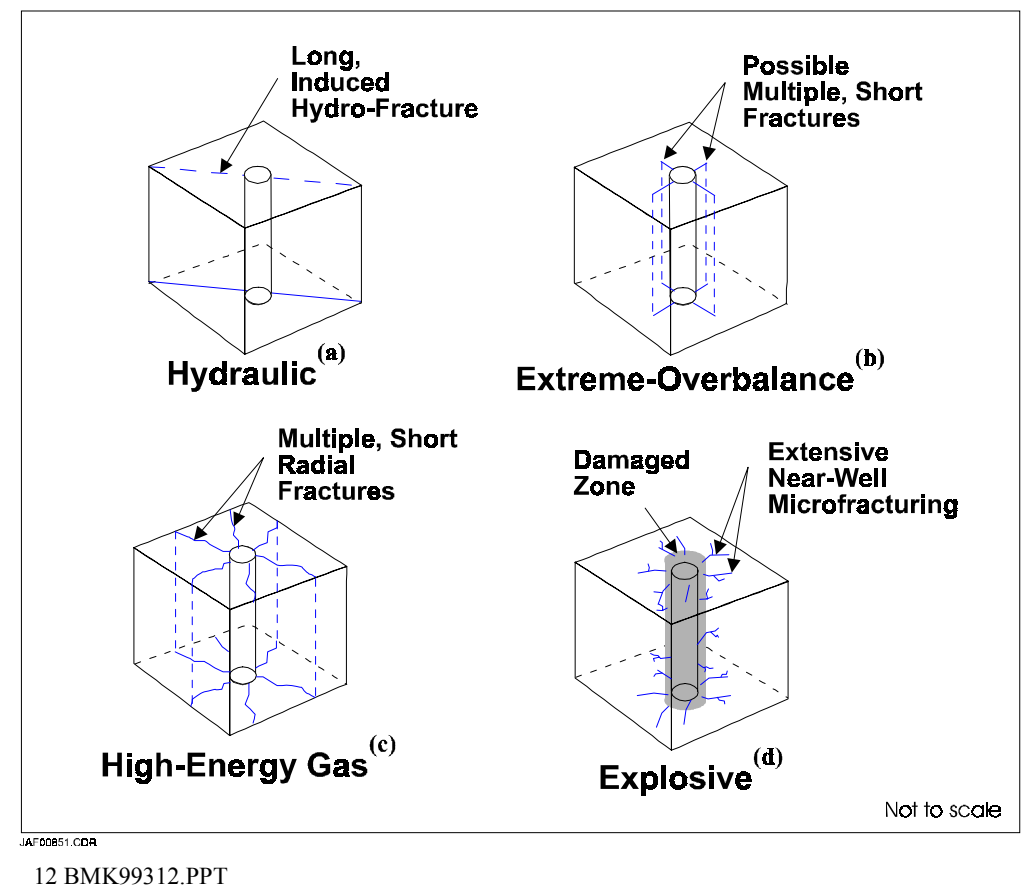


Two of these generalized fracturing techniques, in particular hydraulic and pulse fracturing, hold promise for gas storage applications. Accordingly, the specific technologies that were tested in this project fall into these categories; two are considered hydraulic in nature, tip-screenout (TSO) and liquid carbon dioxide with proppant, and two are pulse in nature, HEGF and EOB. The following sections describe each of the techniques in further detail, and why they are of particular interest for application in gas storage wells.

\subsection{Hydraulic Fracturing}

Hydraulic fracturing involves the creation of a single, planar, vertical fracture (except in shallow zones where horizontal fractures can be created) which theoretically extends in two wings $\left(180^{\circ}\right.$ apart) from a wellbore (Figure $\left.2-3\right)$. The fracture is created by pressurizing the wellbore with a fracturing fluid until the reservoir rock cracks, and then extending that fracture by continued injection of fluid. Fracturing occurs at pressures that slightly exceed the minimum in-situ stress, and the created fracture is oriented perpendicular to this stress direction. A solid proppant, normally sand, is carried with the fluid such that when injection ceases and the fracture closes, it is propped open. This creates a highly conductive flow path for reservoir fluids, in this case stored gas, to be rapidly produced from the reservoir as needed, the proppant serving to maintain the integrity of that flow path.

Figure 2-1: Schematic of a Hydraulic Fracture

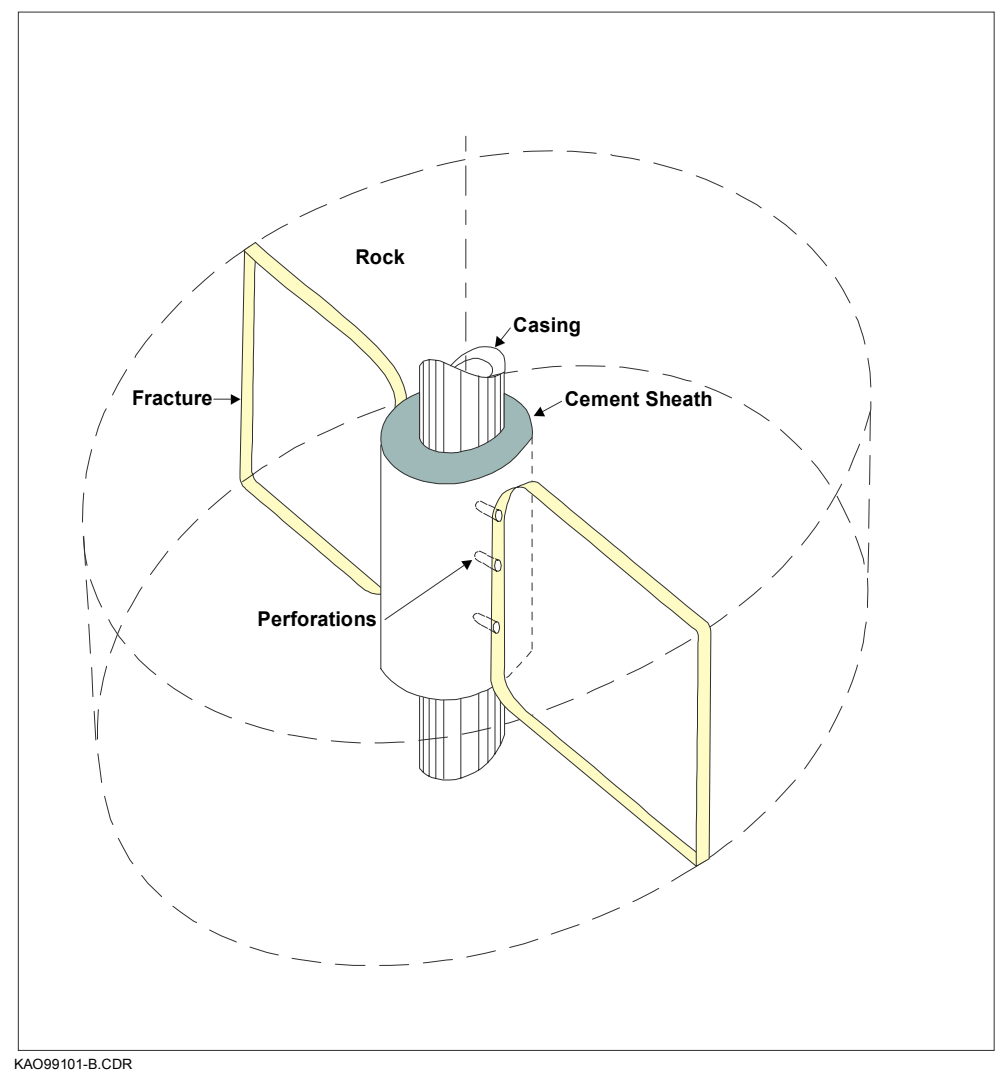


In the oil and gas community, hydraulic fracturing is usually utilized to stimulate production from low permeability reservoirs and, as such, deeply penetrating fractures on the order of hundreds of feet per wing are normally required. The needs of the gas storage industry, however, are quite different. Short fractures, probably no more that 50-100 feet in length, are probably sufficient to penetrate beyond near-wellbore formation damage and enhance well deliverability in these high permeability settings. In addition, because the effectiveness of the fracture is determined by the permeability contrast between the formation and the fracture, and since gas storage reservoirs frequently have relatively high permeabilities, ultra-high fracture conductivities are required. Ultra-high fracture conductivities are not easily achievable with routine hydraulic fracturing approaches, and therefore less conventional techniques are needed. One such method, utilized in this project for this very reason, is tip-screenout fracturing.

\subsubsection{Tip-Screenout Fracturing}

TSO fracturing, originally conceived as a specific design objective in the late 1970's and early 1980's, has now become commonplace in areas such as the Gulf of Mexico, Alaska and the North Sea. With the primary advantage of being able to create fracture conductivities that exceed those possible by manipulation of traditional treatment parameters, such as proppant type, fluid viscosity and injection rate, TSO fracturing is ideally suited to stimulation of higher permeability formations where the primary objective is bypassing near-well damage. The high fracture conductivities are achieved by effecting a screenout at the fracture tip to arrest further extensional growth, widening the fracture with continued pumping, and finally packing it with proppant in a high-density slurry (Figures 2-4 and 2-5). Because damage-bypass is the objective for most gas storage fields, TSO fracturing is an obvious technology to consider. It also has two other potential advantages. First, it can reduce near-well pressure drops during peak withdrawal periods, which may mitigate the mobilization of fines and deposition of scale (some of the primary causes for deliverability decline in gas storage wells), as well as minimizing non-Darcy flow effects. Second, small treatments are generally the norm, and this can, in part, minimize the risk of unacceptable fracture height growth.

\section{Figure 2-1: Top View of a Tip-Screenout}

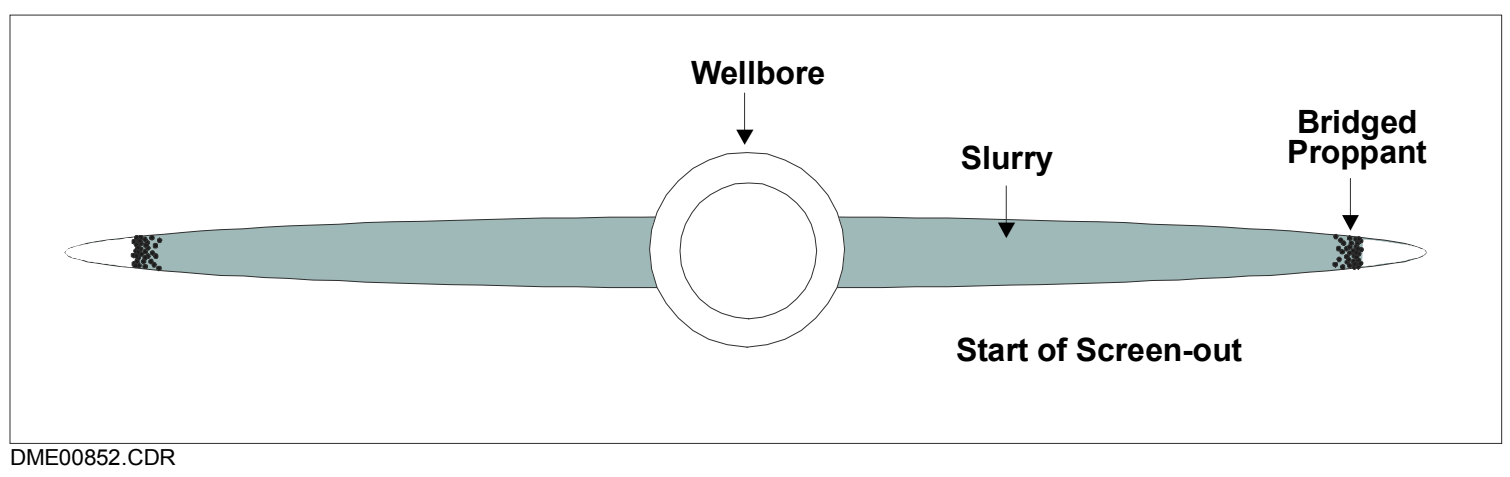


Figure 2-2: Sequence of a Tip-Screenout Fracture Treatment

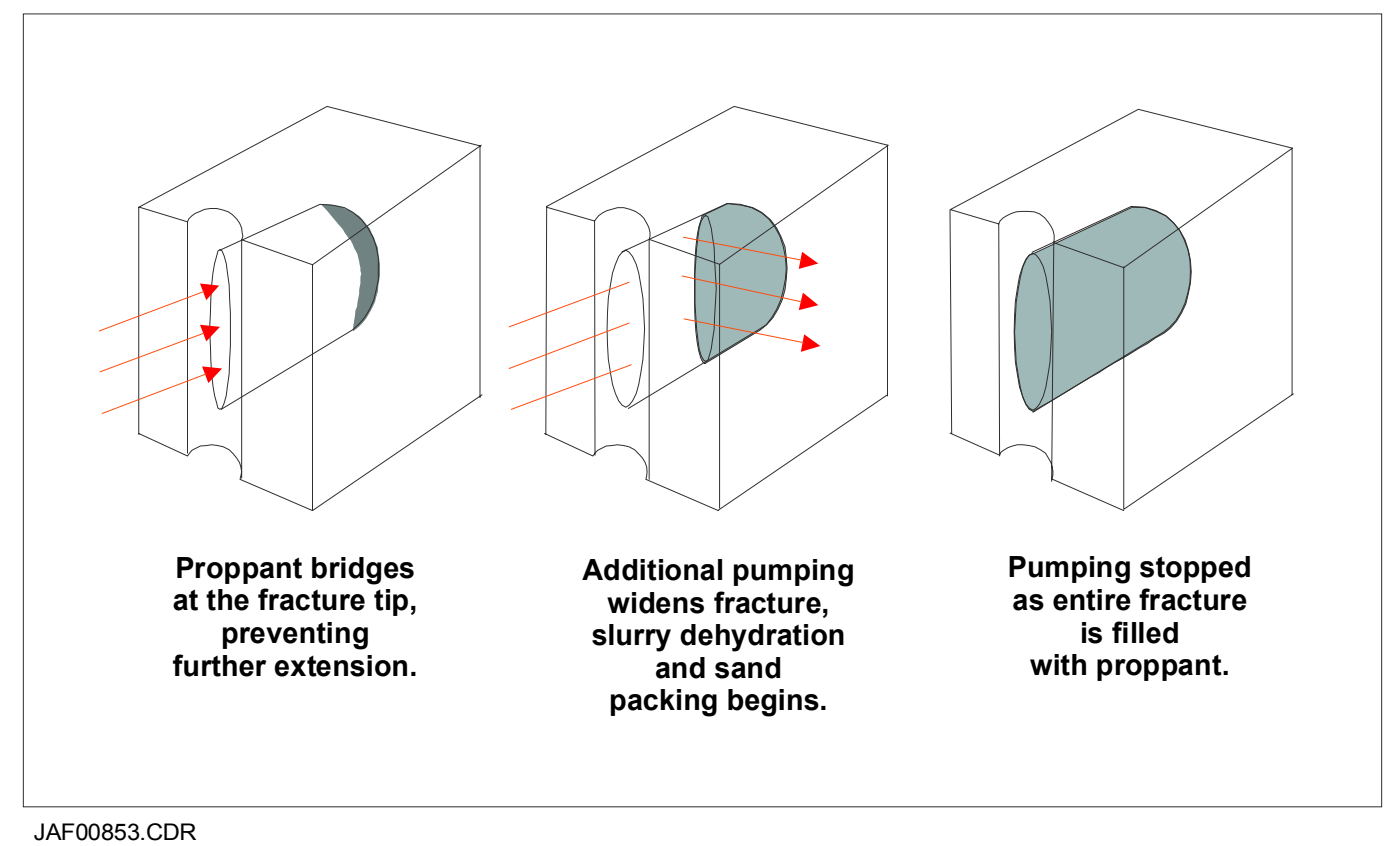

\subsubsection{Liquid $\mathrm{CO}_{2}$ with Proppant Fracturing}

As mentioned earlier, aqueous-based hydraulic fracturing fluids can have a damaging effect on gas storage wells, to a degree that more than offsets the stimulation induced by the created fracture in some cases. As an alternative to aqueous-based stimulation fluids, fracturing with pure liquid $\mathrm{CO}_{2}$ and proppant is a legitimate consideration for application in gas storage wells. This technology, first introduced in the early 1980's in Canada, has since been used to stimulate hundreds (possibly thousands) of gas wells there successfully. Its popularity had not yet extended into the U.S., in part due to the limited availability of specialized blending equipment required to perform liquid $\mathrm{CO}_{2}$ treatments. In recent years, however, the DOE has been instrumental in making the equipment available and demonstrating the successful application of the technique to water-sensitive gas formations in the Lower-48 states. ${ }^{4}$

The pumping of ungelled, pure liquid $\mathrm{CO}_{2}$ as a fracturing fluid involves the use of self-contained pressurized blending equipment, which limits the proppant volumes that can be pumped from a single blender. Currently available blenders (in the U.S.) are capable of holding up to 48,000 pounds of proppant, which is sufficient for most gas storage applications. Also, the low viscosity of the fluid means that injection rate is the primary control over fluid leakoff, fracture width and proppant transport. Rates as high as 50-60 barrels-per-minute can be achieved, however, and have been shown to be sufficient for most applications. Primarily because of the cost of the $\mathrm{CO}_{2}$, treatment costs can be higher than more conventional fracture stimulation treatments; nevertheless, the positive aspects of nonaqueous fracturing fluids for gas storage applications is substantial. 


\subsection{Pulse Fracturing}

Because of the relatively short fracture lengths required to bypass near-wellbore damage in gas storage wells, other fracturing techniques outside of hydraulic fracturing also hold potential for deliverability enhancement. Further, hydraulic fracturing may not be an effective stimulation technique in some settings, such as in high stress settings where large open-hole intervals exist and where casing/cement integrity may be questionable. Therefore, pulse fracturing was also investigated in this project. As described earlier, the primary difference between pulse fracturing and hydraulic fracturing is the rate at which energy is applied to the formation to create fractures. In hydraulic fracturing, this rate is relatively low. Pulse fracturing involves much more rapid energy discharge creating a series of vertical fractures, each perhaps 5 to 20 feet in length, propagating radially outward from the wellbore. One pulse fracturing technique that has been successfully applied in a variety of damage-bypass applications is extreme overbalance fracturing.

\subsubsection{Extreme Overbalance Fracturing}

EOB technology for well stimulation can be traced back to DOE's multi-well experiment (MWX) site in the early 1980's where it was tested as a non-aqueous, lowdamage completion method for the tight, naturally fractured Mesaverde formation. Originally intended for use in conjunction with perforating operations, the technique involves overpressuring the wellbore with a gas (and a liquid at the bottom of the well) to a level that exceeds the formation fracture gradient by a factor of 1.5 to 2.0 , and then quickly exposing that pressure to the formation as the perforator is fired. If pressure levels and rates are sufficient, then multiple fractures extending radially outward may be created (Figure 2-6). Because of the elevated pressures that can be used, in many cases initial fracture orientation can be governed by wellbore and perforation orientation, and not necessarily in-situ stresses. This attribute can be useful when attempting to stimulate horizontal wells or in vertical wells where hydraulic fractures tend to grow horizontally. The potentially radial nature of the created fracture pattern, as well as the limited treatment volumes involved, make the technique well suited to bypass near-well damage. Recent developments in the technology have included the stimulation of already perforated completions through the use of a rupture disk on the end of a tubing string, the introduction of small proppant volumes, and the use of propellants to boost the downhole pressures created. These advancements are of particular importance to the future of EOB technology as a pulse fracturing technique, particularly relative to the potential role of the HEGF method.

Several reasons make EOB technology applicable to gas storage wells. First, the treatment volumes are small which limits the potential for undesirable fracture height growth. Secondly, if created, the multiple radial fracture pattern may provide better nearwell damage bypass characteristics than a normal two-wing hydraulic fracture. Third, small fluid volumes reduce the possibility of fluid-induced damage. Finally, in locations of high in-situ stresses where horizontal fracturing is common (such as in some gas storage fields of the Appalachian Basin) the complete vertical extent of the storage horizon can be stimulated. 
Figure 2-1: Hydraulic vs. EOB Fracture Initiation Profiles

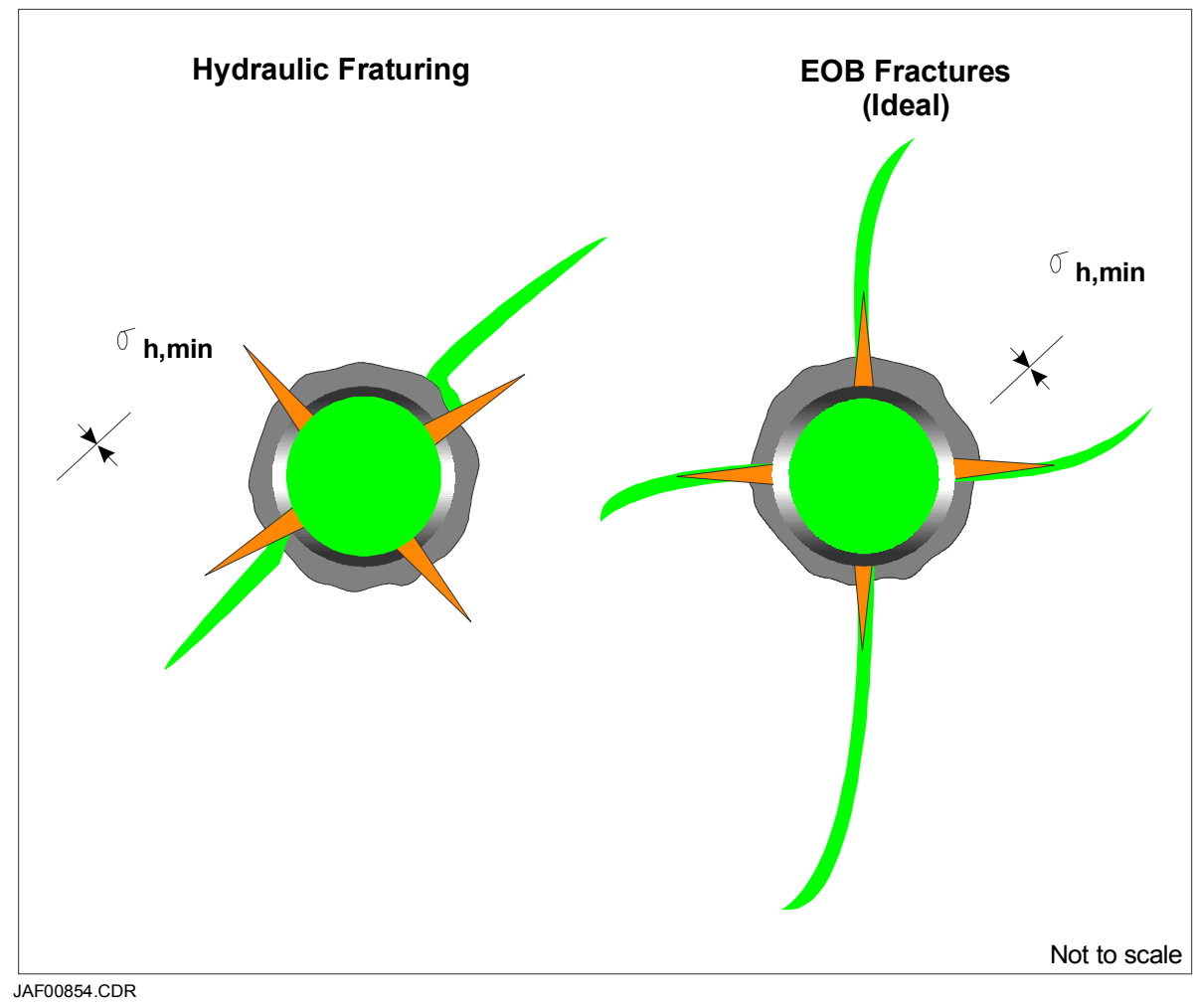

\subsubsection{High-Energy Gas Fracturing}

High-energy gas fracturing, also known as controlled pulse fracturing, tailored pulse loading or propellant fracturing, involves the use of a wireline run (or tubing conveyed), propellant (similar to solid rocket fuel) which is placed across the formation and electrically ignited to create a high pressure pulse that has a duration of only a few milliseconds. Propellant fracturing is designed to increase the pressure above the in-situ and tensile rock stresses to create multiple fractures, but still remain below the yield stress of the rock, thus avoiding the wellbore damage associated with explosive fracturing. This pulse of gas creates multiple short $(5-20 \mathrm{ft})$ radial fractures in the formation which connect to the wellbore and are confined close to the zone stimulated. The propellants in a typical tool burn to form mainly carbon monoxide and some water, but the amounts are small so that fracturing occurs with little introduction of damaging fluid contact. In addition, the small gas volume limits the extent of fracturing both radially and vertically. One of the principal advantages of the HEGF method over the EOB approach is the ability to rapidly elevate downhole pressures which do not reach the surface equipment (rather they are dissipated via the fracturing process), and can reliably create multiple fractures in a radial pattern.

Other than the potential for skin reduction, another reason that HEGF can be considered for gas storage wells is that vertical fracture growth is limited and generally restricted to about one-half the horizontal extent of the fracture. This has been confirmed in laboratory studies and by computer simulation. ${ }^{4}$ The reason is that the fracture growth is 
gas-dynamic, and there is not time nor energy available for the unrestricted height growth that can occur with a large hydraulic fracture. Therefore, knowing the distance to the reservoir cap, an HEGF treatment can be reliably designed to avoid breakthrough. The most obvious disadvantage of propellant technology is that the created fractures are left unpropped and hence are susceptible to closure and plugging. 


\subsection{Test Site Results}

The locations of the eight sites used for the project are illustrated in Figure 3-1, which also provides the operator and stimulation technology investigated at each. Descriptive data for each site are also provided in Table 3-1. Five of the sites tested tipscreenout fracturing, two liquid $\mathrm{CO}_{2}$ with proppant fracturing, three extreme overbalance fracturing, and one propellant fracturing. Table 3-2 presents the test matrix developed in the project.

Figure 3-1: Location of Test Sites

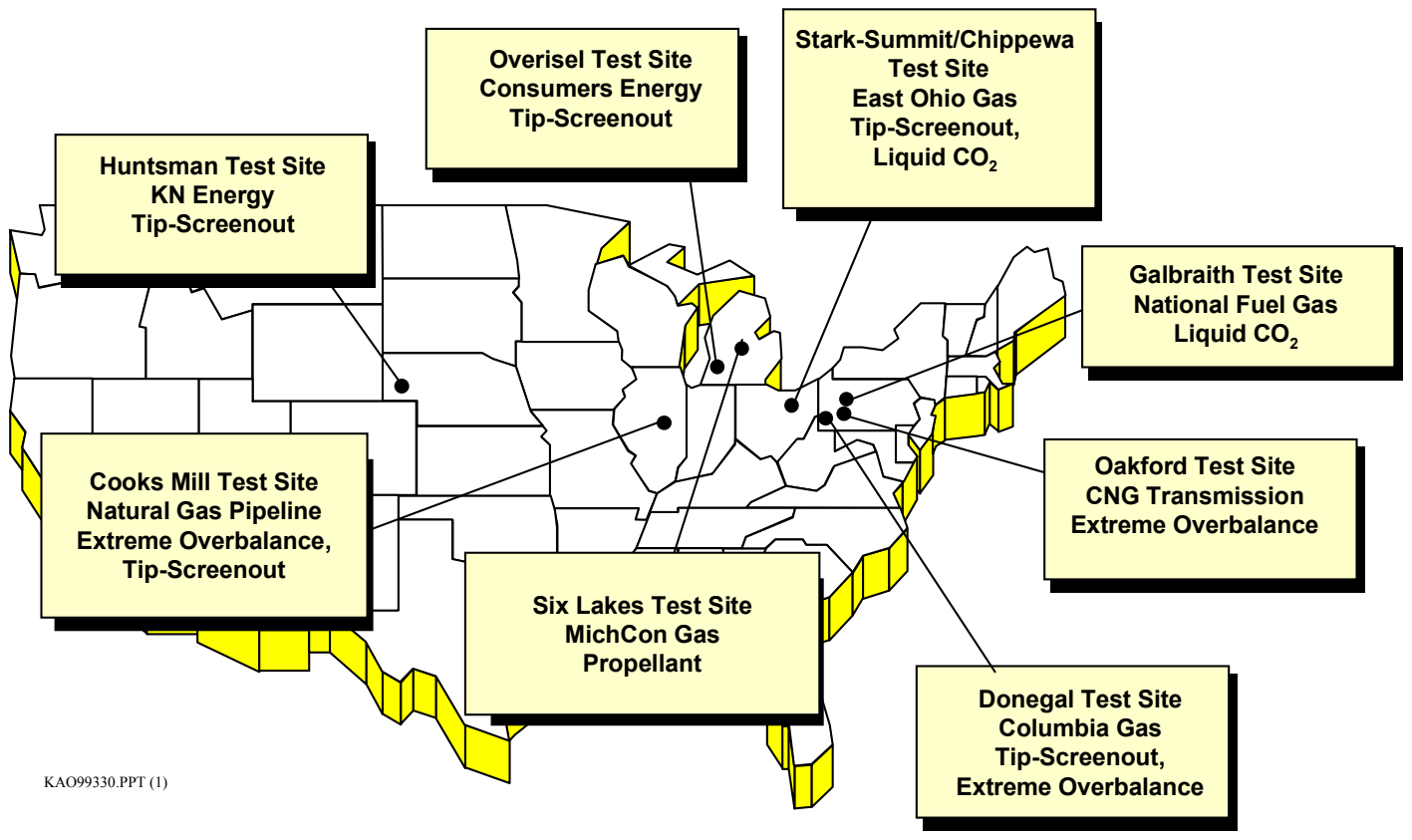

Table 3-3 presents the field activities performed in the project. In total, 29 new and novel fracture treatments have been performed as part of this project, 152 deliverability and pressure transient tests, 28 fracture diagnostics tests (e.g., mini-fracs, step-rate tests, bottomhole treating pressure measurements etc.), and 23 fracture height surveys (e.g., radioactive tracer, temperature, downhole camera surveys), among other tests and diagnostics. This section briefly describes the findings at each site. More detailed technical discussions for each site and stimulation technology can be found in the references. ${ }^{6-8}$

\subsection{Deliverability and Pressure Transient Testing Program}

Before describing the activities and results for each test site, some description and discussion regarding the deliverability and pressure transient testing program is warranted. This is because, for perhaps the first time, detailed information on the impact of fracturing on gas storage well deliverability and completion (stimulation) efficiency in a relatively controlled manner has been collected and published. The information is of a type and quantity that is difficult to present in a concise manner without losing some of the important insights derived, hence this discussion. 
Table 3-1: Test Site Descriptive Data

\begin{tabular}{|c|c|c|c|c|c|c|c|c|}
\hline Site & Huntsman & Overisel & Galbraith & $\begin{array}{l}\text { Stark-Summit/ } \\
\text { Chippewa }\end{array}$ & Donegal & Oakford & Cooks Mills & Six Lakes \\
\hline Company & KN Energy & Consumers Energy & National Fuel & East Ohio Gas & Columbia Gas & CNG Transmission & $\begin{array}{l}\text { Natural Gas } \\
\text { Pipeline }\end{array}$ & MichCon Gas \\
\hline Technology & Tip-Screenout & Tip-Screenout & $\begin{array}{l}\text { Liquid } \mathrm{CO}_{2} \mathrm{w} / \\
\text { Proppant }\end{array}$ & $\mid \begin{array}{c}\text { Tip-Screenout, Liquid } \\
\mathrm{CO}_{2} \text { w/ Proppant }\end{array}$ & $\begin{array}{l}\text { Tip-Screenout, } \\
\text { Extreme } \\
\text { Overbalance }\end{array}$ & $\begin{array}{c}\text { Extreme } \\
\text { Overbalance }\end{array}$ & $\begin{array}{c}\text { Extreme } \\
\text { Overbalance, } \\
\text { Hydraulic } \\
\text { Fracturing } \\
\end{array}$ & Propellant \\
\hline Location & \begin{tabular}{|c} 
Cheyenne Co., \\
NE \\
\end{tabular} & Allegan Co., MI & Jefferson Co., PA & $\begin{array}{l}\text { Stark, Summit \& } \\
\text { Wayne Cos., OH }\end{array}$ & Washington Co., PA & $\begin{array}{c}\text { Westmoreland Co., } \\
\text { PA }\end{array}$ & $\begin{array}{c}\text { Douglas \& Coles } \\
\text { Cos., IL } \\
\end{array}$ & $\begin{array}{c}\text { Mecosta \& Montcalm } \\
\text { Cos., Ml } \\
\end{array}$ \\
\hline Discovery Yr. & 1950 & 1956 & 1917 & $1927 / 1918$ & 1907 & 1887 & 1955 & 1934 \\
\hline Storage Yr. & 1963 & 1960 & 1937 & 1941 & 1940 & 1951 & 1957 & 1953 \\
\hline Formation Age & Cretaceous & Silurian & Devonian & Silurian & Devonian & Devonian & Mississippian & Mississippian \\
\hline \begin{tabular}{|c|} 
Reservoir Type/Trap \\
Type
\end{tabular} & $\begin{array}{l}\text { Deplet. Res., } \\
\text { Structural }\end{array}$ & $\begin{array}{l}\text { Deplet. Res., } \\
\text { Structural } \\
\end{array}$ & $\begin{array}{l}\text { Deplet. Res., } \\
\text { Stratigraphic }\end{array}$ & $\begin{array}{l}\text { Deplet. Res., } \\
\text { Stratigraphic }\end{array}$ & $\begin{array}{l}\text { Deplet. Res., } \\
\text { Stratigraphic }\end{array}$ & $\begin{array}{l}\text { Deplet. Res., } \\
\text { Structural }\end{array}$ & $\begin{array}{l}\text { Deplet. Res., } \\
\text { Stratigraphic }\end{array}$ & $\begin{array}{l}\text { Deplet. Res., } \\
\text { Structural }\end{array}$ \\
\hline Reservoir Name & \begin{tabular}{|c|} 
3rd Dakota "J" \\
Sand
\end{tabular} & A-2 Dolomite & 1st Sheffield Sand & White Clinton Sand & Gordon Stray Sand & Fifth Sand & Cypress (d) Sand & Michigan Stray Sand \\
\hline Avg. Depth & $4,825 \mathrm{ft}$. & $2,612 \mathrm{ft}$. & $2,705 \mathrm{ft}$. & $4,260 / 3,615 \mathrm{ft}$. & $2,630 \mathrm{ft}$. & $1,826 \mathrm{ft}$. & $1,550 \mathrm{ft}$. & $1,256 \mathrm{ft}$. \\
\hline Avg. Thickness & $45 \mathrm{ft}$. & $40 \mathrm{ft}$. & $24 \mathrm{ft}$. & $23 / 8 \mathrm{ft}$. & $10 \mathrm{ft}$. & $25 \mathrm{ft}$. & $23 \mathrm{ft}$. & $26 \mathrm{ft}$. \\
\hline No. I/W Wells & 18 & 163 & 26 & $630 / 99$ & 112 & 228 & 21 & 244 \\
\hline $\begin{array}{c}\text { Working Gas } \\
\text { Volume }\end{array}$ & 7,962 MMcf & 22,000 MMcf & 632 MMcf & 55,737/1,814 MMcf & 3,600 MMcf & $61,202 \mathrm{MMcf}$ & 2,300 MMcf & 40,000 MMcf \\
\hline Max Deliv. & 105 MMcfd & 200 MMcfd & 20 MMcfd & 2.1/0.5 MMcfd & 223 MMcfd & 1,005 MMcfd & 150 MMcfd & 500 MMcfd \\
\hline Max Pres. & 1,169 psig & 1,520 psig & 620 psig & 1,550/1,500 psig & 1,260 psig & 1,100 psig & 900 psig & 705 psig \\
\hline
\end{tabular}

SiteData.xls 
Table 3-2: Mix of Reservoir Types, Stimulation Technologies and Test Sites

\begin{tabular}{|c|c|c|c|c|c|c|c|c|}
\hline \multirow[b]{2}{*}{$\begin{array}{c}\text { Reservoir } \\
\text { Type }\end{array}$} & \multirow[b]{2}{*}{$\begin{array}{l}\text { Reservoir } \\
\text { Lithology }\end{array}$} & \multirow[b]{2}{*}{$\begin{array}{c}\% \\
\text { Reservoirs }\end{array}$} & \multirow[b]{2}{*}{$\begin{array}{c}\% \\
\text { Wells }\end{array}$} & \multirow[b]{2}{*}{$\begin{array}{c}\% \\
\text { Working } \\
\text { Gas }\end{array}$} & \multicolumn{2}{|c|}{ Hydraulic } & \multicolumn{2}{|c|}{ Pulse } \\
\hline & & & & & $\begin{array}{c}\text { Tip- } \\
\text { Screenout }\end{array}$ & $\begin{array}{l}\text { Liquid } \\
\mathrm{CO}_{2} \text { with } \\
\text { Proppant }\end{array}$ & $\begin{array}{c}\text { Extreme } \\
\text { Overbalance }\end{array}$ & Propellant \\
\hline \multirow[t]{3}{*}{$\begin{array}{l}\text { Depleted } \\
\text { Oil or Gas }\end{array}$} & \multirow[t]{2}{*}{ Sandstone } & \multirow[t]{2}{*}{67} & \multirow[t]{2}{*}{77} & \multirow[t]{2}{*}{61} & $\begin{array}{l}\text { Huntsman, } \\
\text { Donegal, } \\
\text { Cooks Mills }\end{array}$ & Galbraith & \multirow[t]{2}{*}{$\begin{array}{c}\text { Donegal, } \\
\text { Oakford, } \\
\text { Cooks Mills }\end{array}$} & \multirow[t]{2}{*}{ Six Lakes } \\
\hline & & & & & \multicolumn{2}{|c|}{ Stark-Summit/Chippewa } & & \\
\hline & Carbonate & 22 & 13 & 28 & Overisel & -- & -- & -- \\
\hline \multirow[t]{2}{*}{ Aquifer } & Sandstone & 10 & 9 & 11 & -- & -- & --- & -- \\
\hline & Carbonate & 1 & 1 & $<1$ & --- & --- & --- & --- \\
\hline
\end{tabular}


Table 3-3: Summary of Field Activities Performed

\begin{tabular}{|c|c|c|c|c|c|c|c|c|c|c|c|c|}
\hline \multirow[b]{2}{*}{ Activity } & \multicolumn{5}{|c|}{ Tip-Screenout } & \multicolumn{2}{|c|}{ Liquid $\mathrm{CO}_{2}$} & \multicolumn{3}{|c|}{$\begin{array}{c}\text { Extreme } \\
\text { Overbalance }\end{array}$} & \multirow{2}{*}{\begin{tabular}{|l||} 
Propellant \\
Six Lakes \\
\end{tabular}} & \multirow[b]{2}{*}{ Tota } \\
\hline & Huntsman & Donegal & $\begin{array}{c}\text { Stark-Summit/ } \\
\text { Chippewa }\end{array}$ & Overisel & $\begin{array}{c}\text { Cooks } \\
\text { Mills } \\
\end{array}$ & Galbraith & $\begin{array}{c}\text { Stark-Summit/ } \\
\text { Chippewa }\end{array}$ & Donegal & Oakford & $\begin{array}{l}\text { Cooks } \\
\text { Mills }\end{array}$ & & \\
\hline $\begin{array}{l}\text { New and Novel Fracture } \\
\text { Treatments Performed }\end{array}$ & 2 & 2 & 3 & 3 & 3 & 3 & 3 & 4 & 2 & 1 & 3 & 29 \\
\hline $\begin{array}{l}\text { Pre-Fracture Deliverability and } \\
\text { Pressure Transient Tests } \\
\text { Performed/Analyzed }\end{array}$ & 7 & 3 & 18 & 4 & 5 & 4 & 13 & 13 & 4 & 1 & 4 & 76 \\
\hline Acoustic Logs Run/Analyzed & - & - & - & - & - & - & - & 1 & - & - & - & 1 \\
\hline Core Plugs Taken/Tested & - & - & - & - & - & - & - & 6 & - & - & - & 6 \\
\hline \begin{tabular}{|l|} 
Step-Rate Tests \\
Performed/Analyzed
\end{tabular} & 2 & 2 & 1 & 3 & - & - & - & - & - & - & - & 8 \\
\hline Mini-Fracs Performed/Analyzed & 4 & 1 & 1 & 3 & - & - & - & - & - & - & - & 9 \\
\hline $\begin{array}{l}\text { Main Frac Bottomhole Treating } \\
\text { Pressure Records }\end{array}$ & 2 & - & - & 3 & - & - & 1 & - & 2 & - & 3 & 11 \\
\hline Radioactive Tracer Surveys & 3 & 3 & 1 & 1 & - & - & - & 2 & - & - & - & 10 \\
\hline Temperature Surveys & 3 & - & 2 & - & - & - & - & - & - & - & - & 5 \\
\hline Downhole Camera Surveys & - & - & - & - & - & - & - & - & 1 & - & 7 & 8 \\
\hline $\begin{array}{l}\text { Post-Fracture Deliverability and } \\
\text { Pressure Transient Tests } \\
\text { Performed/Analyzed }\end{array}$ & 3 & 4 & 3 & 2 & 3 & 4 & 1 & 9 & 2 & - & 3 & 34 \\
\hline $\begin{array}{l}\text { Annual Deliverability and } \\
\text { Pressure Transient Tests } \\
\text { Performed/Analyzed }\end{array}$ & 3 & 6 & 7 & 2 & 3 & 3 & 4 & 7 & 3 & - & 4 & 42 \\
\hline
\end{tabular}

ItemTally101599.xls 
Several aspects of the deliverability and transient testing program make it unique. In particular, 1) the evaluation of multi-point deliverability data to document the impact of fracturing on the slope of the deliverability curve, 2) the analysis of non-Darcy flow and how it is affected by fracturing, and 3) the collection of deliverability and pressure transient data at different points in time to begin to understand the time-dependency of treatment effectiveness. The test procedures typically followed the modified isochronal method, whereby a well was flowed at several rates and levels of pressure drawdown for several hours, each flow period being followed by a shut-in period of equal or greater duration than the preceding flow period. The shut-in periods typically lasted twice as long as the preceding flow periods. For this project, four flow/shut-in periods were utilized to establish a deliverability curve with confidence, the first three flow periods were typically two to four hours in duration each, with the final flow/shut-in period being considerably longer (four to eight hours) to ensure stabilized rates were achieved and that a transient pressure analysis could be performed. Pressures were recorded with downhole electronic gauges, and gas rates with surface metering equipment.

A typical bottomhole pressure and gas rate profile for one of the tests is illustrated in Figure 3-2. This particular example is the post-stimulation anniversary test for well \#2960 at the Galbraith field. The logarithmic and semi-log analytic plots for the final shut-in period are provided in Figures 3-3 and 3-4, and illustrate the high quality of the data typically collected. Note the interference (or boundary) effects observed at the latter stages of the shut-in period; this observation was frequent in the data collected throughout the project. Each shut-in period was similarly analyzed to arrive at an estimate of formation permeability (to gas), and total skin factor (total skin is the sum of both true skin - i.e., mechanical - and that attributed to non-Darcy flow effects). To allocate the relative contribution of each, multi-point data was utilized for non-Darcy flow analysis.

The multi-point data was first used to establish the deliverability curve. The deliverability curve for this example is illustrated in Figure 3-5. As can be seen, the use of four flow periods which should plot along a straight line on a deliverability curve provides a high level of confidence in the result. The second utility of the multi-point data was to separate the skin factor for a particular well into its respective true and non-Darcy components. By plotting the total skin derived for each flow period versus the flow rate, and extrapolating that line back to a flow rate of zero, the true skin can be determined. That plot for the example test is presented in Figure 3-6. The slope of the line, the non-Darcy component "D", can be used to estimate the non-Darcy skin at any flow rate. Decreasing the value of this component represents a reduction in non-Darcy skin, a favorable outcome.

A final note is that deliverability responses to the treatments are presented at mid-season operating conditions (i.e., at a delta pressure squared value that is typical for a field in the middle of the withdrawal season). Since the mid-season deliverability of a well can improve substantially after a fracture stimulation treatment, the actual value of the non-Darcy skin can increase at this given value of delta pressure squared (due to a higher flow rate) suggesting that it has been adversely affected, when in fact the value for the non-Darcy component "D" has actually decreased. This distinction is important when reviewing the test results. With this brief introduction to the yardsticks by which well improvements were measured in this project, the following sections describe the actual results from each test site. 
Figure 3-1: Example Pressure and Flow Rate Response from a Deliverability and Pressure Transient Test

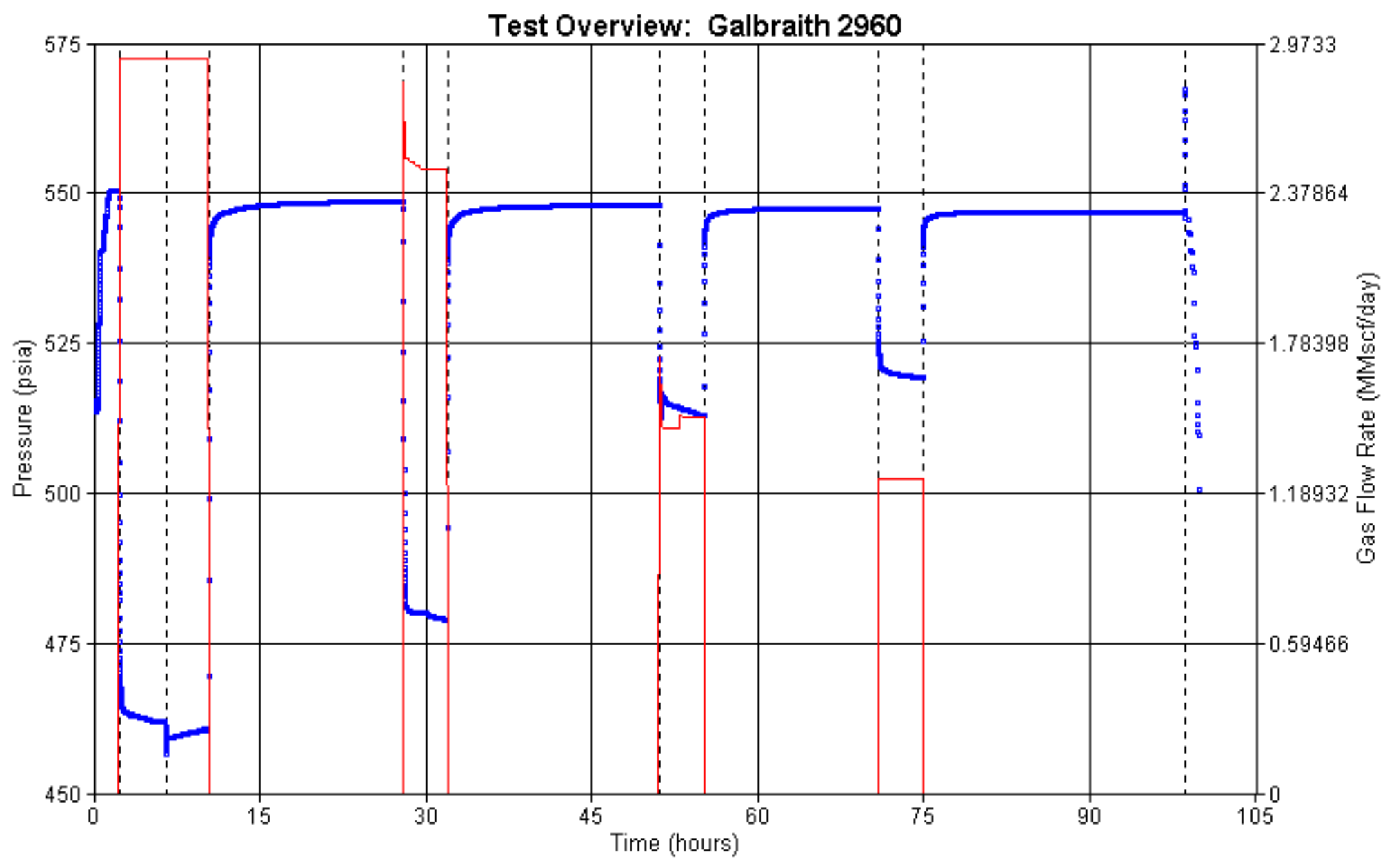

DME971E6.WPD 
Figure 3-2: Example Logarithmic Plot for the Final Shut-In Period

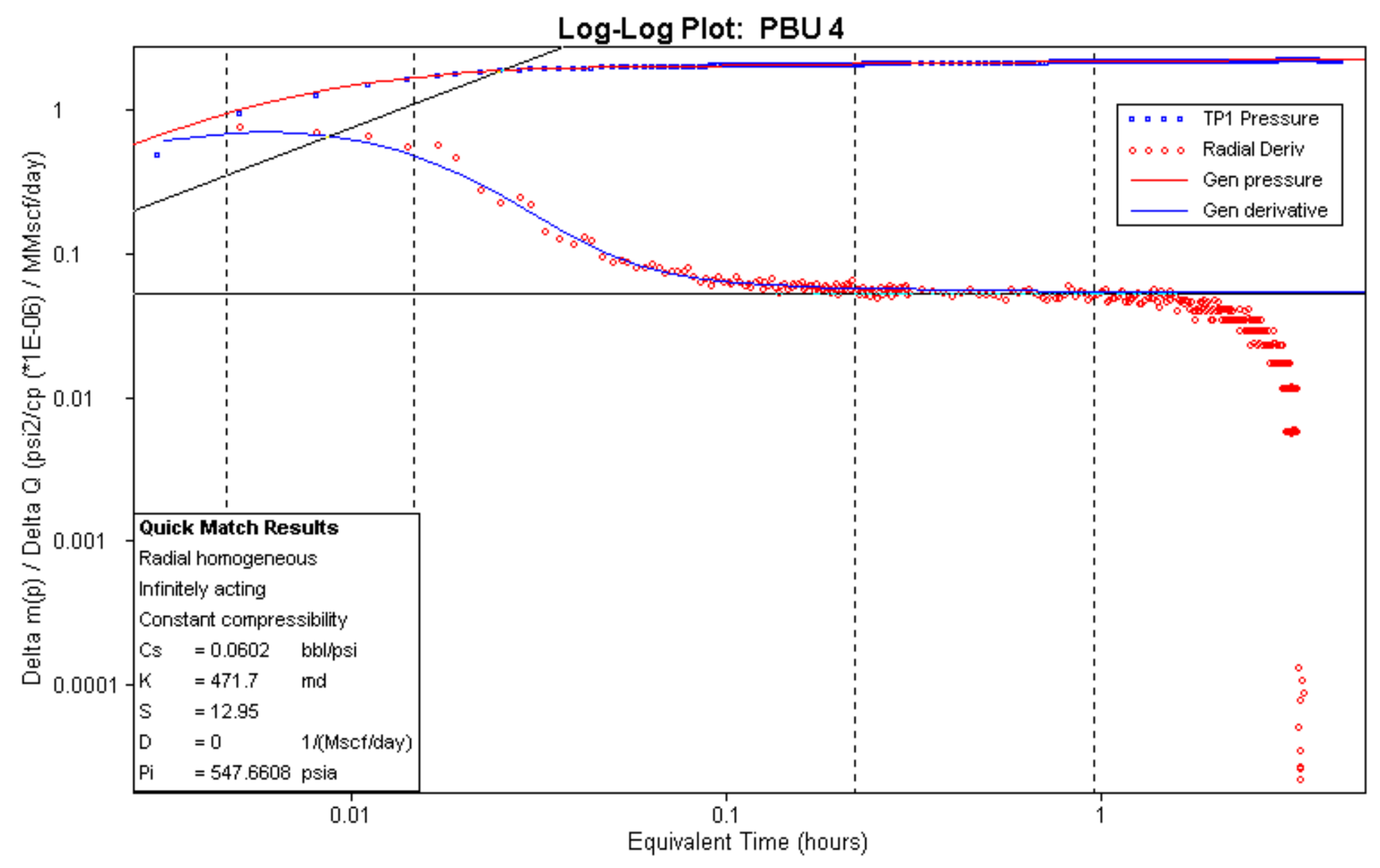

DME971E6.WPD 
Figure 3-3: Example Semi-Log Plot for the Final Shut-In Period

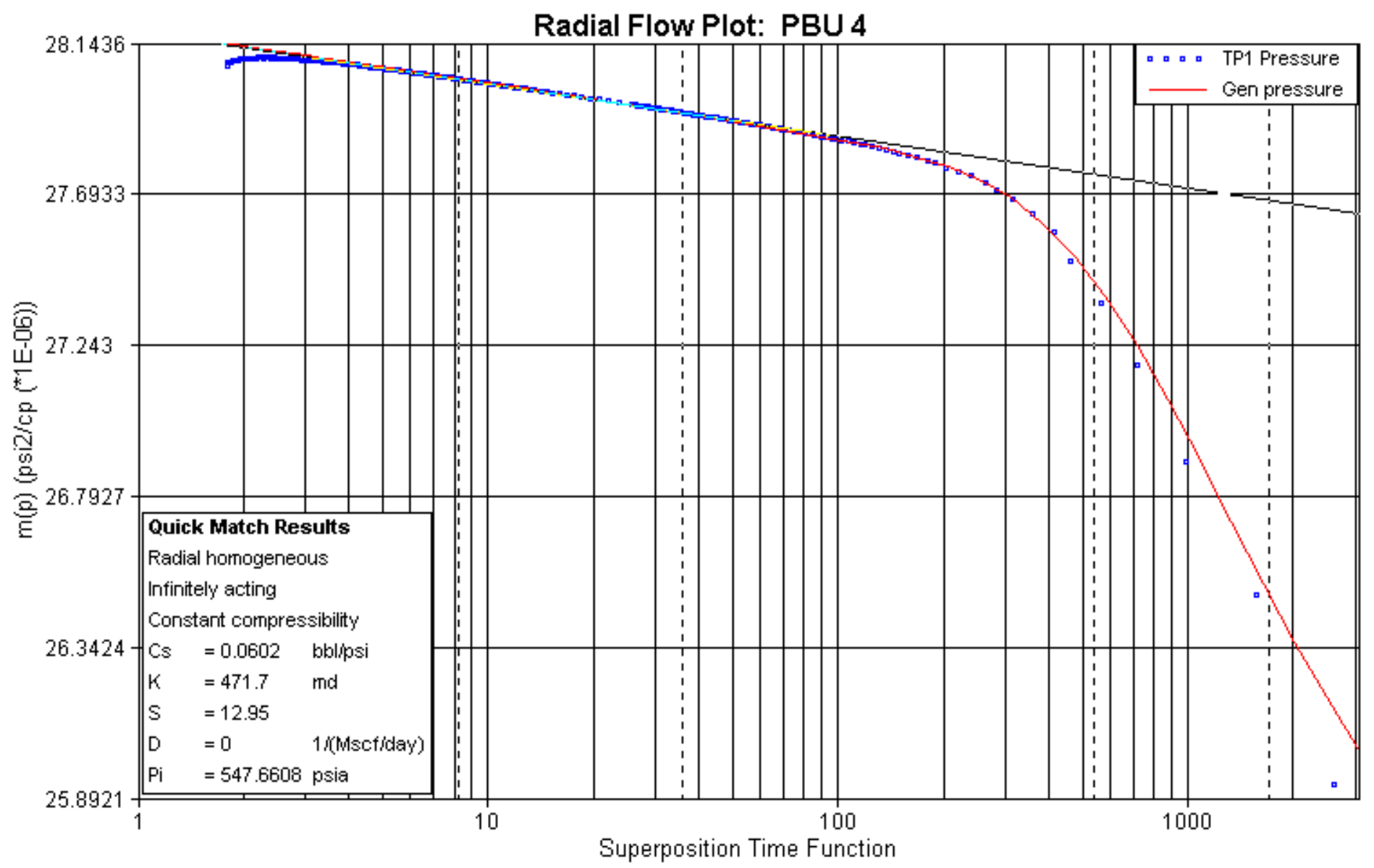

DME971E6.WPD 
Figure 3-4: Example Deliverability Curve

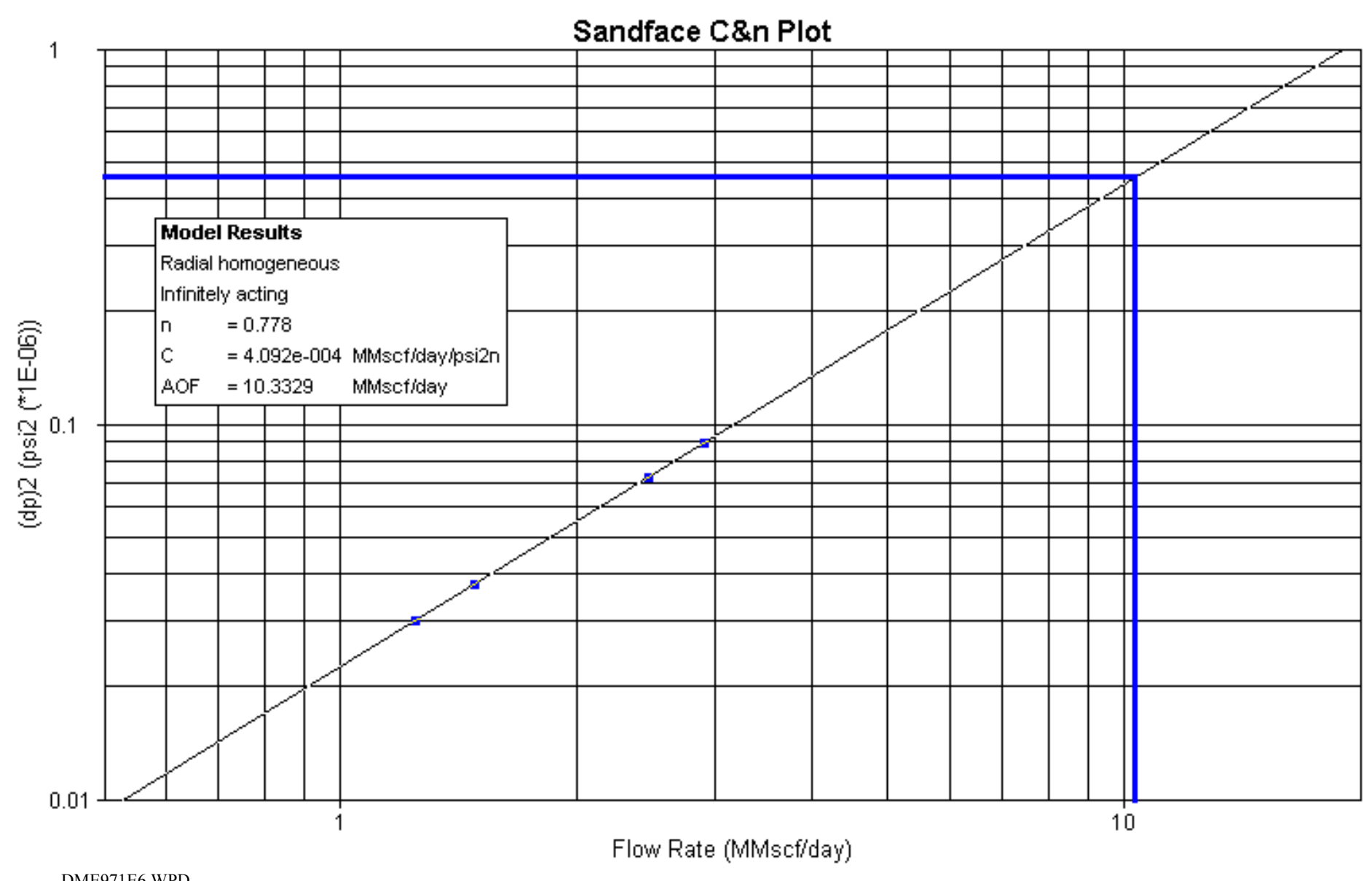

DME971E6.WPD 
Figure 3-5: Example Non-Darcy Flow Analysis Plot

Skin vs Flowrate Plot

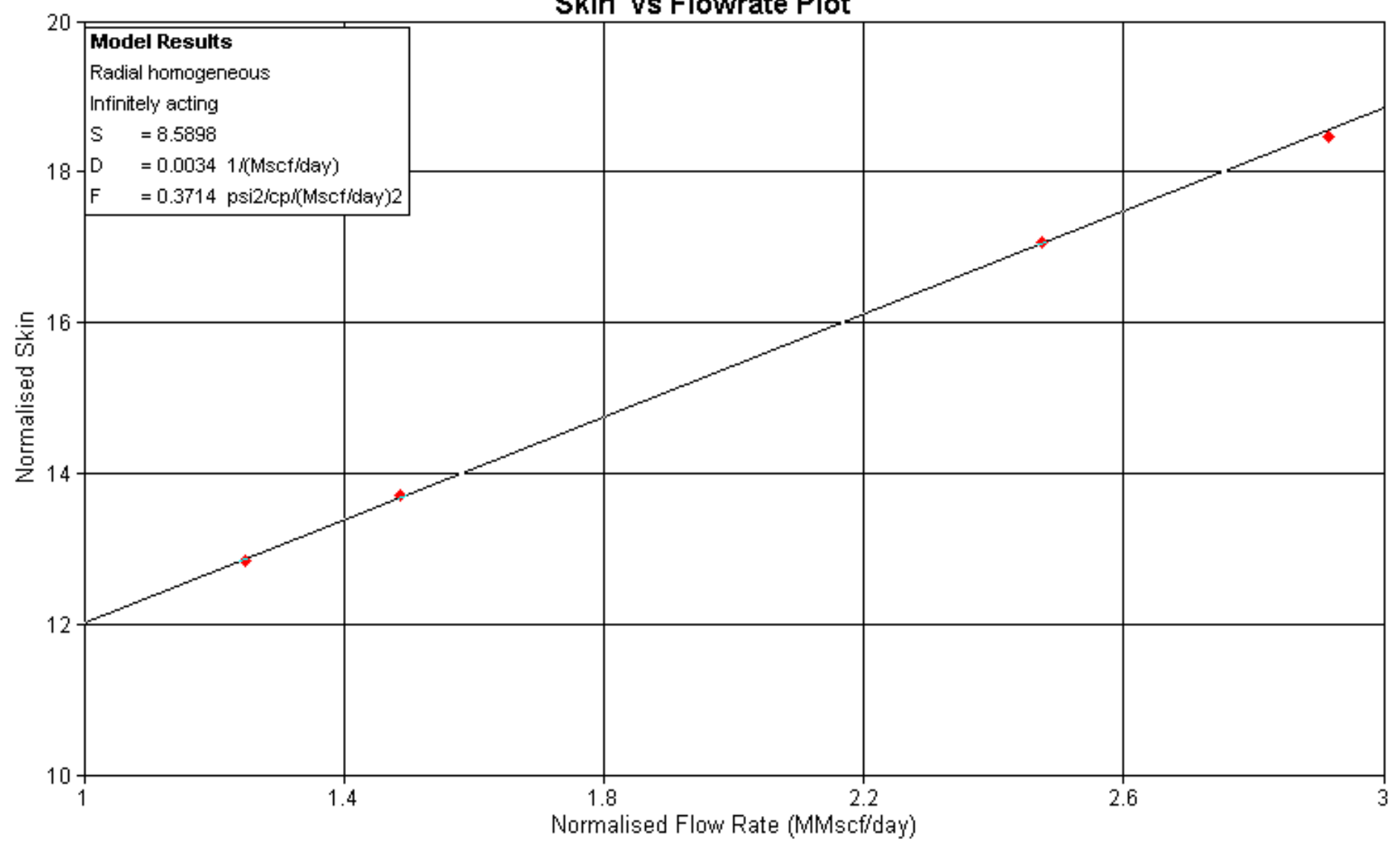

DME971E6.WPD

kao99137

23 


\subsection{Tip-Screenout Fracturing}

Five sites were utilized to test the application of tip-screenout fracturing. Those sites were the Huntsman field (Nebraska), the Donegal field (Pennsylvannia), the StarkSummit/Chippewa field (Ohio), the Overisel field (Michigan), and the Cooks Mills field (Illinois). (Note that the Cooks Mills stimulations were more akin to small-scale skinremoval treatments than tip-screenout fracturing.) Table 3-1, presented earlier, provides details on each of these fields. At Huntsman, only two wells were treated due to budgetary constraints imposed on the operator midway though the field activities. Also, only two treatments were performed at Donegal, after it was realized that TSO fracturing was probably not the most effective approach for the field. Three wells were treated at each of the other three fields. However, post-treatment testing could only be performed in two of the Overisel wells; the third well filled with debris and could not be tested. Details on the field activities, treatments, tests, etc. can be found in separate technology reports created for this project. ${ }^{6}$ However, the results of the stimulations are summarized here.

The first measure of treatment success, deliverability improvement, is presented for each well at each of the five TSO test sites in Figure 3-7. The pre-stimulation, poststimulation and post-stimulation anniversary test results are each presented to provide a perspective on how deliverability responded to the stimulation treatment.

While TSO fracturing was a huge success at the Huntsman Storage Field and while at least one well at every test site had an increase in deliverability, the overall improvements in deliverability at Stark-Summit, Overisel and Donegal Storage Fields were small compared to expectations from fracture stimulation (real or not). Nevertheless, the most consistently effective stimulation technology tested in this project was tip-screenout hydraulic fracturing. Benefits were seen at each of the four test sites with fracture cleanup continuing through to the post-frac anniversary testing. TSO led to the largest increase in deliverability at the Huntsman Storage Field where the Huntsman 45 well gained nearly 50 MMcfd. The results for Donegal storage well 4019 were surprising since horizontal fractures were believed to have been created during the job, further evidence that only limited fracture length and connection with the storage horizon was needed to bypass nearwell damage.

What is also obvious is that for many wells, mid-season deliverability actually declined following a TSO treatment, and then rebounded to a level near or exceeding the pre-treatment level after one to two years. This, it is believed, is the fluid damage effect described earlier (i.e., a fluid saturation is re-established in the dehydrated near-well region, reducing relative permeability to gas). In most cases, however, a significant increase in deliverability was achieved after two years of cleanup (the vertical scale is logarithmic).

It is interesting to consider Figure 3-7 together with the permeability estimates derived from these tests. The permeability values are presented in Figure 3-8. There is an obvious correlation between deliverability and estimated permeability. The significance of this observation is that permeability is being estimated over a large reservoir area, hundreds of feet away from the wellbore, and the reduction in gas permeability that leads to temporary 
deliverability decline exists deep into the reservoir. However, this effect is less pronounced in the higher-permeability wells (Huntsman and Cooks Mills). One might then conclude that TSO fracturing temporarily reduces permeability to gas a significant distance from the well, which directly impacts deliverability, but this effect is reduced in higher permeability formations, which could be due to a smaller capillary retention in the high perm wells.

Figure 3-1: Deliverability Results, Tip-Screenout Treatments

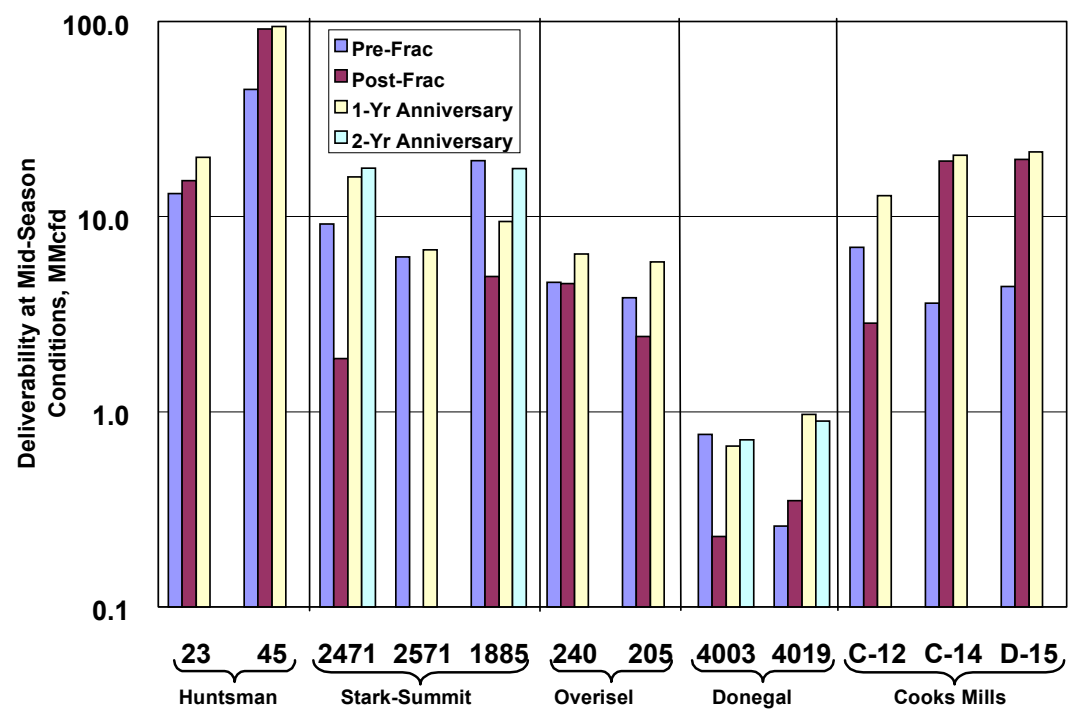

QMID.XLS

Figure 3-2: Permeability Results, Tip-Screenout Treatments

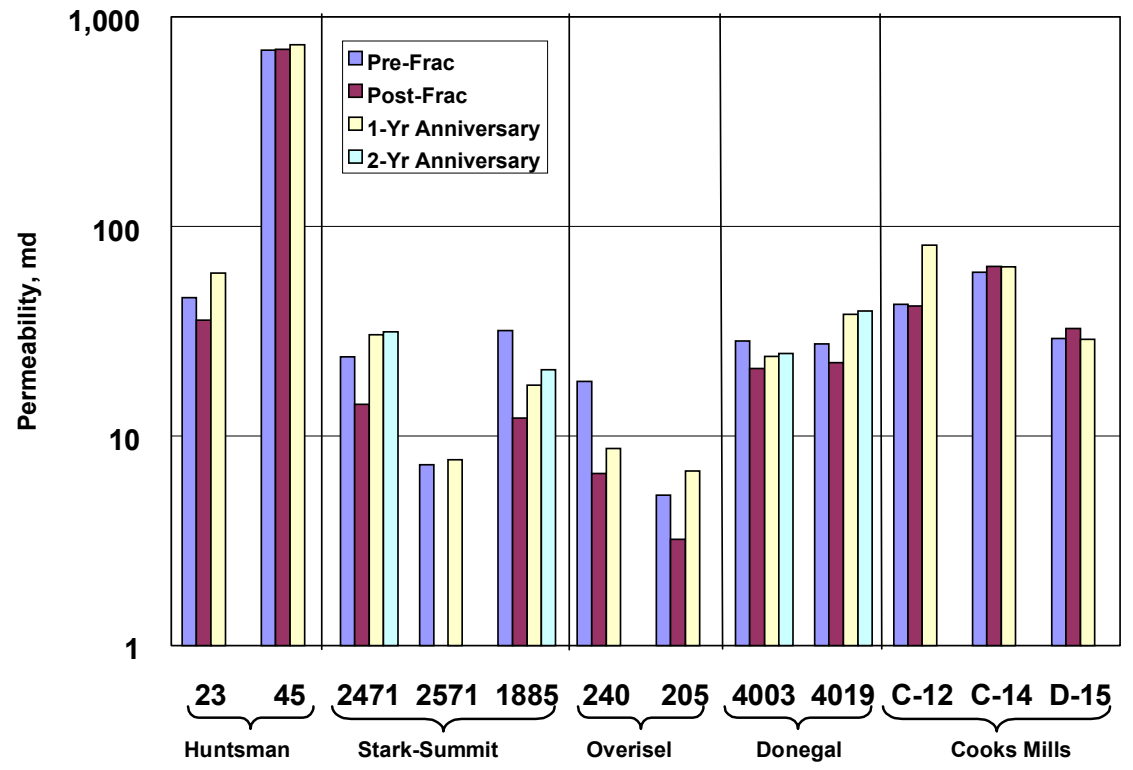

PERMEABILITY.XLS 
The skin factor results for each test are presented in Figures 3-9 to 3-11. Figure 3-9 provides the total skin factor at the midseason operating conditions, Figures 3-10 and 3-11 present the mechanical and non-Darcy skin components respectively. While it appears that in most wells a reduction in total skin was achieved with the TSO treatments, how it was achieved is different in each case. Looking at the plots of mechanical and non-Darcy skins, in the case of Huntsman (high permeability), the benefit came from reducing mechanical skin (dramatically in the case of the \#45 well). At the Stark-Summit/Chippewa, Overisel, and Cooks Mills fields, the pre-stimulation mechanical skins were already negative, questioning the usefulness of a stimulation treatment. However, deliverability improvements were achieved by reducing the non-Darcy skin components. Due to limited test data available at Donegal and Cooks Mills, the specific source of skin reduction could not be conclusively determined for these sites. Knowing that deliverability enhancement must come from a reduction in non-Darcy skin ahead of time is useful to aid the stimulation design objectives.

Beyond the deliverability enhancement results, and the understanding behind them, a particularly noteworthy accomplishment from these tests was that these results were achieved without compromising reservoir seal integrity, a concern of most gas storage operators and a significant barrier to the adoption of fracture stimulation technologies. In all cases, precautions were taken to ensure fracture height growth would not be problematic, and were successful in predicting this outcome. For example, at Huntsman, where a mere 50 feet of shale separated the storage horizon from an overlying thief zone, TSO fracturing was successfully performed without breaching this barrier (Figure 3-12).

While taken individually, these findings are each useful; in aggregate, they begin to provide important insights into the mechanics of gas storage deliverability enhancement. The next sections add to this understanding by reviewing the responses of gas storage wells to different stimulation techniques using these same performance yardsticks.

Figure 3-3: Total Skin Results, Tip-Screenout Treatments

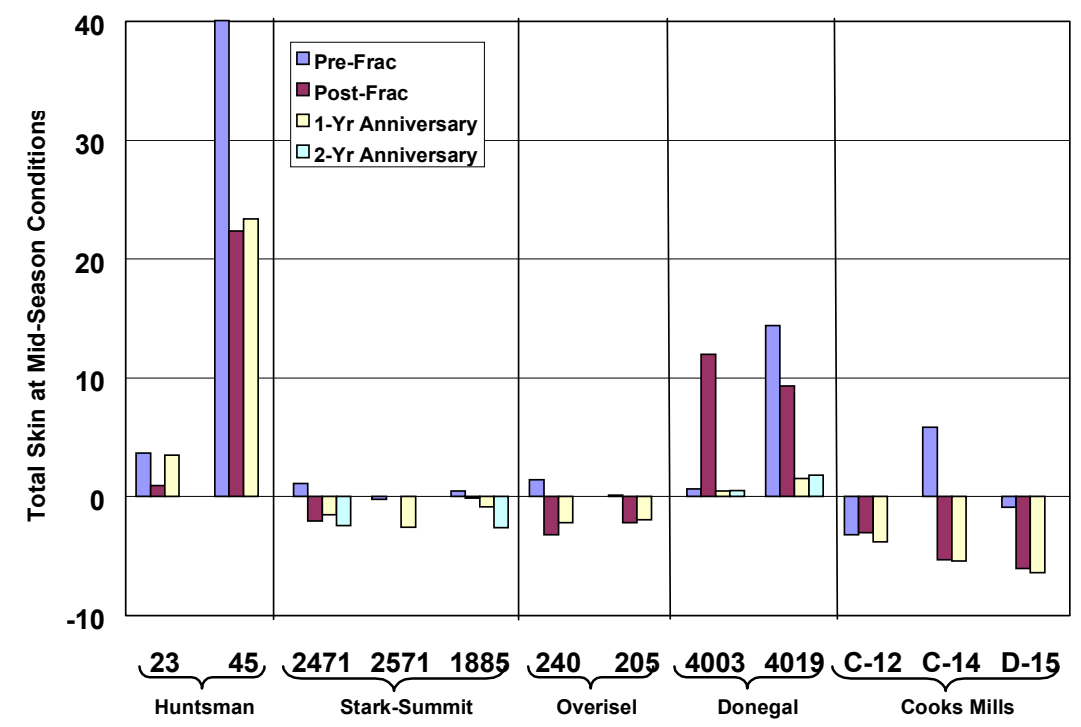

TOTAL SKIN.XLS 
Figure 3-4: Mechanical Skin Results, Tip-Screenout Treatments

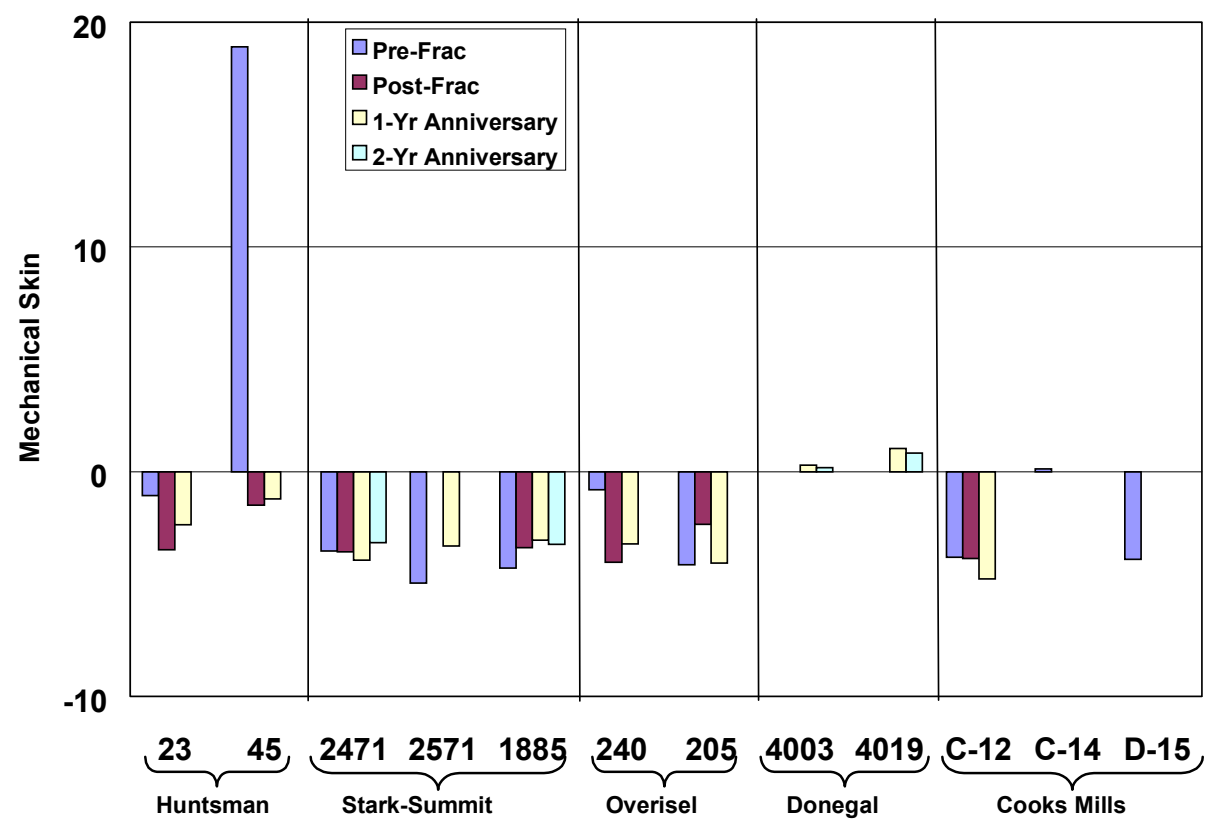

MECHANICAL SKIN.XLS

Figure 3-5: Non-Darcy Skin Results, Tip-Screenout Treatments

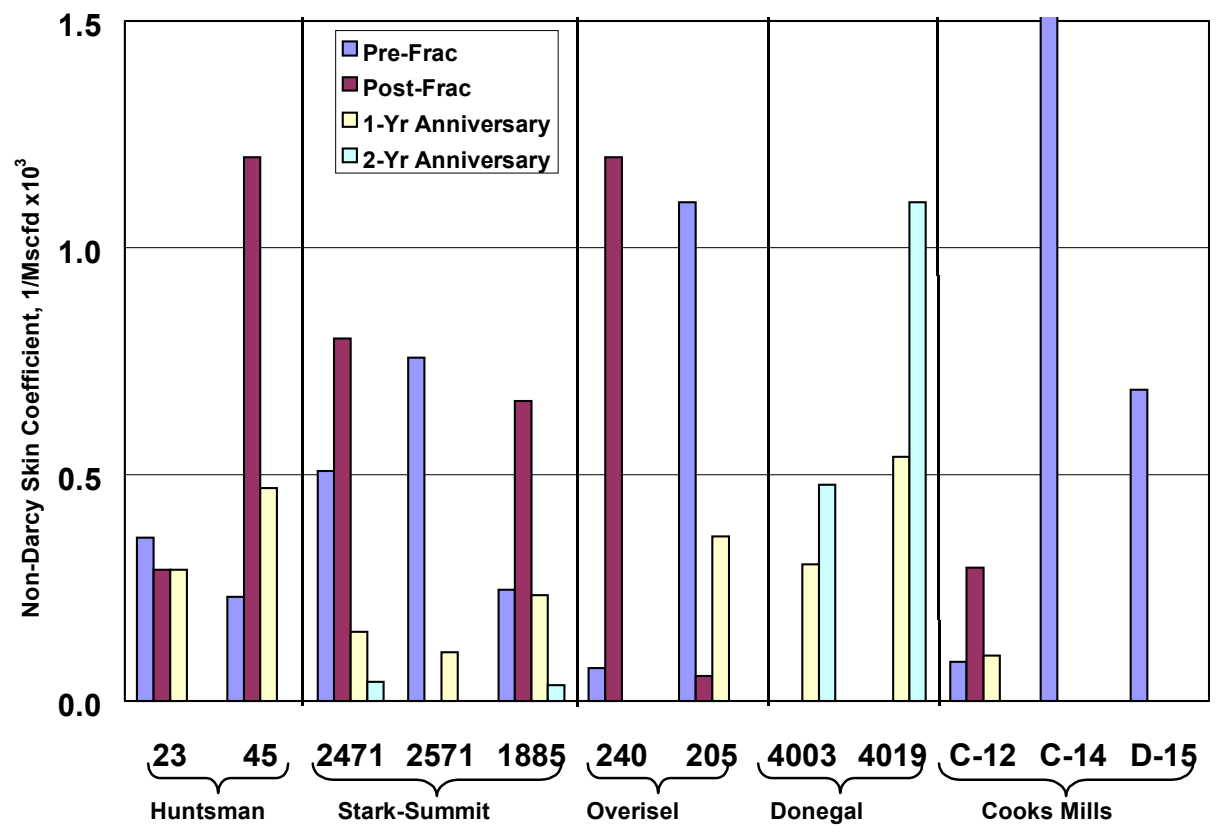

D COEFFICIENT.XLS 
Figure 3-6: Post-Frac Multiple-Isotope Tracer Log, Huntsman 23

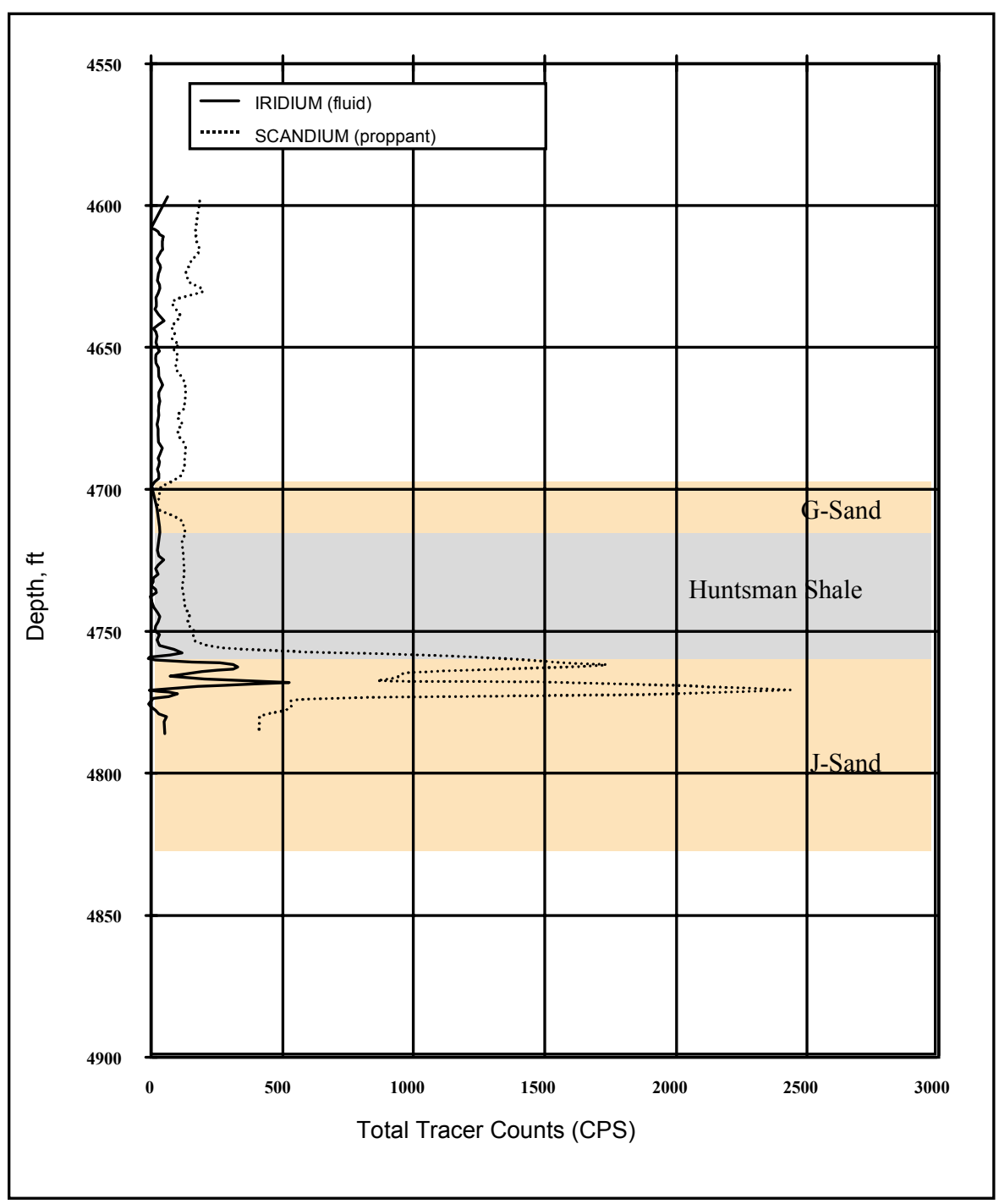

JAF00433.PPT

\subsection{Liquid $\mathrm{CO}_{2}$ with Proppant Fracturing}

Liquid $\mathrm{CO}_{2}$ with proppant fracturing was performed at two test sites, the Galbraith field in Pennsylvania and the Stark-Summit/Chippewa field in Ohio. Table 3-1, presented earlier, provides details on these two fields. Details on the field activities, treatments, tests, etc. can be found in separate technology reports created for this project. ${ }^{7}$ However, the results of the stimulations are summarized here. 
The deliverability enhancement results for these treatments are presented in Figure 3-13. At Galbraith, immediate and significant improvements in deliverability were achieved; the cleanup times required with aqueous fracturing appeared to be effectively eliminated. For all practical purposes, however, no improvement was achieved with this technique at Stark-Summit/Chippewa. This is discussed further below.

\section{Figure 3-1: Deliverability Results, Liquid $\mathrm{CO}_{2}$ Treatments}

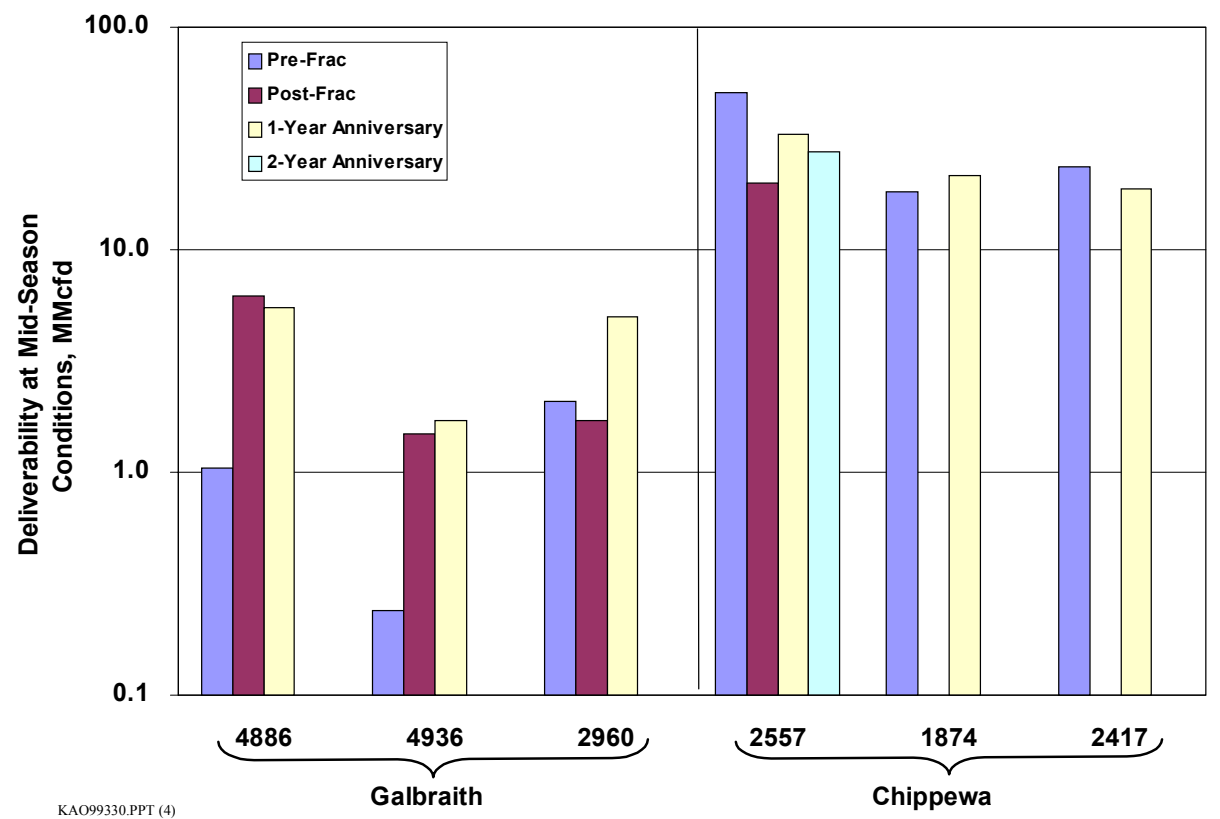

The permeability estimates resulting from each test are presented in Figure 3-14. The Galbraith permeabilities are quite high, similar to those at Huntsman. Therefore, it is difficult to state with certainty that the lack of a cleanup time is due to the use of liquid $\mathrm{CO}_{2}$, or an artifact of the high-permeability nature of the storage horizon (which presumably minimizes the fluid-cleanup effect as discussed in the previous section). However the case of Galbraith \#4936, with a (moderate) permeability similar to Huntsman \#23, showed an immediate improvement in deliverability whereas the Huntsman \#23 required a year of cleanup. Further, prior fracture treatments at Galbraith with water-based gels required years of cleanup. This suggests that the liquid $\mathrm{CO}_{2}$ does in fact provide the non-aqueous benefits expected from it. Note that the treatment appears to have little effect on the estimated permeability value, further suggesting that liquid $\mathrm{CO}_{2}$ does not create a deeply penetrating reduction in gas relative permeability. 
Figure 3-2: Permeability Results, Liquid $\mathrm{CO}_{2}$ Treatments

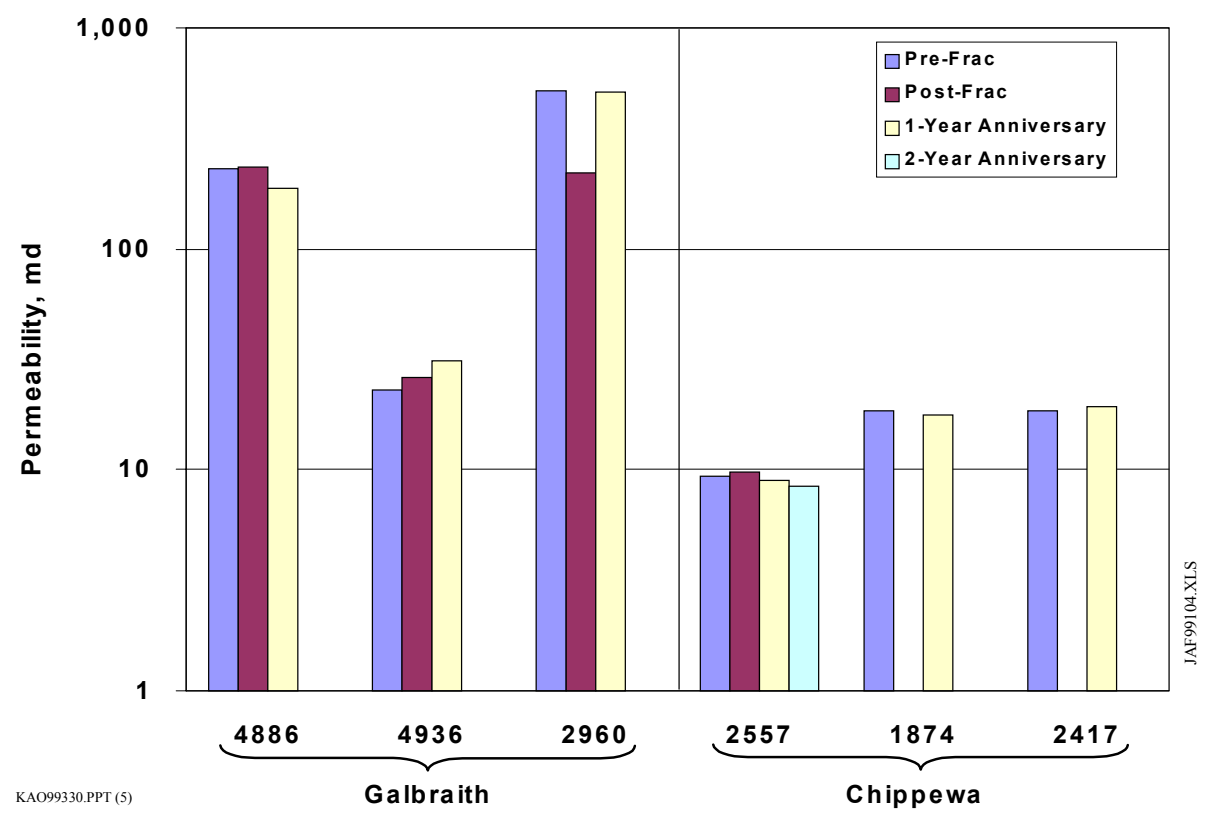

The skin factor results, total, mechanical and non-Darcy, are provided in Figures 3-15 to 3-17. Galbraith was characterized by high total skin values, which were effectively eliminated with the liquid $\mathrm{CO}_{2}$ and proppant fracture treatments. Unfortunately, the test data was insufficient to differentiate between mechanical and non-Darcy skin in these tests, so which component was responsible for the improvement cannot be conclusively determined in this case. For the Stark-Summit/Chippewa field however, this information is very informative. Similar to the wells which were treated at this field with the TSO techniques, the liquid $\mathrm{CO}_{2}$ candidates exhibited uniformly negative mechanical skins, and with little non-Darcy damage. Given the low viscosity of the liquid $\mathrm{CO}_{2}$, and an associated limited proppant carrying capacity, it was difficult for this technique to further enhance the conductivity of the pre-existing hydraulic fracture to improve these particular wells. While some reduction in mechanical skin was achieved, it was not significant and did not materially impact deliverability. It is interesting to note that at the StarkSummit/Chippewa field, due to the pervasively negative mechanical skins, significant deliverability enhancement could only be achieved through the reduction of non-Darcy skin. This is illustrated in Figure 3-18, where between the TSO and liquid $\mathrm{CO}_{2}$ treatments combined, deliverability enhancement was only achieved in those wells where the prestimulation value of the non-Darcy skin coefficient exceeded a value of $0.3 \times 10^{-3} 1 / \mathrm{MMcfd}$.

Similar to the TSO experiments, technological advancements were made with liquid $\mathrm{CO}_{2}$ fracturing that extended beyond demonstrating the deliverability results. Several lingering questions were answered with respect to whether the $\mathrm{CO}_{2}$ was actually in a liquid or vapor state at downhole conditions, and whether it would significantly contaminate the natural gas in storage. For the first time, a downhole pressure/temperature record was 
obtained and reported for a liquid $\mathrm{CO}_{2}$ with proppant treatment, at the StarkSummit/Chippewa field. That record is shown in Figure 3-19. Based on this information, the downhole conditions were plotted on a $\mathrm{CO}_{2}$ phase diagram (Figure 3-20), which conclusively demonstrated that the $\mathrm{CO}_{2}$ was in the liquid state at downhole conditions. Note that the temperature probe was immersed in a water column beneath the perforations and provided a very conservative (warm) temperature estimate. Thermodynamic simulations were performed to estimate the temperature range that existed at the perforations during the treatment.

To evaluate the contamination issue, at Galbraith, the post-stimulation flowback gas for two wells was monitored for $\mathrm{CO}_{2}$ content. The results of that monitoring, shown in Figure 3-21, reveal that all of the $\mathrm{CO}_{2}$ is effectively recovered after 50-70 hours of flowback. Hence, $\mathrm{CO}_{2}$ contamination does not appear to be a significant barrier to the use of this method.

Figure 3-3: Total Skin Results, Liquid $\mathrm{CO}_{2}$ Treatments

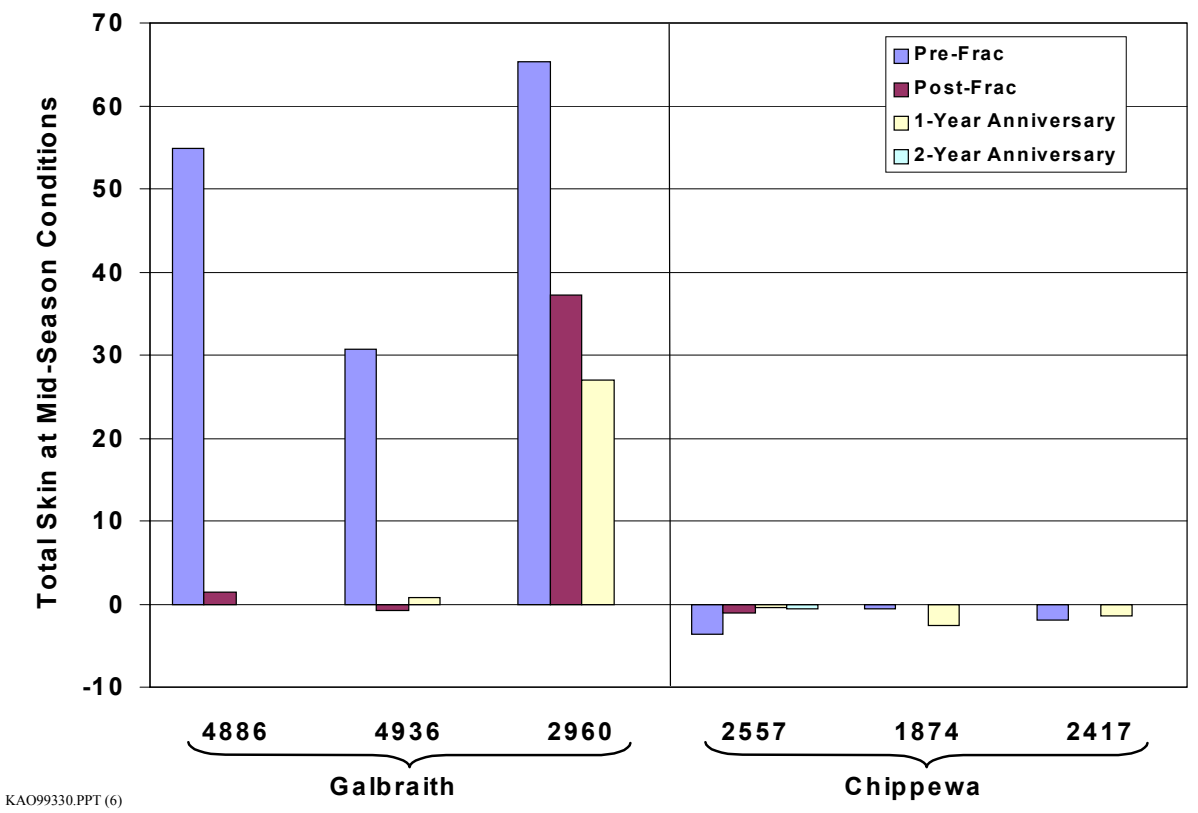


Figure 3-4: Mechanical Skin Results, Liquid $\mathrm{CO}_{2}$ Treatments

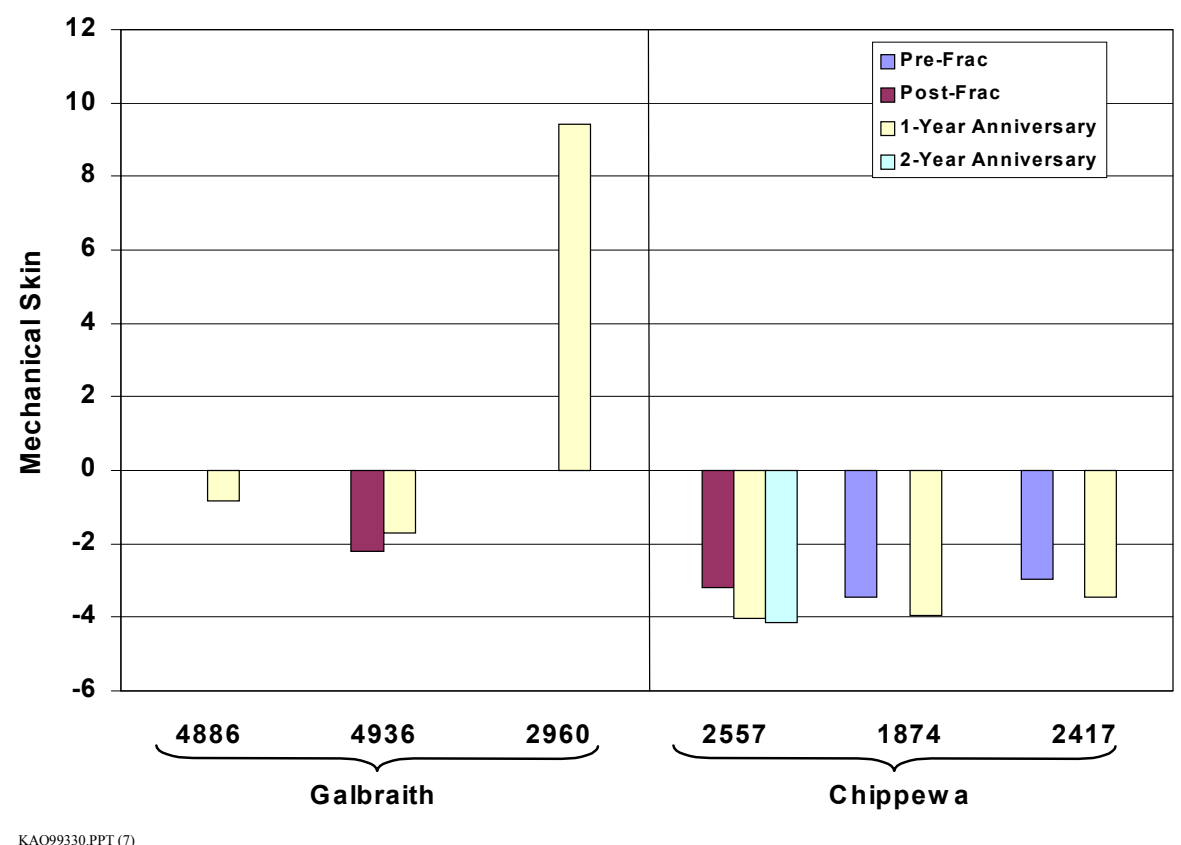

Figure 3-5: Non-Darcy Skin Results, Liquid $\mathrm{CO}_{2}$ Treatments

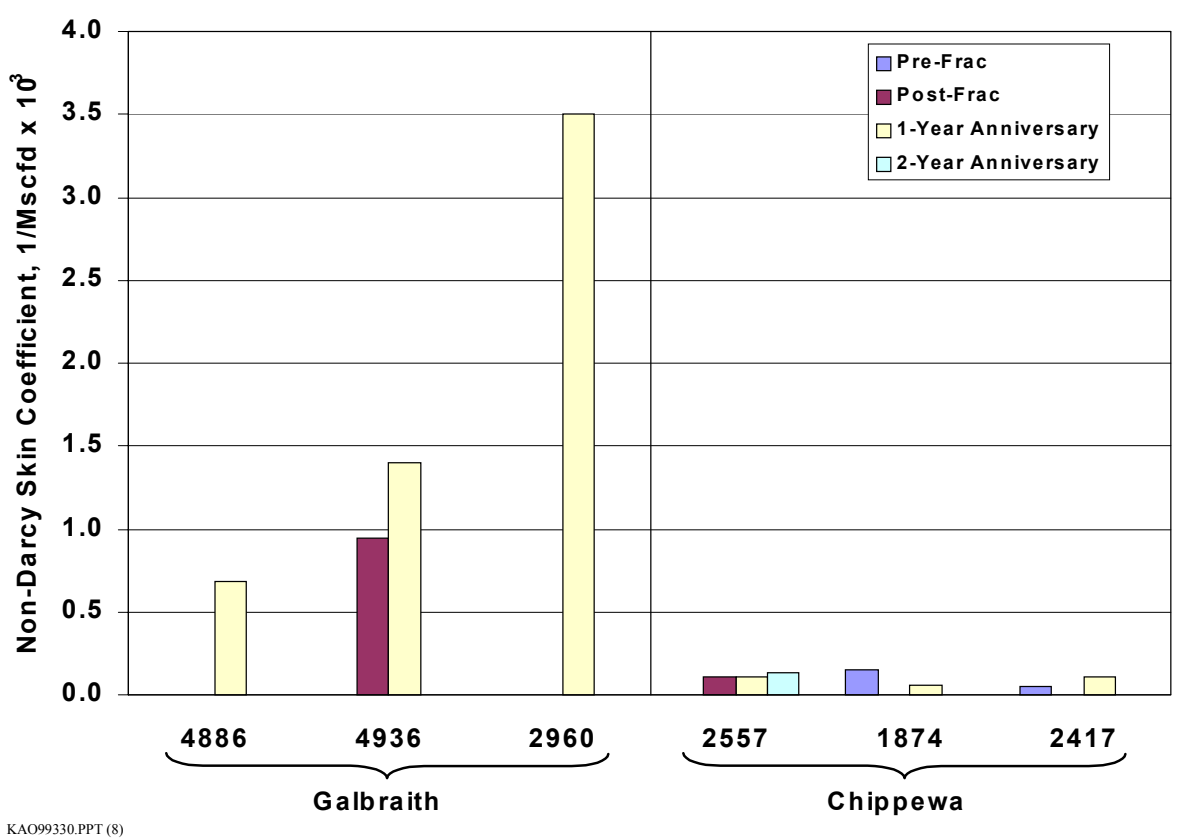


Figure 3-6: Pre-stimulation Non-Darcy Skin Coefficients, Stark-Summit/Chippewa Field

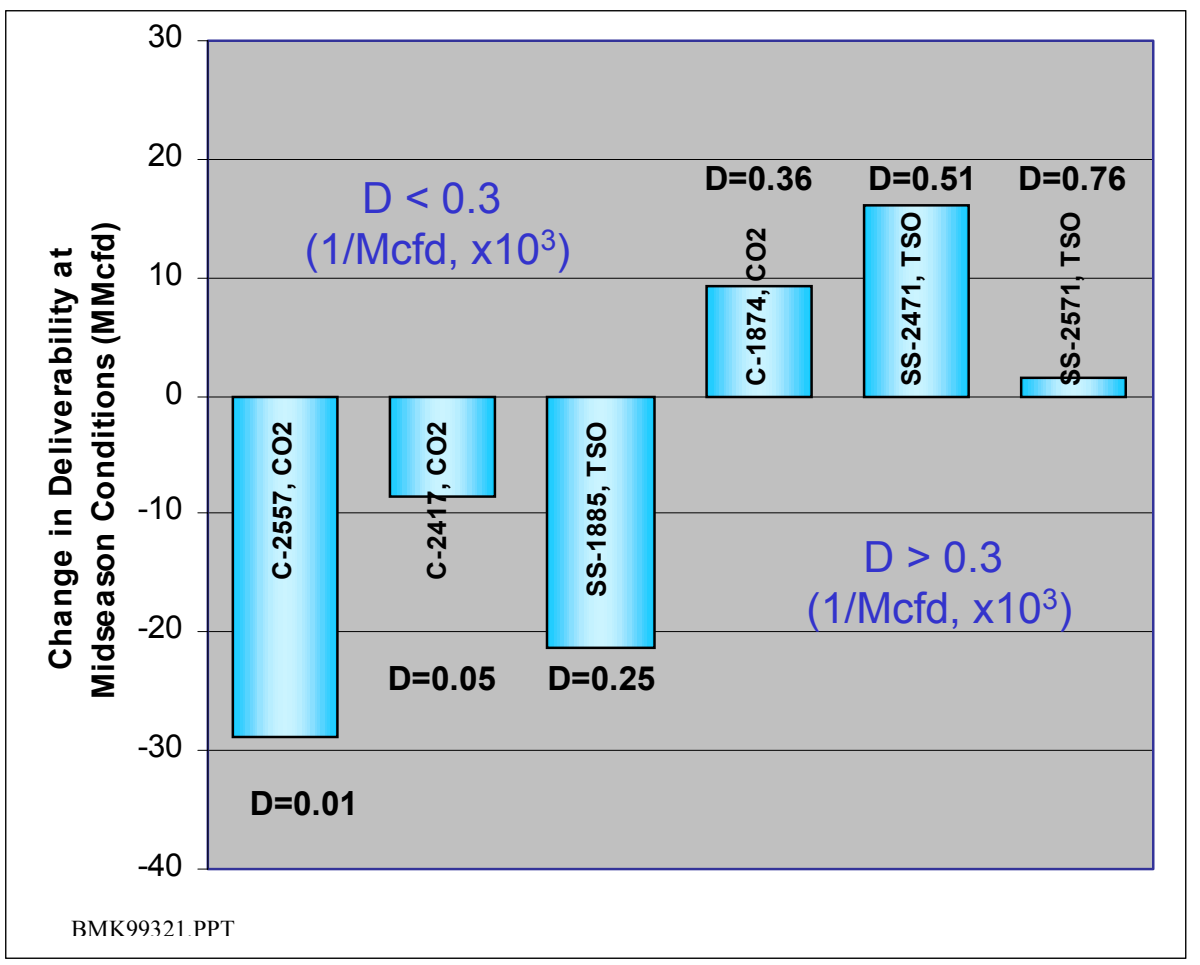

Figure 3-7: East Ohio Gas \#C-1874 Liquid $\mathrm{CO}_{2}$ Frac, Bottomhole Pressure/Temperature Record

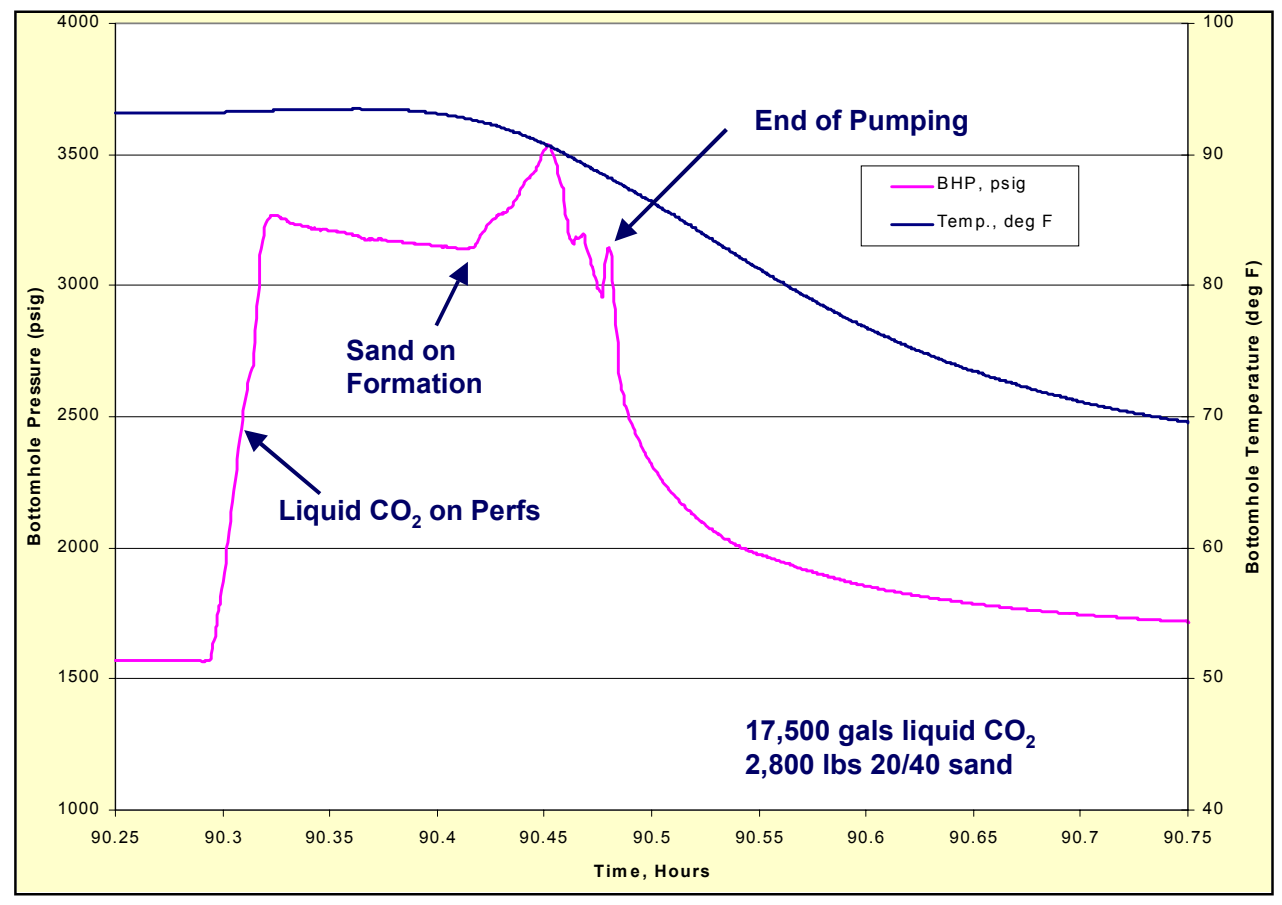

24 BMK99312.PPT 
Figure 3-8: $\mathrm{CO}_{2}$ Phase Diagram, Stark-Summit/Chippewa Well \#C-1874

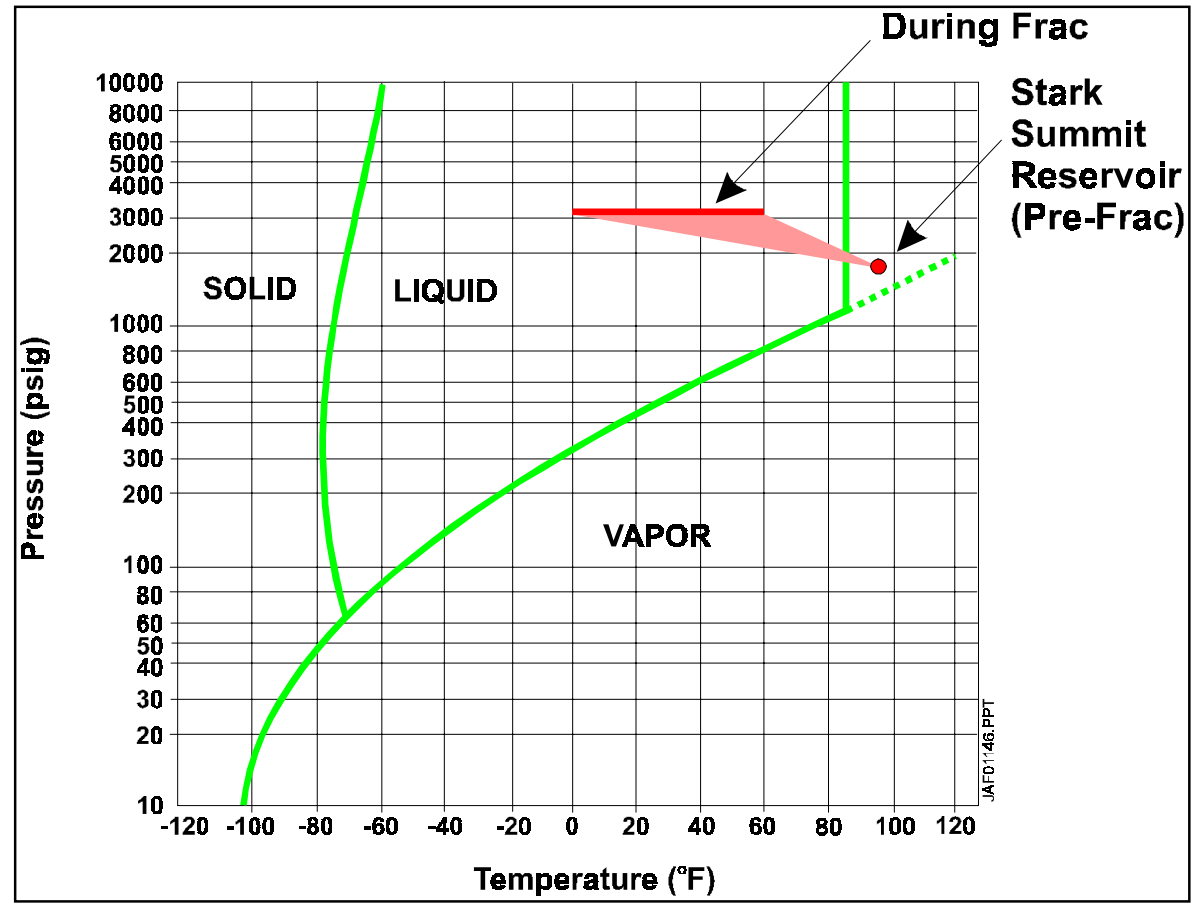

16 JAF00672.PPT

Figure 3-9: $\mathrm{CO}_{2}$ Content of Flowback Gas, Galbraith Test Site

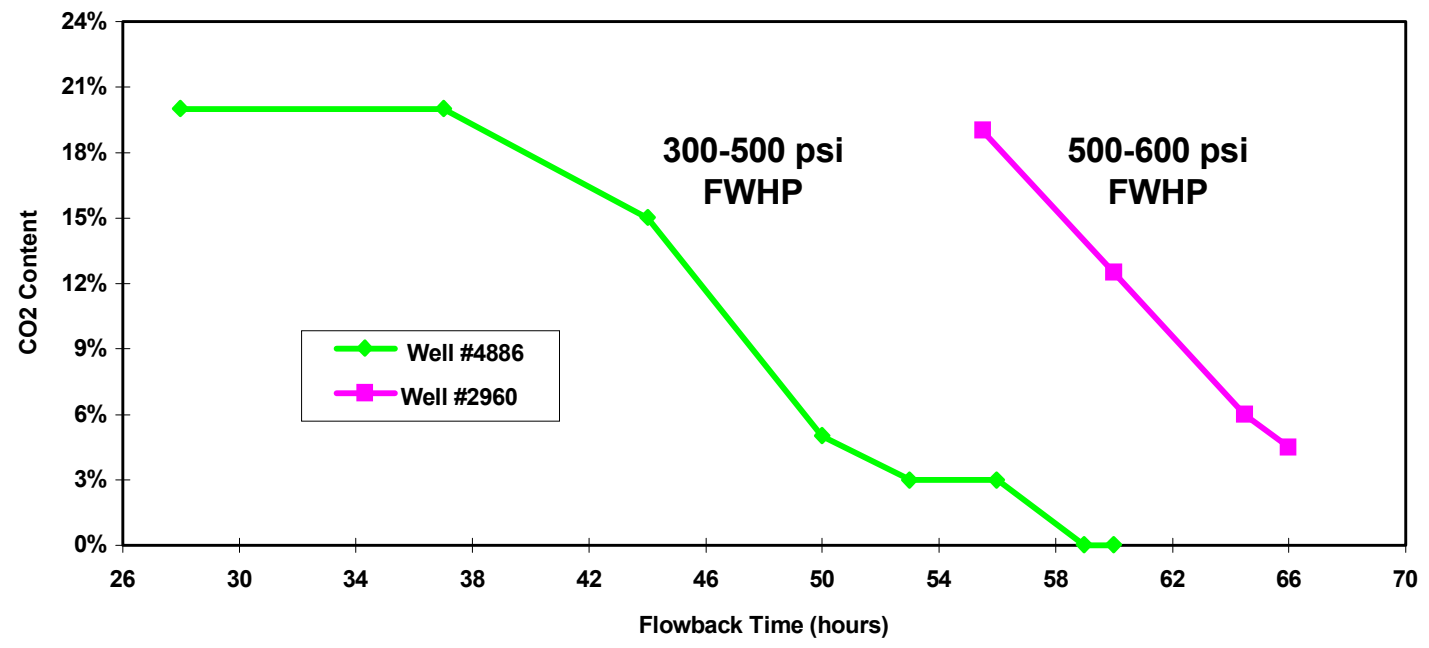

DME971M6.WPD 


\subsection{Pulse Fracturing}

Pulse fracturing methods, including both the EOB and HEGF techniques, were performed at four test sites. The EOB method was used at two wells at each the Donegal and Oakford fields, both in Pennsylvania, and in one well at the Cooks Mills site in Illinois. The HEGF method was tested on three wells in the Six Lakes field in Michigan. Note that four wells were actually treated at the Donegal site; two were in conjunction with recompletion operations and are therefore not valid for comparing pre- and post-stimulation deliverabilities. While the technical results of all four treatments are discussed in a separate report, ${ }^{8}$ only the results of the two "non-recompletion" treatments are presented here. Further, as also discussed elsewhere, ${ }^{8}$ the treatment at the Cooks Mills site failed mechanically, and hence no results are available to present here. Table 3-1, presented earlier, provides details on each of these fields. Details on the field activities, treatments, tests, etc. can be found in a separate technology report. ${ }^{8}$ However, the results of the stimulations are summarized here.

The deliverability results for the selected treatments are presented in Figure 3-22. What is clear is that in every case, deliverability declined immediately following each treatment. This was unexpected due to the small liquid volumes employed for these treatments. Further, little if any deliverability improvement was achieved even after "cleanup."

Figure 3-1: Deliverability Results, EOB and HEGF Fracturing Treatments

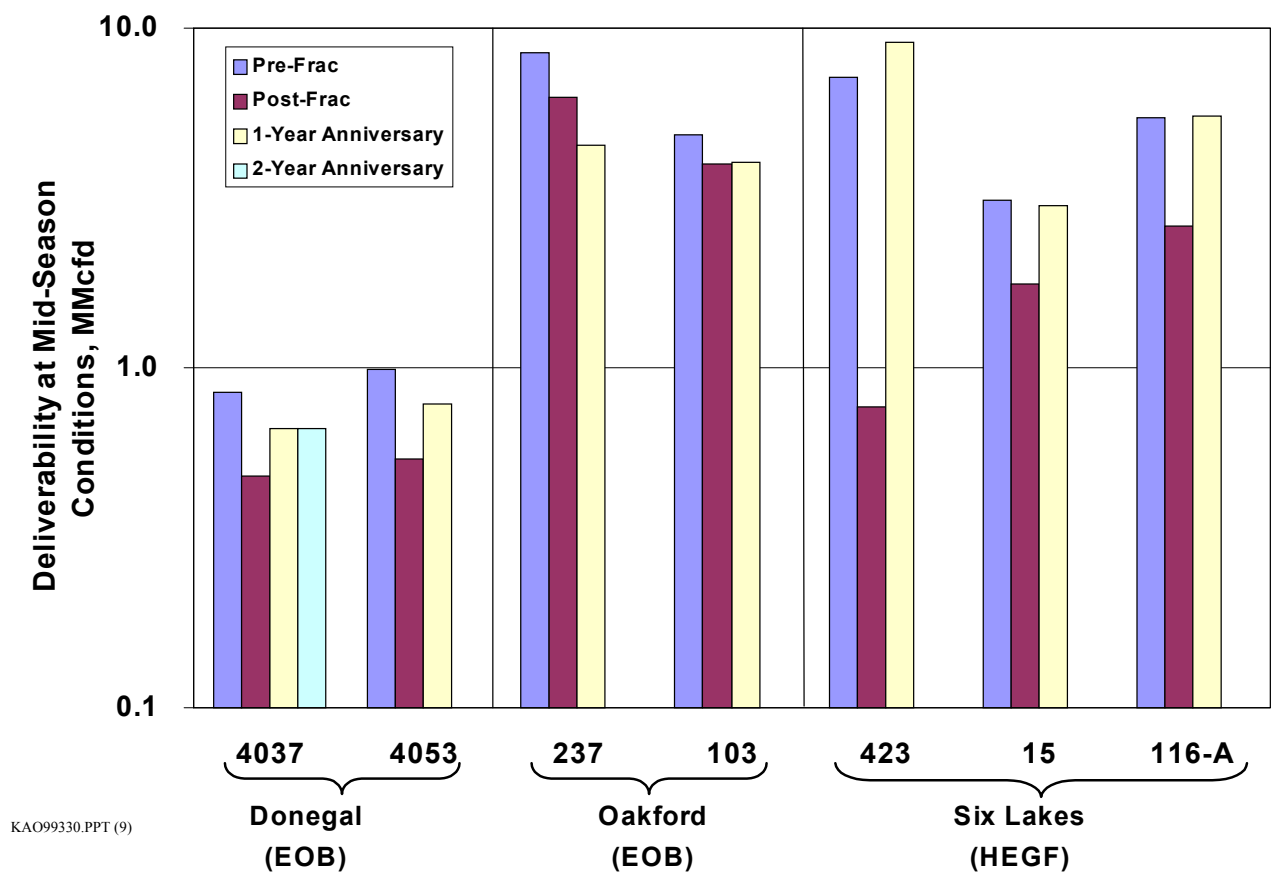


The permeability and total skin results from the tests are provided in Figures 3-23 and 3-24. From these plots it can be deduced that the treatments did not affect the estimated permeability values, hence the deliverability results must have been primarily governed by near-well (skin) phenomena. Figure 3-24 in fact shows a that a correlation appears to exist between the total skin factor and the deliverability. Total skin was relatively unaffected by the treatments at Donegal, appeared to get worse following the treatments at Oakford, and provided slight reductions in skin where the HEGF treatments were employed at Six Lakes (after cleanup). Examination of the mechanical and non-Darcy skin components does not provide further insights into these results, unfortunately (Figures 3-25 and 3-26).

Figure 3-2: Permeability Results, EOB and HEGF Treatments

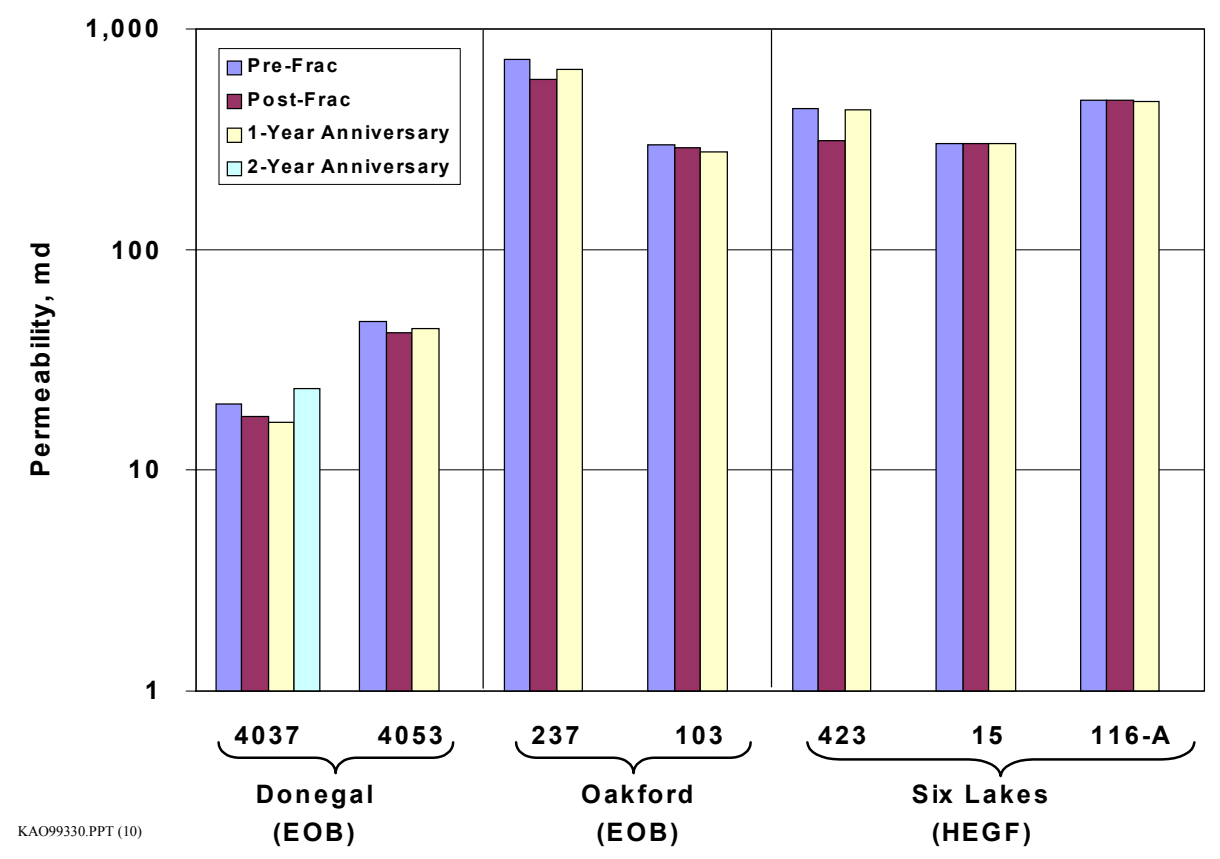


Figure 3-3: Total Skin Results, EOB and HEGF Treatments

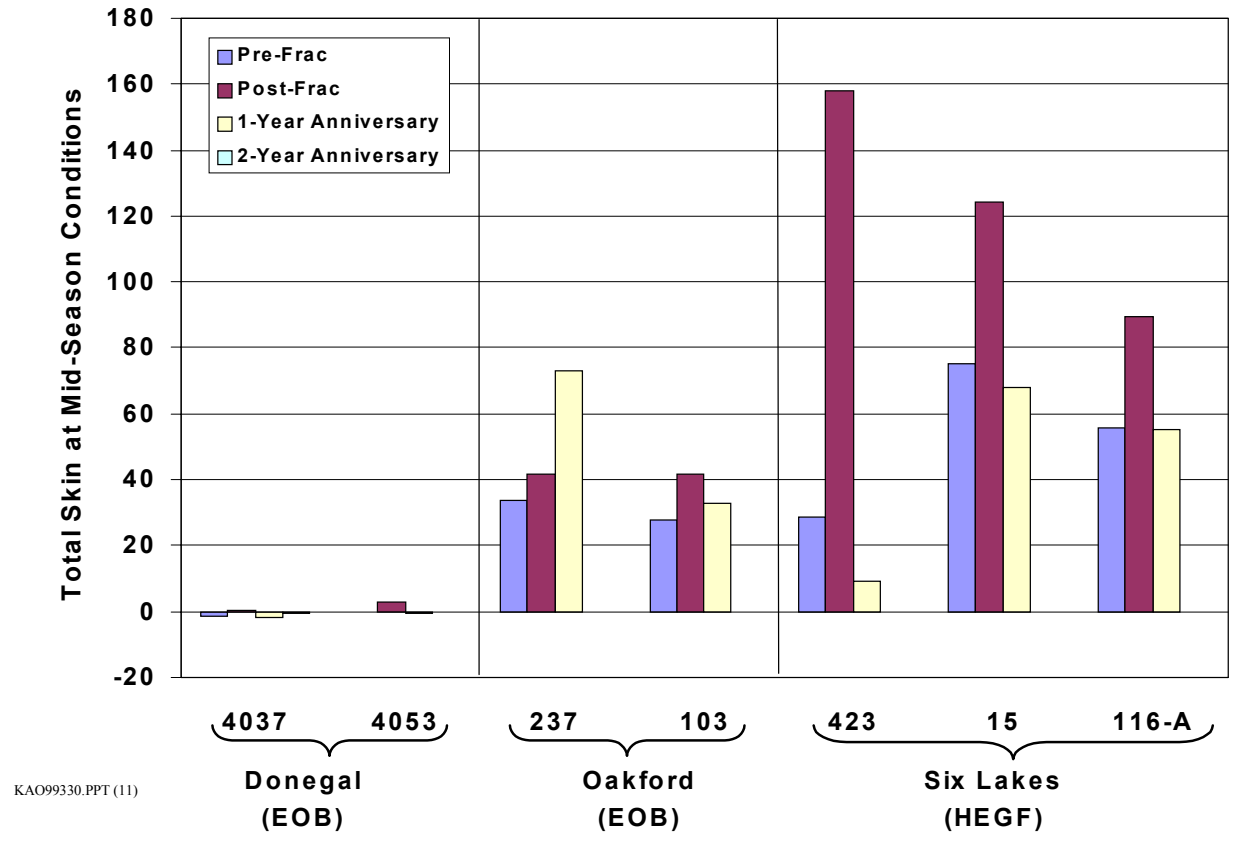

Figure 3-4: Mechanical Skin Results, EOB and HEGF Treatments

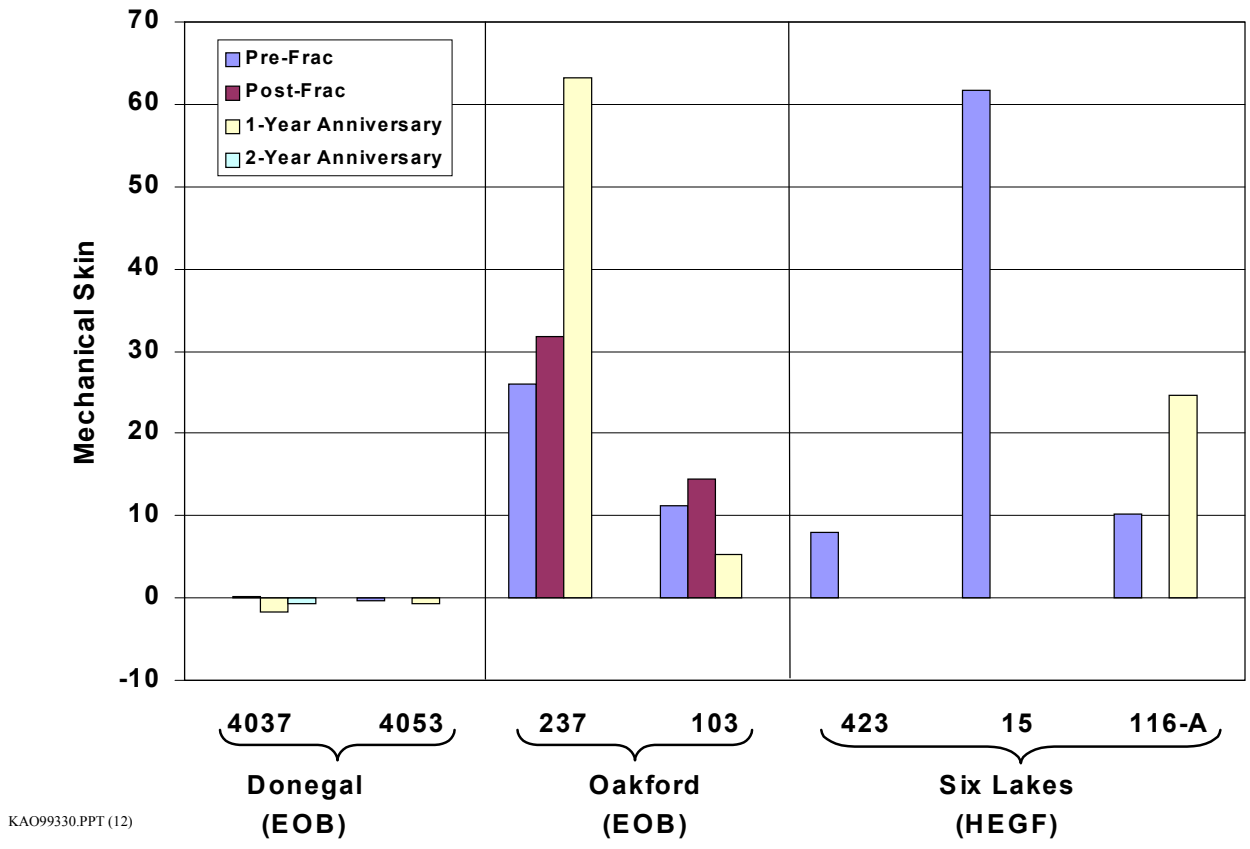


Figure 3-5: Non-Darcy Skin Results, EOB and HEGF Treatments

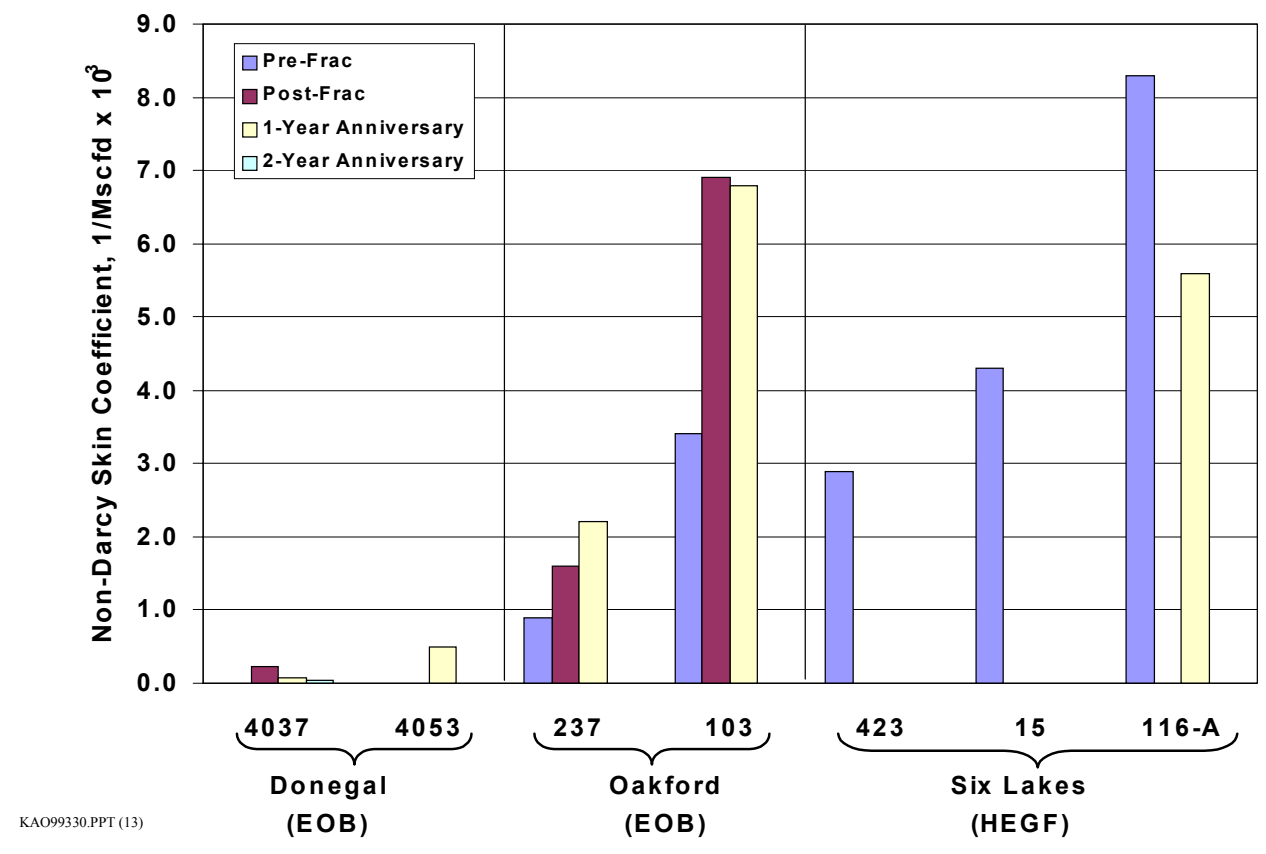

A brief discussion of the field activities is warranted to provide some insight into these results. At Donegal, the first EOB site in the program, an overall lack of engineering design tools (and their need) became apparent. Limitations were encountered in achieving formation breakdown by pressuring up the entire casing, and hence the treatments were of limited effectiveness. As a consequence, a dynamic simulation model was developed under the project for designing and analyzing EOB treatments. A sample output from that model is illustrated in Figure 3-27. Analysis of the EOB process using this model revealed that treatment success depends on achieving an optimum balance of fracturing fluid volume (the liquid at the bottom of the well), gas volume above it (to provide the energy), and the pressurization achieved. Too much liquid and there is not enough gas energy to create the momentum needed for fracture creation and extension (a common occurrence and the case at Donegal). Too little fluid results in small fractures. The optimization process, graphically illustrated in Figure 3-28, usually involves making trade-offs between the tubulars to convey the treatment (smaller tubulars allow higher pressures but limit liquid and gas volumes), and the liquid/gas volumes/heights. 
Figure 3-6: Sample EOB Model Output

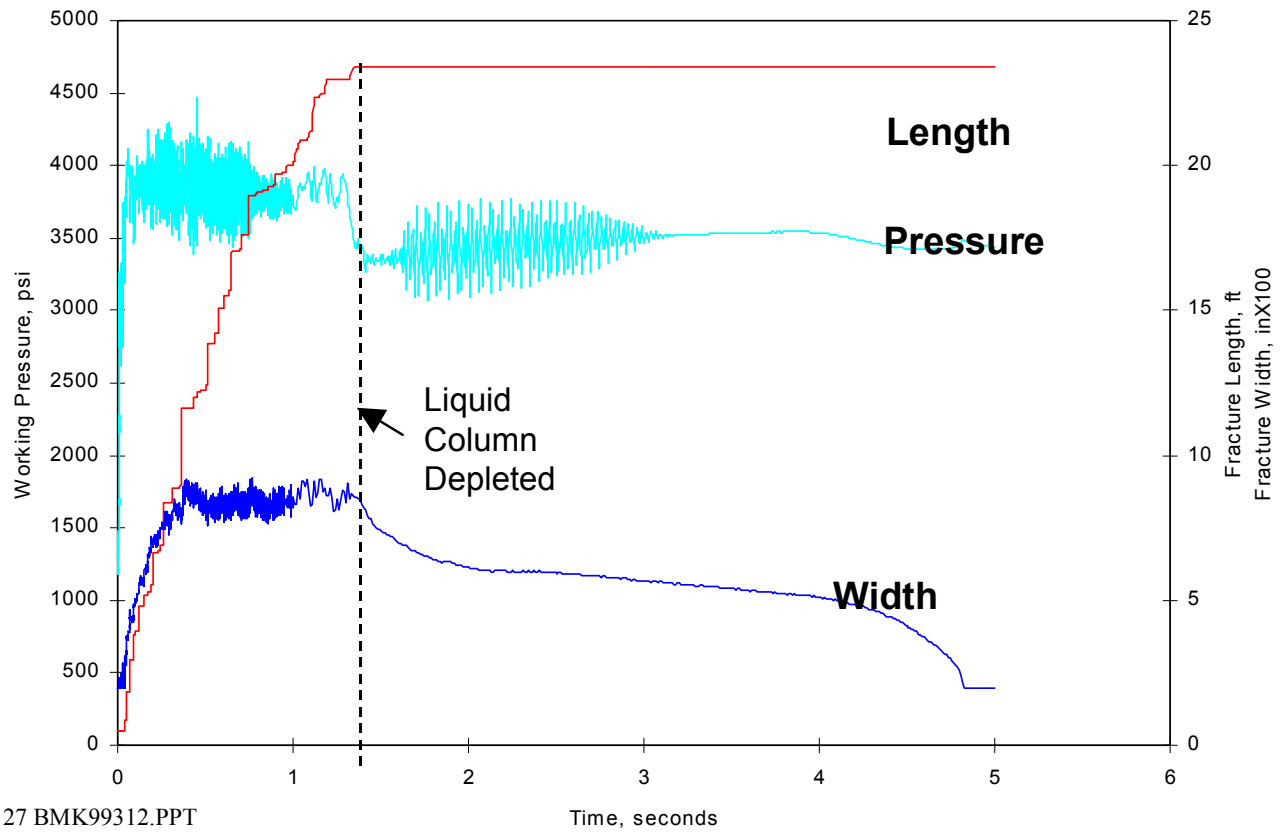

Figure 3-7: EOB Optimization Process

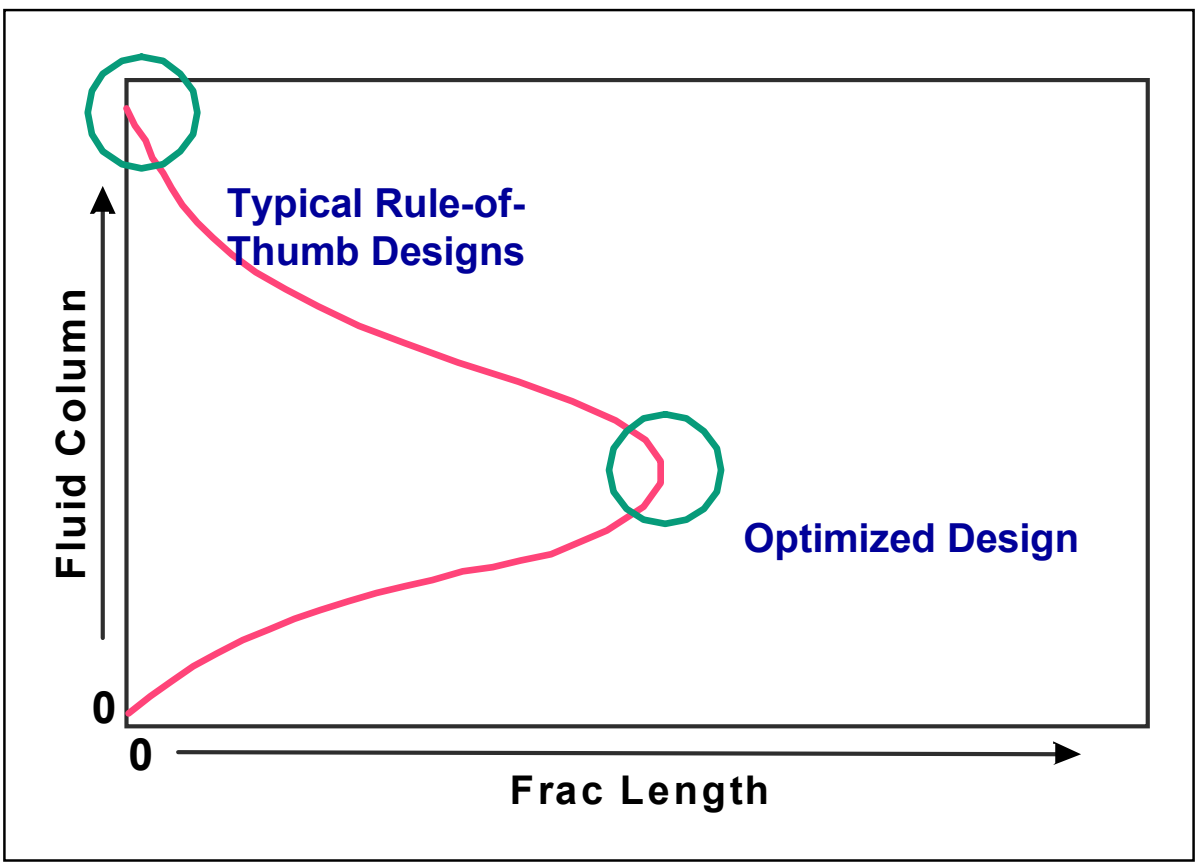

28 BMK99312.PPT 
At Oakford, with the benefit of the new model, a high-pressure work string was employed to convey the treatment. However, operational complexities associated with the downhole configuration resulted in mechanical failures. Nevertheless, for the first time a downhole pressure record was obtained for a storage well EOB treatment (Figure 3-29). Subsequent fishing operations with kill fluid in the well is surmised to have voided any potential stimulation effect achieved with the treatments. Hence, while it became obvious in the program that a better understanding of the mechanics of the process was needed to design effective treatments, and that operational procedures should be kept simple, achieving both objectives simultaneously can be difficult.

Figure 3-8: Downhole Pressure Record of EOB Treatment, Oakford \#103

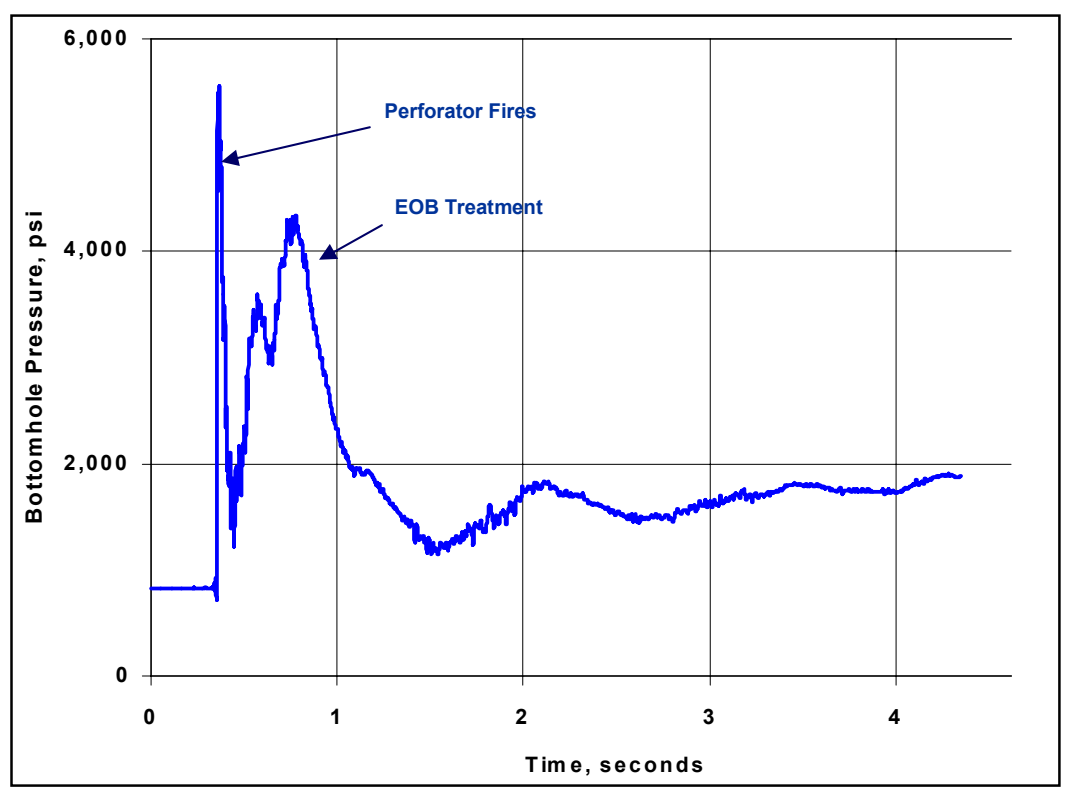

26 BMK99312.PPT

The HEGF approach can, at least partially, solve these challenges. The downhole pressures reached are much higher than those achieved with the EOB technique (over $10,000 \mathrm{psi}$ ), and they are relatively simple to implement (similar to perforating). A downhole pressure record for a well at the Six Lakes field is presented in Figure 3-30. Due to the high downhole pressures reached, concerns exist over the pressure rating of the surface equipment. However, since the treatment volumes are small and designed such that pressure was directed through the perforations and not up the hole, the surface impact was minimal. The surface pressure record corresponding to the downhole record in Figure 3-30 is presented in Figure 3-31, and shows that this was in fact the case. In the specific instance of the Six Lakes field, while the treatments were successfully executed and slight improvements in skin were achieved, deliverability was not materially enhanced. The damage mechanism leading to deliverability decline in this field is known to be salt deposition. Simply put, creating a series of unpropped fractures near the well may not substantially mitigate this type of damage, and therefore deliverability was not improved. 
Figure 3-9: Downhole Pressure Record of HEGF Treatment, Six Lakes \#15

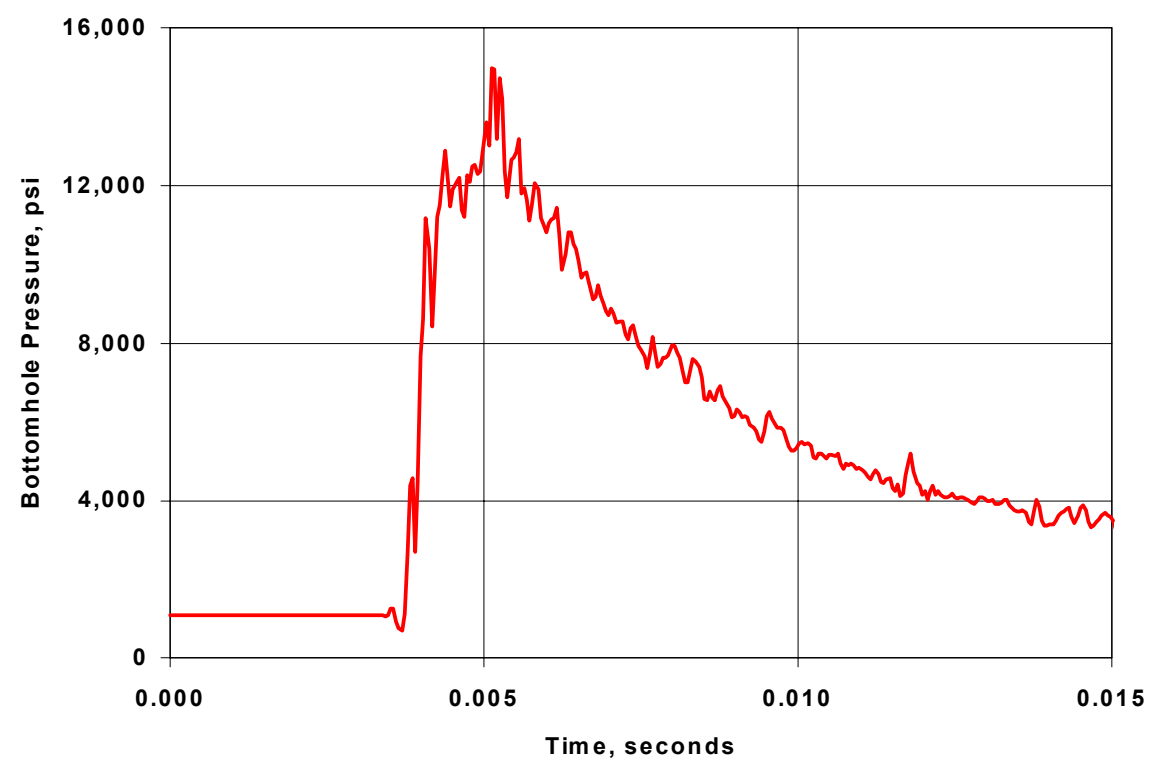

11 JAF00674.PPT

Figure 3-10: Surface Pressure Record of HEGF Treatment, Six Lakes

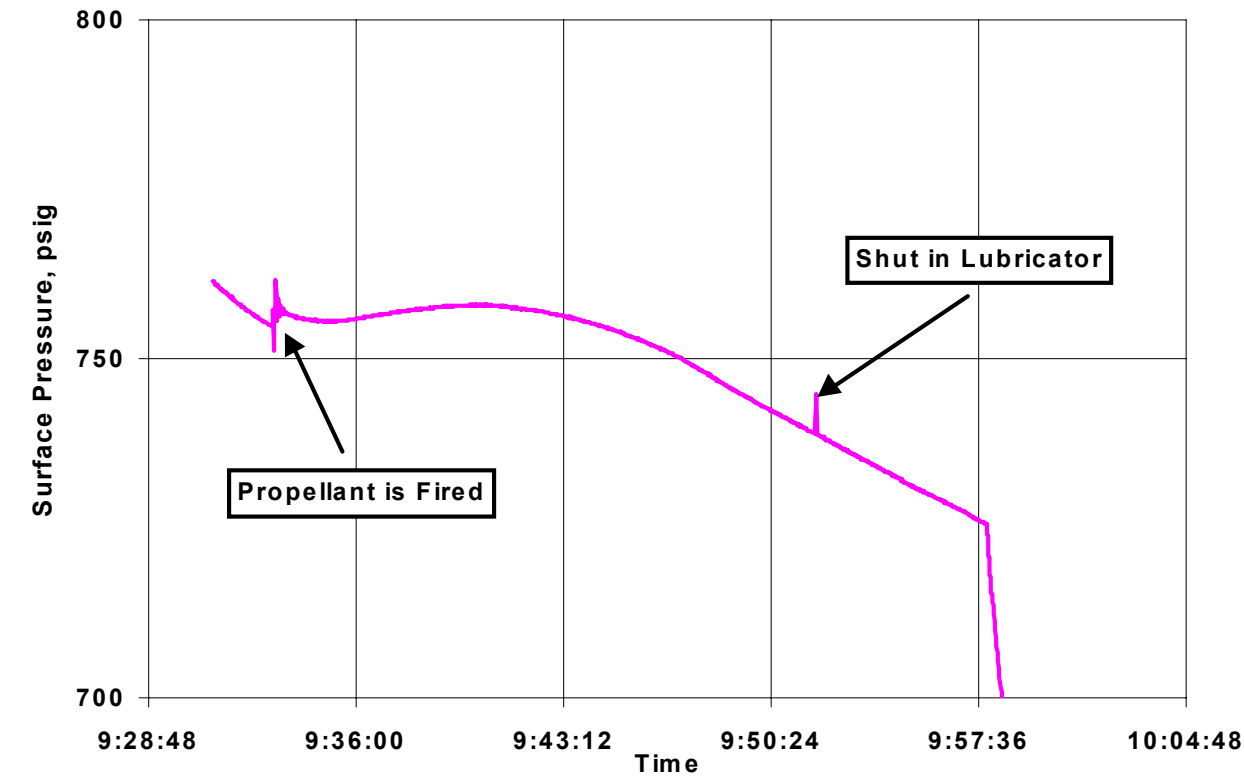

12 JAF00674.PPT 
Hence, while deliverability enhancement was not demonstrated with the pulse fracturing technologies in this project, much was learned about them. Further, advances to the technologies in terms of data, design and design tools were achieved, which should improve the opportunities for their application in the future. 


\subsection{Economic Assessment of Deliverability Enhancement}

While important technical issues have been addressed in this project regarding the applicability of fracturing for gas storage wells, the fundamental question is whether such "new and novel" stimulation methods are more economically attractive than those stimulation methods historically employed by gas storage operators. Hence, the analytic approaches used by industry to economically evaluate deliverability enhancement activities became an important component of the investigation. In the following sections, the economic analysis methods currently utilized by industry for this purpose are described, as well as their limitations, and two proposed new methods (each with a different objective) are presented. Economic evaluation results for each technique at each test site, compared with the "conventional" stimulation benchmarks, are also presented.

\subsection{Current Evaluation Approaches and Limitations}

It was discovered over the course of the project, based on discussions with many operators on the subject, that the most common approach to evaluating the economics of deliverability enhancement is to measure the immediate improvement in deliverability achieved from a given activity, and then to divide that into the cost of the stimulation treatment (or workover, new well, etc.), to arrive at a cost metric in units of $\$ / \mathrm{Mcfd}$. Obviously, operators seek to perform deliverability enhancement activities that minimize the value of this metric. While at first pass this approach seems reasonable, it is important to understand what is being evaluated with this approach, and the several important limitations it has.

Most fundamentally, rather than being a true economic evaluation method in the sense of estimating the value created for a given investment, it is a measure of the cost of deliverability maintenance. In other words, the approach is based upon the fact that a certain deliverability level for a well or field must be maintained for facility certification purposes in a given market (both geographic and storage service type), with the challenge being to minimize the cost of maintaining that deliverability level and assuming some deliverability decline rate if left unaddressed. While in concept this approach is valid in a normal operational setting, it is important to recognize that it is a measurement of cost, not value creation.

Technically, however, there are limiting assumptions this simple approach possesses compared to what actually occurs in practice. Three issues are particularly noteworthy. First, as most storage operators know, the deliverability response of a well to a stimulation (or other) treatment is not static over time. Rather, the deliverability is highly variable, and the magnitude and extent of that variability are at least in part a function of the treatment performed. To illustrate, Figure 4-1 provides a hypothetical deliverability response to a stimulation treatment in a gas storage well. At first, and not uncommon, there may actually be a reduction in deliverability immediately following a treatment, possibly a result of nearwell fluid resaturation effects. Over time, that "damage" is cleaned up and the deliverability benefit of the stimulation treatment is only then realized. These effects have been observed in the field results from this project. After a certain amount of time, deliverability should again decline as the damage mechanisms that originally led to deliverability deterioration, 
such as fines mobilization, scale deposition, the introduction of foreign particulate matter, etc., become the dominant factor for decreasing well deliverability until, ultimately, the prestimulation condition is again reached. Clearly, the overall life-cycle deliverability impact, including the magnitude of maximum deliverability enhancement as well as the duration over which enhancement is gained, must be the overriding consideration for an economic evaluation, and not just the immediate impact, which can be misleading.

Secondly, the cost of both the treatment and subsequent costs over the life-cycle must be considered. For example, a hydraulic fracture treatment may provide a considerable and long-lasting deliverability improvement (after a period of fluid cleanup), but may also require subsequent workovers to remove accumulated proppant from the wellbore that can flow-back over the normal course of gas withdrawal operations. These subsequent costs must also be considered when comparing the costs of various deliverability enhancement approaches. Third, and particularly important when making comparisons of deliverability responses to different treatments in different wells with different pre-stimulation conditions, is how to normalize them to a common baseline. For example, a $10 \mathrm{MMcfd}$ improvement in deliverability for a well with "high" permeability and "high" pre-stimulation skin condition may not be as effective a treatment as achieving the same result in a "low" permeability well with "low" pre-stimulation skin. Being able to normalize these comparisons to a common pre-stimulation deliverability level is critical when evaluating the relative effectiveness of various well enhancement methods. Only then can the most effective deliverability enhancement strategies be identified.

\section{Figure 4-1: Hypothetical Deliverability History Following a Stimulation Treatment}

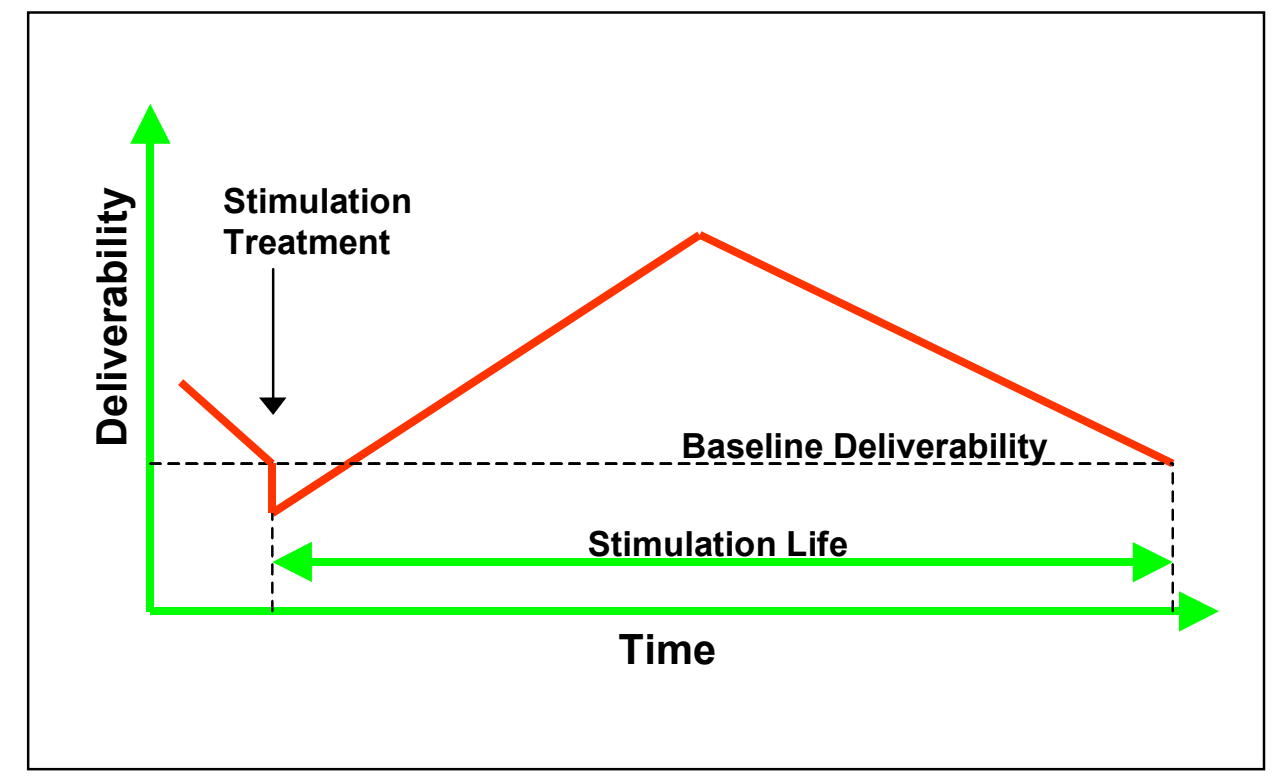

1 BMK99323.PPT 
While these three issues address improvements to measuring the cost of deliverability maintenance, another approach is to economically evaluate, in the more traditional sense, the economic benefit (return) that can be achieved by increasing overall field deliverability. In this case, an example would be if deliverability from a given field could be improved by a certain amount, could that storage facility then be utilized for shorter-term, higher-value service with a corresponding increase in revenue? To illustrate, Figure 4-2 presents a hypothetical relationship between the revenue generation potential of a gas storage field as a function of the term of service being offered. Shorter-term, higherdeliverability service is synonymous with higher value assets. Further, a 1996 GRI study found deliverability was the most sought-after aspect of storage service; deliverability was generally equated with flexibility in service provision ${ }^{9}$, and hence customers are willing to pay more for it. The rapidly evolving nature of storage service availability and price transparency has only recently made this second approach relevant.

Figure 4-2:

Hypothetical Revenue Generation Potential of a Storage Asset vs. Service Type (fixed working gas volume)

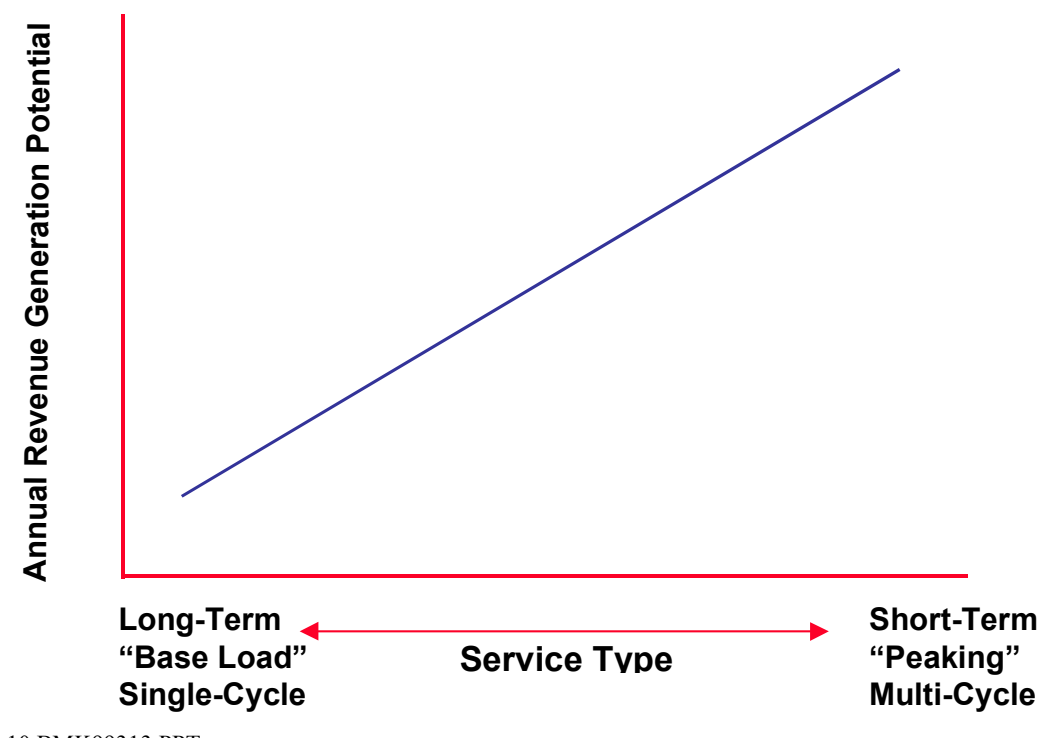

10 BMK99313.PPT

\subsection{Proposed New Methods}

The following section presents two new approaches for evaluating the economics of gas storage well deliverability enhancement, which begin to address the issues raised in the preceding discussion. The first method is specifically designed for evaluating the cost of deliverability maintenance, and the second is for application when the economic viability of facility upgrade to shorter-term, higher-value service is being considered. Note that these methods are not suggested to be the definitive solutions to the economic evaluation challenge. Rather, they are put forth as a framework within which such evaluations should 
be performed, but with many potential variations (and improvements) possible for each particular application.

\subsubsection{Cost/Benefit Analysis for Deliverability Maintenance}

While the new method for deliverability maintenance cost/benefit analysis still incorporates many simplifying assumptions, it represents a considerable improvement over the more commonly applied approach that utilizes only instantaneous deliverability and cost information. First, for each treatment (or well), an average deliverability improvement over the "stimulation life" is estimated (Figure 4-3). Both the average deliverability and the "stimulation life" require some knowledge of the deliverability profile over time; since this information is frequently unknown in a timely manner (if ever), some probability analysis is required to deal with this uncertainty. However, the information collected as part of this project, namely one pre- and two post-stimulation deliverability and pressure transient tests for each well in the project, has provided an opportunity to better understand this profile.

\section{Figure 4-1: Conceptual Illustration of Cost/Benefit Analysis Approach}

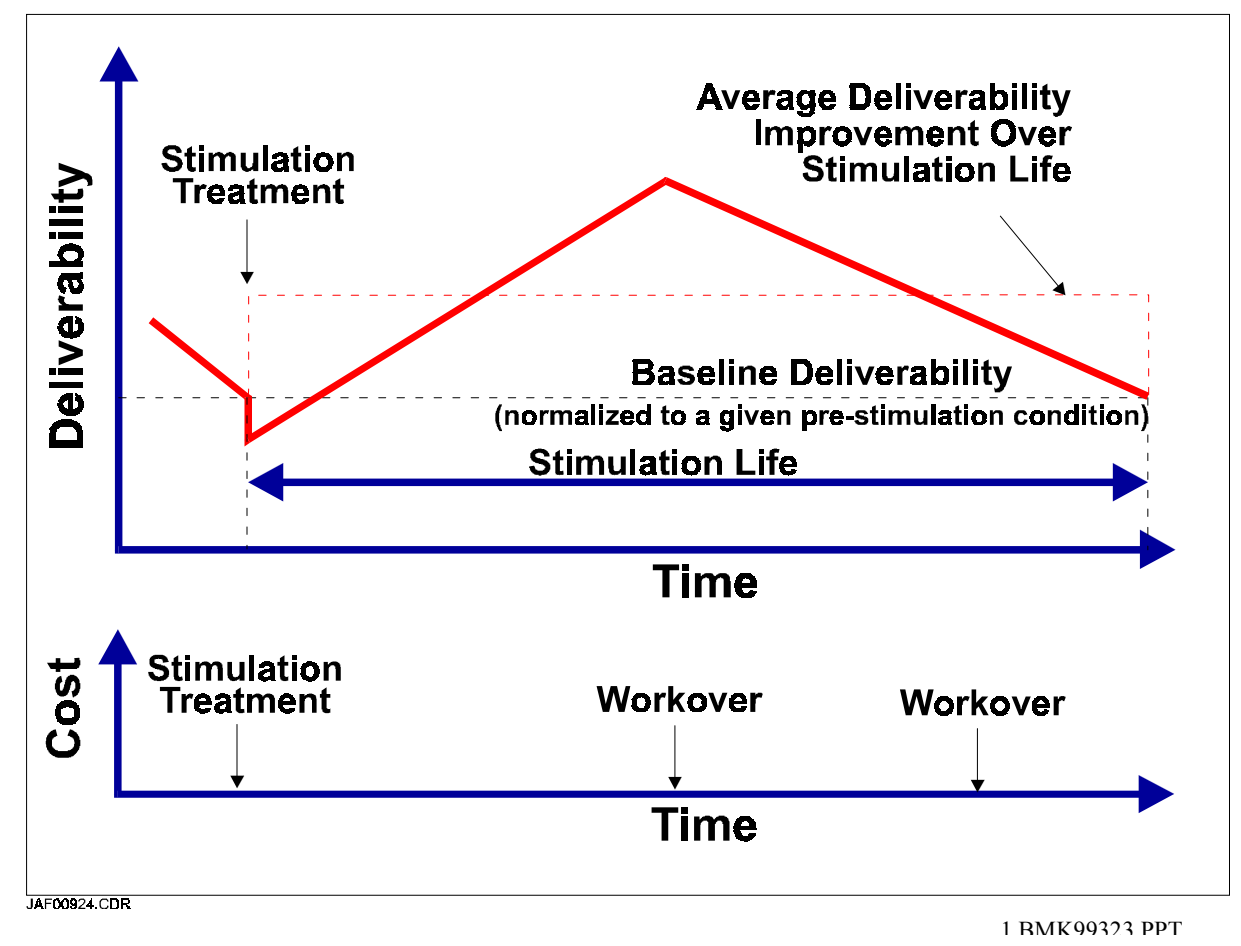

Using the average deliverability enhancement over the "stimulation life" is a necessary simplification because there is no currently identified approach to evaluate the time-value of deliverability. This highlights an important area for further investigation. Even with this new proposed approach, two wells with the same average deliverability enhancement, stimulation life and stimulation cost will have the same estimated cost of deliverability enhancement. However, it seems intuitively obvious that if one provided a greater deliverability response in early time, it would be more "valuable." Hence, the 
concept of the time-value of deliverability should, at some point, also be considered and incorporated into the analysis.

Second, to account for the total costs associated with a stimulation treatment, including subsequent workovers that could be required, as well as differing "stimulation lives", all life-cycle costs are estimated at a discounted net present value and then divided by the "stimulation life" to obtain an estimated annual expenditure (in present-value dollars). To compute the cost/benefit ratio, the average deliverability enhancement is then divided into this value, and the resulting metric is $\$ / \mathrm{Mcfd} / \mathrm{year}$. This metric can then be used to compare the cost of deliverability maintenance between different deliverability enhancement approaches.

Finally, and important if comparisons are to be made between wells with very different pre-stimulation conditions, the baseline deliverability level should be normalized to a consistent pre-stimulation condition which approximates the average conditions at the field in question. The post-stimulation deliverability enhancement level is then determined by using folds-of-increase (FOI) estimates as determined from actual well responses. In this manner, comparisons between treatments can be made from a consistent baseline deliverability level. An important assumption in this approach is that the post-treatment skin factor achieved in each well would be the same as that achieved for a well with the baseline permeability and pre-stimulation skin condition.

\subsubsection{Economic Evaluation of Storage Asset Upgrading}

The more traditional approach to economic evaluation is to estimate the "value" created resulting from an investment using net-present-value (NPV) concepts. In the discussion above, that approach was not applied since "value" is not being created, but rather deliverability is being maintained. A cost/benefit approach is therefore more appropriate for that situation. However, as conceptually illustrated in Figure 4-2, a significant increase in the revenue generation potential of a gas storage facility may be possible by improving deliverability such that it can be utilized for shorter-term, highervalue service. While the potential for and attractiveness of a facility upgrade is largely dependent upon the given storage reservoir characteristics as well as market conditions in the immediate vicinity, the approach to economic evaluation is, at least in concept, relatively straightforward. In essence, a conventional NPV analysis is performed using the investment required to upgrade the facility to the desired service type, and the potential additional revenue estimated.

Several important issues must be considered when performing such an evaluation. First, on the investment side of the equation, the total costs to upgrade a facility must be considered, not just costs to stimulate wells. For example, additional infill wells may be required, as would upgrades to the gathering, compression and gas treating facilities. Hence, a total system approach must be adopted. On the revenue side of the equation, some consideration must be given to the degree to which the full revenue generation potential of the upgraded facility would be realized, and over what time period (e.g., for five or ten years, in perpetuity, etc.). In addition, how many injection/withdrawal cycles could be realized in a year with each service type? While these types of issues are familiar to 
financial analysts, it is worthy to note their existence and importance to the problem being discussed here.

\subsection{Example Applications}

Below are three examples of the proposed new economic evaluation approaches. The first is a cost/benefit analysis of two well enhancement techniques that were tested at the Huntsman gas storage field in Nebraska. The second example, taken from the Galbraith gas storage field in Pennsylvania, is similar in nature, but includes the procedure to normalize the pre-stimulation deliverability. The final example is a case where the upgrade of a storage asset to shorter-term, higher-value service is being considered. This last (hypothetical) example examines the maximum capital expenditures that could be afforded to upgrade a facility to different levels of shorter-term service and yield an attractive return on investment.

It should be noted that the cost values for deliverability maintenance presented should be viewed in a relative and not absolute sense, and for general guidance only. With the many assumptions inherent in the analytic results, the quantitative values must be viewed with caution. For example, changing the stimulation life alone can have an important effect on the analytic outcome. Thus, as presented at the beginning of this chapter, these approaches are suggested as a working framework, not absolute procedures.

\subsubsection{Tip-Screenout Fracturing vs. Wellbore Cleanouts}

The first example is taken from the Huntsman field in Nebraska, operated by KN Energy. In this case, tip-screenout fracturing was being evaluated as a means to improve deliverability in this high-permeability (i.e., hundreds of millidarcies) reservoir. For benchmarking purposes, a wellbore cleanout with coiled tubing was performed in one well, a deliverability enhancement approach frequently used in the field, to compare the costs and benefits of each technique. The comparison serves as a useful example of a cost/benefit analysis of an inexpensive, short-term enhancement technique versus a longer-term, more expensive one using the new economic evaluation method.

The information needed to perform the analysis is summarized in Table 4-1. Here, the only parameters for which actual data exists are the pre- and post-stimulation deliverability levels, and the treatment costs. This raises an important issue with respect to both typical data gathering procedures of gas storage operators, and the proposed approach to cost/benefit analysis. First, the deliverability information presented in this example was obtained via a multi-point deliverability and pressure transient test using downhole instrumentation, and is believed to be of high quality and accuracy. Unfortunately, such data for gas storage wells is not common; rather, single-point surface deliverability data is usually collected, the results of which are highly dependent upon reservoir and surface conditions at the time of testing, and hence can be misleading when comparisons are made. Secondly, given the uncertainty in the remaining data, statistical methods such as MonteCarlo simulation are advised to perform the cost/benefit analysis, at least until such time as more and better information on deliverability profiles following stimulation treatments are collected. The collection of such information on deliverability profiles of gas storage wells 
should therefore be a topic of future research, as well as a priority of operators to improve the economic performance of their assets.

The remaining (unknown) input data were estimated as follows. First, the average deliverability decline rate for the field is about $9 \%$ per year. For the cleanout treatment, a decline rate of $50 \%$ greater was assumed since the added effect of wellbore fill would tend to accelerate the decline; for the fracture treatment, a value of $50 \%$ less was assumed since the lesser (near well) pressure drop resulting from the induced hydraulic fracture would likely mitigate most formation damage mechanisms (e.g., fines mobilization, scale deposition, etc.). Second, the time to reach the peak rate would be zero for the cleanout treatment, but a value of 5 years was assumed for the fracture treatment. This is not inconsistent with deliverability histories observed from other gas storage fields. Finally, the maximum peak rate for the fracture treatment was assumed to be $50 \%$ greater than the immediate post-stimulation response. Again, improvements in deliverability response from fracture treatments of several orders of magnitude have been observed in some cases, and hence a $50 \%$ value is not unrealistic (and may be conservative). The peak rate for the cleanout treatment would be the immediate post-treatment response. The resulting deliverability profiles for each well are illustrated in Figure 4-4.

Finally, no subsequent workovers would be expected for the cleanout treatment, but one wellbore cleanout workover to remove accumulated proppant every fifth year for the fractured well was assumed, at a cost of $\$ 13,600$ each. Lastly, for the purposes of MonteCarlo simulation, a standard deviation for each of the assumed parameters of $25 \%$ of the mean value was used. While no actual data exists to support this assumption, it is not unreasonable for the purpose of this example.

Table 4-1: Economic Parameters for Huntsman Field

\begin{tabular}{|c|c|c|c|c|}
\hline \multirow[b]{2}{*}{ Deliverability Profile } & \multicolumn{2}{|c|}{$\begin{array}{c}\text { Well HS-8 } \\
\text { Coiled Tubing Cleanout }\end{array}$} & \multicolumn{2}{|c|}{$\begin{array}{c}\text { Wells HS-23/45 } \\
\text { Tip-Screenout Fracs }\end{array}$} \\
\hline & $\underline{\text { Mean Value }}$ & $\frac{\text { Standard }}{\text { Deviation }}$ & $\underline{\text { Mean Value }}$ & $\frac{\text { Standard }}{\text { Deviation }}$ \\
\hline Pre-Stimulation Deliverability (MMcfd)* & 45.0 & $\mathrm{~N} / \mathrm{A}$ & 29.0 & $\mathrm{~N} / \mathrm{A}$ \\
\hline Post-Stimulation Deliverability (MMcfd)* & 61.8 & $\mathrm{~N} / \mathrm{A}$ & 50.0 & $\mathrm{~N} / \mathrm{A}$ \\
\hline Peak Post-Stimulation Deliverabiity (MMcfd)* & 61.8 & N/A & 75.0 & 18.8 \\
\hline Time to Reach Peak (Years) & 0.0 & N/A & 5.0 & 1.3 \\
\hline Post-Peak Decline Rate (\%/Year) & 13.5 & 3.4 & 4.5 & 1.1 \\
\hline \multicolumn{5}{|l|}{ Cost Information } \\
\hline Stimulation Cost (\$) & $\$ 13,600$ & N/A & $\$ 26,900$ & N/A \\
\hline Subsequent Workover Cost (\$) & N/A & N/A & $\$ 13,600$ & N/A \\
\hline Workover Frequency (years between) & N/A & N/A & 5.0 & 1.3 \\
\hline \multicolumn{5}{|l|}{ Financial Assumptions } \\
\hline Discount Rate $(\% /$ Year $)$ & 12.0 & N/A & 12.0 & $\mathrm{~N} / \mathrm{A}$ \\
\hline
\end{tabular}


Figure 4-1: Deliverability Forecasts, Huntsman Field, Nebraska

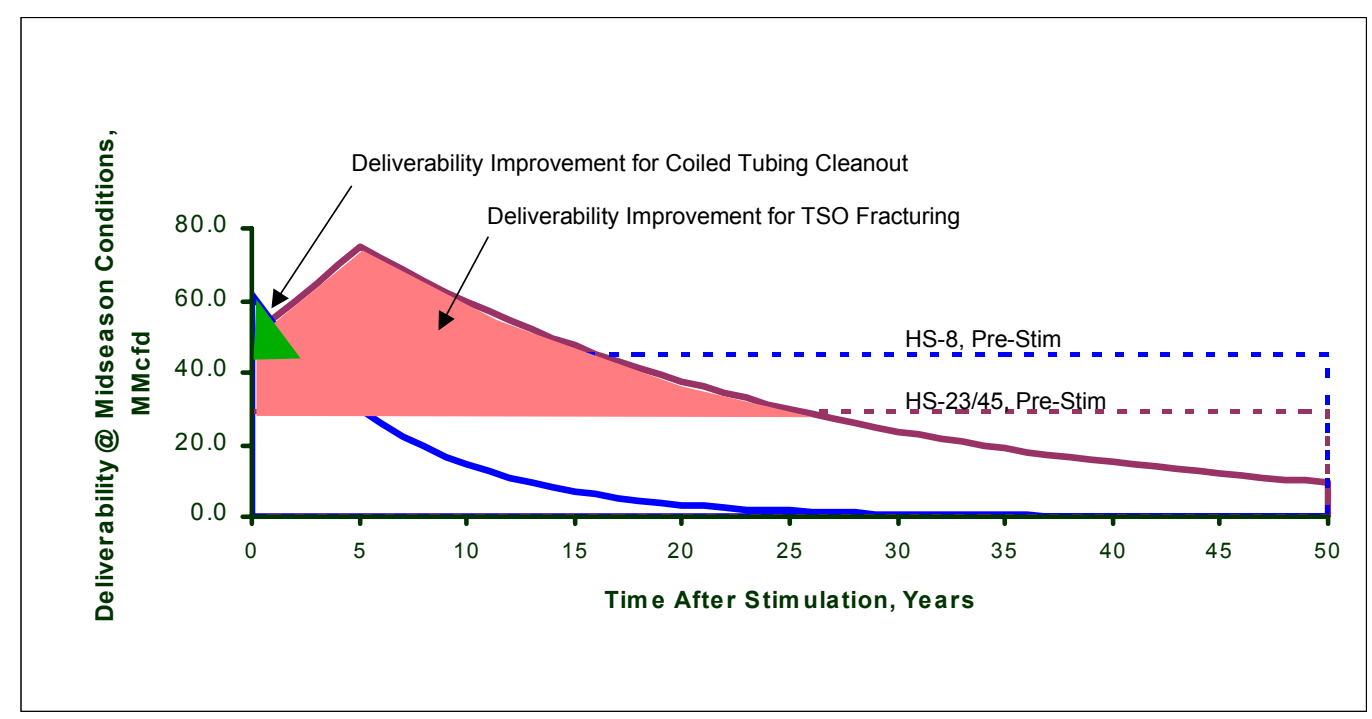

KAO99330.PPT (15)

The results of the analysis are shown in Figure 4-5. The average cost of deliverability maintenance is $\$ 0.08 / \mathrm{Mcfd} /$ year for the tip-screenout treatment, and $\$ 0.77 / \mathrm{Mcfd} /$ year for the cleanout treatment. In contrast, if only immediate deliverability response and costs were considered, one would deduce that the cleanout treatments were more cost effective, providing added deliverability at a cost of $\$ 0.81 / \mathrm{Mcfd}$ as compared to $\$ 1.28 /$ Mcfd for the tip-screenout treatments. This example clearly shows why life-cycle deliverabilities and costs must be considered when comparing deliverability enhancement strategies, not just short-term data.

Figure 4-2: Cost/Benefit Analysis Results, Huntsman Field

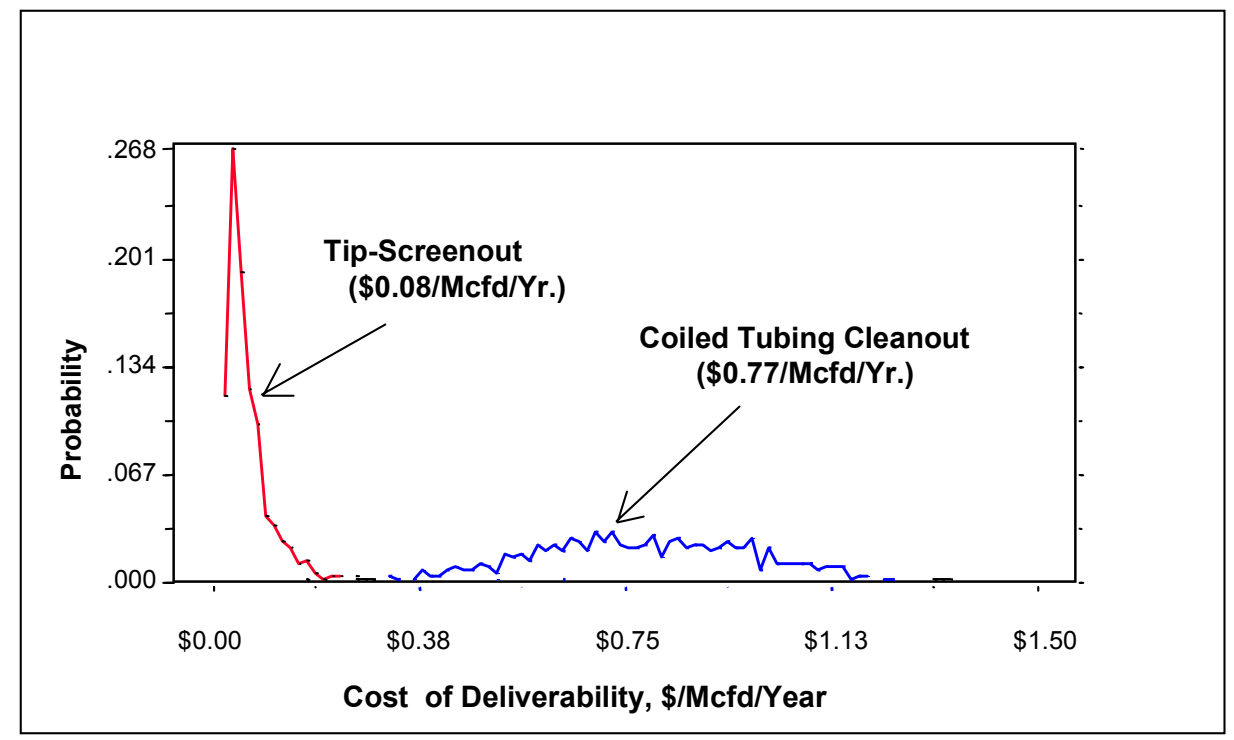

KAO99330.PPT (16) 


\subsubsection{Liquid $\mathrm{CO}_{2}$ with Proppant Fracturing vs. Conventional Gelled- Water Fracturing}

The second example is taken from the Galbraith field in Pennsylvania, operated by National Fuel Gas Supply. Here, the benefit of fracturing with liquid $\mathrm{CO}_{2}$ and proppant was being investigated; substantial deliverability benefits were realized earlier at the field when fracturing with traditional aqueous-based (gelled-water) systems, but required over ten years in some cases to fully realize the deliverability gain (presumably due to fluid damage and cleanup reasons). Liquid $\mathrm{CO}_{2}$ is a non-aqueous, non-damaging fracturing fluid that may hold considerable potential in achieving immediate deliverability benefits from fracturing in gas storage wells by eliminating the fluid cleanup period, although it is more expensive. An additional consideration needed for this example is related to the fact that the wells in which the gelled-water treatments were performed had different pre-stimulation deliverability conditions than where the liquid $\mathrm{CO}_{2}$ with proppant treatments were performed. Hence some normalization of the deliverability responses to a common pre-stimulation baseline is required.

The input data for the analysis is provided in Table 4-2. Unlike the previous example, longer-term deliverability and cost information was actually available to perform the analysis (mostly single-point surface data however). An average baseline pre-stimulation deliverability level of 1.1 MMcfd was determined from the well tests on the liquid $\mathrm{CO}_{2}$ stimulated wells, and the FOI was based on similar types of well tests for the liquid $\mathrm{CO}_{2}$ stimulated wells, and on single-point surface deliverability data for the gelledwater treated wells (which were the only pre- /post-stimulation data available). A poststimulation deliverability decline rate of $5 \%$ per year was estimated for both sets of wells based on historical deliverability information for the field. It was assumed that the time to reach the peak rate for the liquid $\mathrm{CO}_{2}$-treated wells was zero (i.e., no fluid cleanup time), but was 14 years for the gelled water treatments, again based on actual single-point deliverability data. The peak FOI for the gelled-water treatments was about 4.7 based on the single-point data, and was 5.0 (the immediate post-stimulation response) for the liquid $\mathrm{CO}_{2}$ treatments. The immediate post-stimulation FOI for the gelled-water treatments was 1.3. The resulting deliverability profiles for each treatment type are illustrated in Figure 4-6. 
Table 4-1: Economic Parameters for Galbraith Field

\begin{tabular}{|c|c|c|c|c|}
\hline \multirow[b]{2}{*}{$\underline{\text { Deliverability Profile }}$} & \multicolumn{2}{|c|}{$\begin{array}{c}\text { Wells 4139,4140,4699 } \\
\text { Conventional Gelled-Water Fracs }\end{array}$} & \multicolumn{2}{|c|}{$\begin{array}{c}\text { Wells 2960,4886,4936 } \\
\text { Liquid } \mathrm{CO}_{2} \text { w/Proppant Fracs }\end{array}$} \\
\hline & Mean Value & $\underline{\text { Standard Deviation }}$ & Mean Value & $\underline{\text { Standard Deviation }}$ \\
\hline Pre-Stimulation Baseline Deliverability (MMcfd)* & 1.1 & NA & 1.1 & NA \\
\hline Post-Stimulation Folds-of-Increase* & 1.3 & NA & 5.0 & NA \\
\hline Peak Post-Stimulation Folds-of-Increase* & 4.3 & 1.2 & 5.0 & NA \\
\hline Time to Reach Peak (Years) & 14.0 & 3.5 & 0.0 & N/A \\
\hline Post-Peak Decline Rate (\%/Year) & 5.0 & 1.3 & 5.0 & 1.3 \\
\hline \multicolumn{5}{|l|}{$\underline{\text { Cost Information }}$} \\
\hline Stimulation Cost (\$) & $\$ 21,200$ & NA & $\$ 50,300$ & NA \\
\hline Subsequent Workover Cost (\$) & $\$ 9,000$ & NA & NA & NA \\
\hline Workover Frequency (years between) & 5.0 & 1.3 & NA & NA \\
\hline \multicolumn{5}{|l|}{ Financial Assumptions } \\
\hline Discount Rate (\%/Year) & 12.0 & NA & 12.0 & N/A \\
\hline
\end{tabular}

KAO99330.PPT (17)

Figure 4-1: Deliverability Forecasts, Galbraith Field

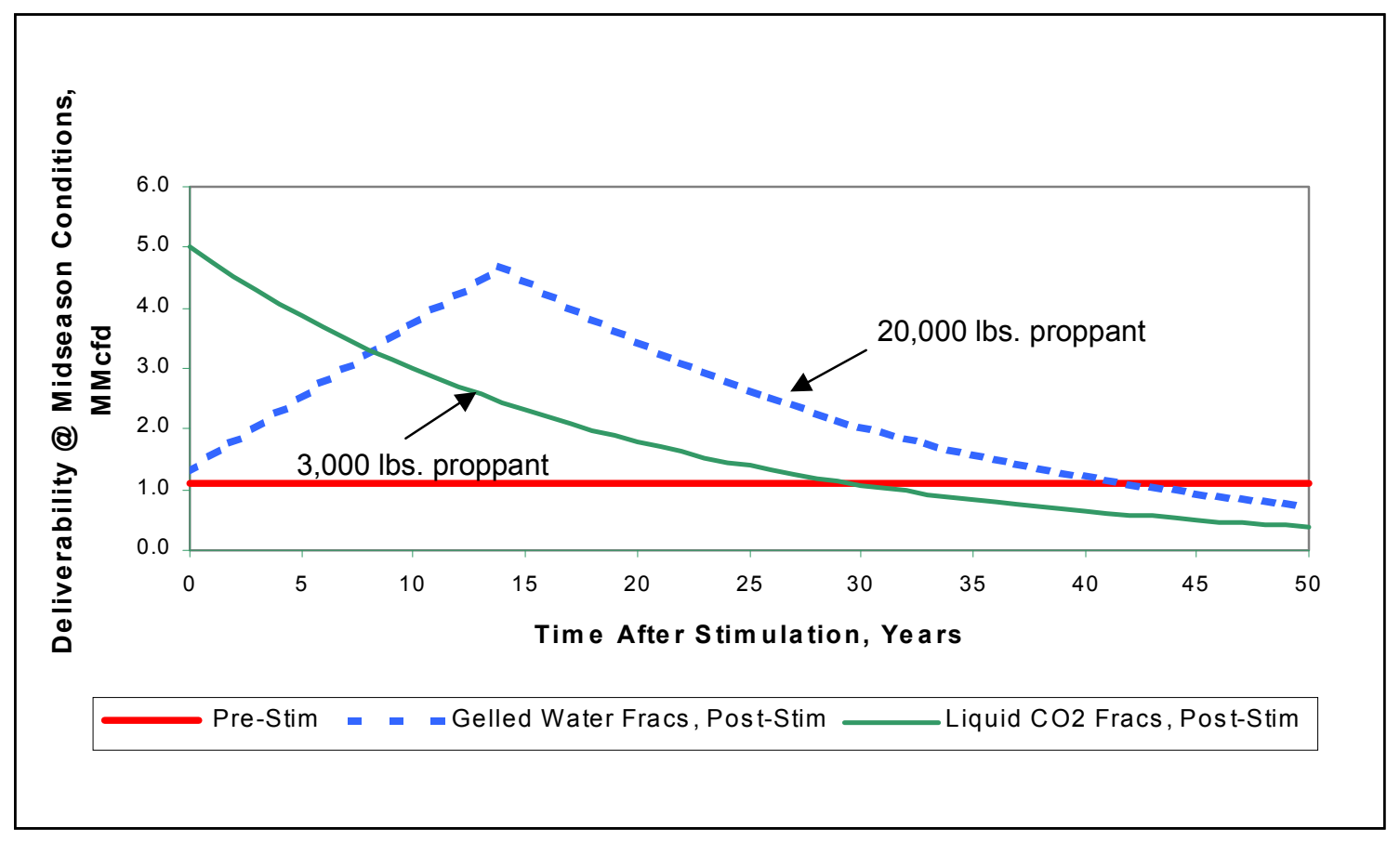

19 BMK99313.PPT 
Subsequent workovers were expected for cleaning out accumulated proppant from the wellbores with an (assumed) frequency of once every seven years for the gelled-water treatments; no cleanouts were assumed for the liquid $\mathrm{CO}_{2}$-treatments (the gelled-water treatments used over 10 times more proppant than the liquid $\mathrm{CO}_{2}$-stimulated wells). Finally, the standard deviations for each parameter were assumed using the same procedure as for the first example (i.e., $25 \%$ of the mean value).

The results of the cost/benefit analysis are shown in Figure 4-7. The average cost of deliverability maintenance is $\$ 0.98 / \mathrm{Mcfd} /$ year for the liquid $\mathrm{CO}_{2}$ with proppant treatments, and $\$ 0.50 / \mathrm{Mcfd} /$ year for the gelled-water hydraulic fracture treatments. In contrast, if only immediate deliverability response and costs were considered, one would deduce that the liquid $\mathrm{CO}_{2}$ treatments were more cost effective, providing added deliverability at a cost of $\$ 11.43 / \mathrm{Mcfd}$ as compared to $\$ 64.24 / \mathrm{Mcfd}$ for the gelled-water with proppant treatments.

These results, while believed correct in this instance, should be considered further with respect to the potential utility of liquid $\mathrm{CO}_{2}$ with proppant fracturing to gas storage wells. In this case a superior peak rate was achieved with the liquid $\mathrm{CO}_{2}$ treatment despite a much smaller proppant volume being placed. If, however, a larger proppant volume (and hence hydraulic fracture properties) could be created with the liquid $\mathrm{CO}_{2}$ fluid, then a deliverability profile as shown in Figure 4-8 would be expected (i.e., the peak deliverability for the gelled-water treatment should be slightly below that for the liquid $\mathrm{CO} 2$ decline rate due to imperfect fracture fluid cleanup). Keeping all other parameters constant (but adding proppant and workover costs for the liquid $\mathrm{CO}_{2}$ treatments) provides a cost of deliverability maintenance using the liquid $\mathrm{CO}_{2}$ of $\$ 0.36 / \mathrm{Mcfd} /$ year, compared to $\$ 0.50 / \mathrm{Mcfd} /$ year for the gelled-water treatments. Further, since the deliverability enhancement gained with the liquid $\mathrm{CO}_{2}$ treatments is realized earlier, there is a (currently unquantified) benefit in terms of the time-value of deliverability. Hence the utility of fracturing with liquid $\mathrm{CO}_{2}$ and proppant is believed to hold merit for gas storage deliverability enhancement, albeit limited to those environments where "large" proppant volumes can be placed.

Figure 4-2: Cost/Benefit Analysis Results, Galbraith Field

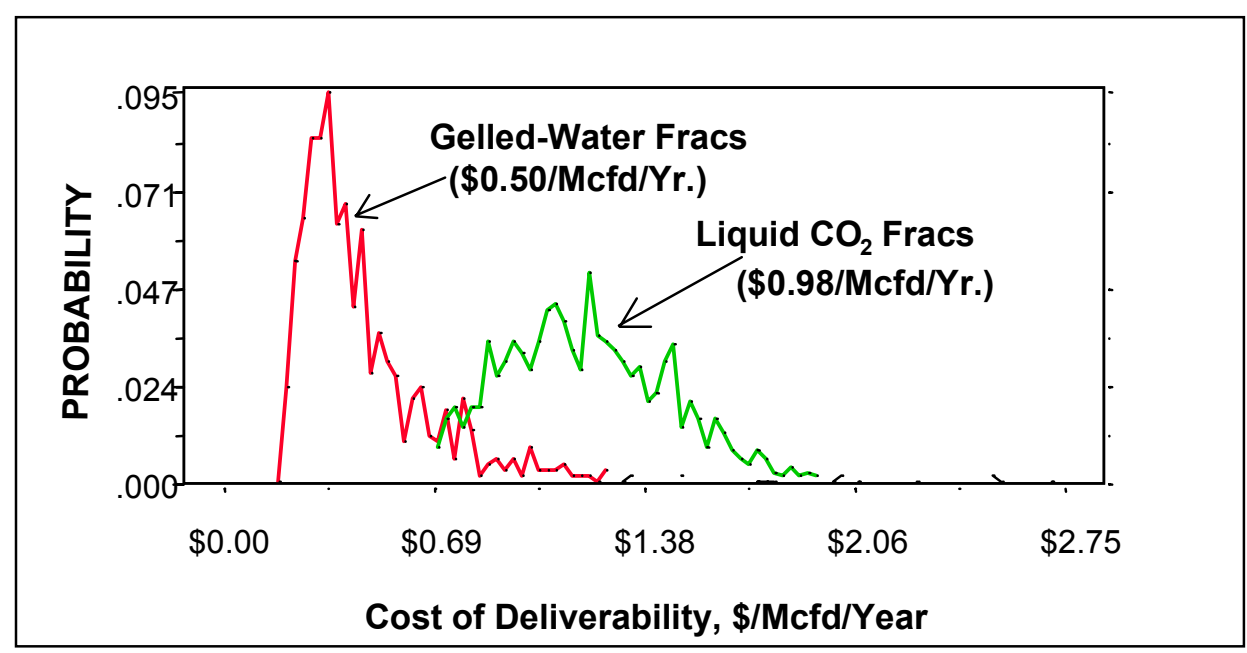

20 BMK99313.PPT 


\section{Figure 4-3: Deliverability Forecasts with Idealized Conditions, Galbraith Field}

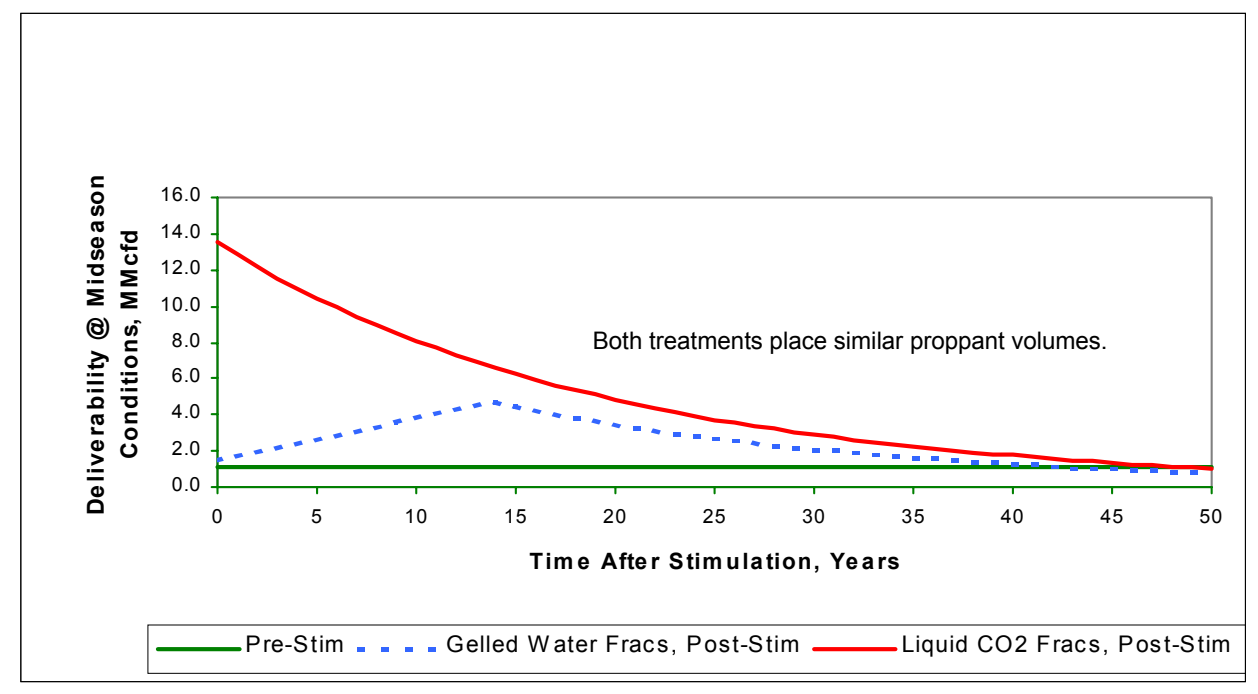

23 BMK99313.PPT

\subsubsection{Economic Assessment of a Storage Facility Upgrade}

The third and final example presents an approach to evaluate the economic attractiveness of upgrading an existing, baseload facility to shorter-term, higher-value service. As suggested earlier, the concept behind this approach is straightforward; determine the deliverability improvement needed to provide a selected shorter-term service, estimate the cost of achieving that, and perform a standard NPV analysis on the incremental revenue expected to be generated. This analysis, while relatively simple, has only recently become relevant due to the increased demand for shorter-term, higher deliverability services from storage providers.

This example is structured such that a capital budget for deliverability enhancement program is developed for each class of service that one may want to provide, and that will yield an attractive return on investment. It should again be remembered however that the capital expenditures would not only include stimulation treatments for existing wells, but also potentially new wells, and upgrades to gas gathering, treatment and compression facilities as well. To perform this example, the relationships presented in Table 4-3 are used; it is also assumed that an evaluation period of 5 years is appropriate, as is a discount rate of $12 \%$ (which may or may not be the weighted average cost of capital for storage companies).

The single-cycle annual service values indicated in Table 4-3 for 135 to 90-day services are typical for established Upper Midwestern and Appalachian service offerings. This includes ratable injections over the summer and ratcheted withdrawals over a 150-day winter withdrawal window. The upgraded services (60, 45 and 30-day service) are assumed to offer enhanced injections as well as withdrawals affording true multi-cycling capabilities. 
These services have not been thoroughly tested in the marketplace and represent only an estimate of market clearing prices. Clearly, location premiums could significantly uplift the single annual cycle rate available for such services.

Table 4-1: Storage Asset Upgrading Example, Input Parameters

\begin{tabular}{|rcccc|}
\hline $\begin{array}{r}\text { Term of } \\
\text { Service }\end{array}$ & $\begin{array}{c}\text { Deliverability } \\
\text { Needed* } \\
\text { (MMcfd) }\end{array}$ & $\begin{array}{c}\text { No. Cycles } \\
\text { per Year }\end{array}$ & $\begin{array}{c}\text { Cost of } \\
\text { Storage } \\
(\$ / M c f)\end{array}$ & $\begin{array}{c}\text { Annual } \\
\text { Incremental } \\
\text { Revenue } \\
\text { Potential }\end{array}$ \\
\hline 135-day & 74 & 1 & 0.38 & N/A \\
110-day & 91 & 1 & 0.45 & $\$ 0.7 \mathrm{MM}$ \\
90-day & 111 & 1 & 0.53 & $\$ 1.5 \mathrm{MM}$ \\
60-day & 167 & $1-11 / 2$ & 0.70 & $\$ 3.2 \mathrm{MM}$ \\
45-day & 222 & $2-21 / 2$ & 0.85 & $\$ 4.7 \mathrm{MM}$ \\
30-day & 333 & $3-31 / 2$ & 1.20 & $\$ 8.2 \mathrm{MM}$ \\
& *10 bcf Working Gas Capacity & & & \\
\hline
\end{tabular}

The results of this example analysis are presented in Figure 4-9. To clarify, this example investigates the potential to upgrade an existing, $10 \mathrm{Bcf}$ working gas capacity field providing 135-day baseload service to various levels of shorter-term service; the breakeven capital costs have been estimated based on the incremental revenue generation potential for each level of shorter-term service. Figure 4-9 illustrates that, to be economic in delivering 90-day service from this facility, it must be achieved at a capital cost of no more than $\$ 5.4$ million (\$146/Mcfd). Alternatively, 30-day service would be economical to provide at a capital cost of $\$ 29.6$ million or less $(\$ 114 / \mathrm{Mcfd})$. Based on discussions with operators, these capital costs are not unreasonable for the deliverability improvements sought, and imply that some existing, baseload gas storage fields may hold untapped profit potential that could be captured if they were to be upgraded to shorter-term, higher-value service. 
Figure 4-1: Breakeven Capital Budget to Upgrade a 10 Bcf, 135-day Baseload Facility to Shorter-Term Service

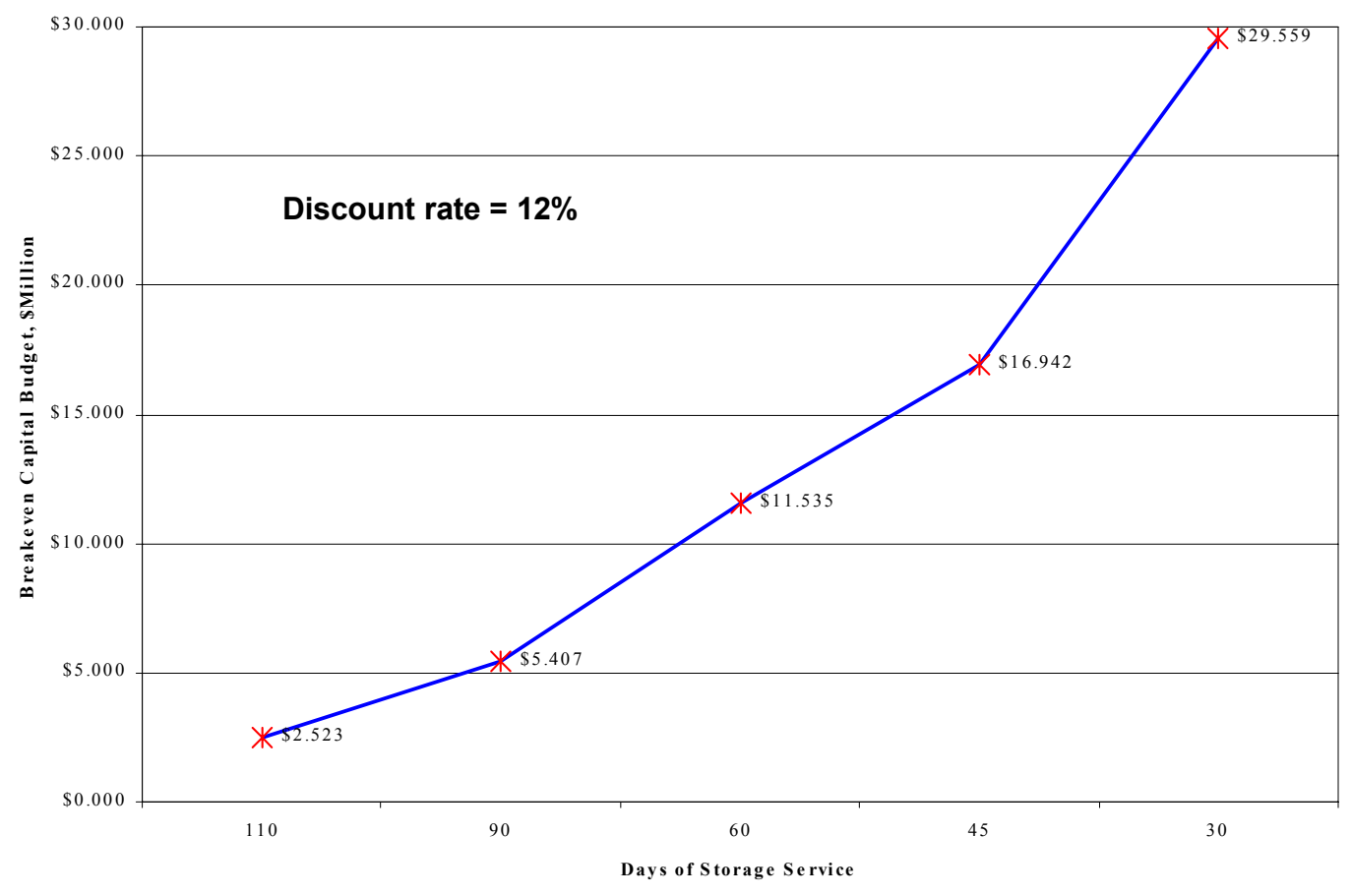

\subsection{Results from Test Sites}

Having presented the general approaches developed for economic evaluation, the field results from this project were analyzed. Specifically, cost/benefit analyses were performed for each site comparing the "new and novel" fracture stimulation technology with the conventional "benchmark" treatment appropriate for each field. The results of these analyses are presented in Table 4-4.

These results suggest that TSO fracturing provided a more cost effective solution to deliverability maintenance at every site where it was tested, and over conventional techniques such as wellbore cleanouts, reperforating, acidizing and even conventional and advanced (high proppant concentration) hydraulic fracturing. Hence, this technique should be seriously considered by gas storage operators where it can be safely applied (i.e., where some fracture height growth can be tolerated).

The benefits of liquid $\mathrm{CO}_{2}$ with proppant fracturing were not as conclusive, but are believed considerable in the appropriate environments. The pulse fracturing methods did not provide more cost-effective deliverability enhancement (except at Donegal; however TSO fracturing was significantly more effective than the EOB treatments). 
Table 4-1: Cost/Benefit Analysis Results for Each Test Site

\begin{tabular}{|c|c|c|c|c|}
\hline \multirow[t]{2}{*}{ Test Site } & \multirow{2}{*}{$\begin{array}{c}\text { New and } \\
\text { Novel } \\
\text { Technology }\end{array}$} & \multirow[t]{2}{*}{ Benchmark Method } & \multicolumn{2}{|c|}{$\begin{array}{l}\text { Cost of Deliverability Maintenance } \\
\text { (\$/Mcfd/Yr) }\end{array}$} \\
\hline & & & New and Novel & Benchmark \\
\hline Huntsman & TSO & Coiled Tubing Cleanout & $\$ 0.08$ & $\$ 0.77$ \\
\hline $\begin{array}{l}\text { Stark-Summit/ } \\
\text { Chippewa }\end{array}$ & TSO & $\begin{array}{l}\text { Advanced hydraulic } \\
\text { fracturing }\end{array}$ & $\$ 0.05$ & $\$ 0.08$ \\
\hline Overisel & TSO & Acidizing & $\$ 0.27$ & $\$ 0.47$ \\
\hline Donegal & TSO & Reperforating & $\$ 0.79$ & $\$ 37.71$ \\
\hline Cooks Mills & TSO & Reperforating & $\$ 0.09$ & No improvement \\
\hline Galbraith & Liquid $\mathrm{CO}_{2}$ & $\begin{array}{l}\text { Conventional hydraulic } \\
\text { fracturing }\end{array}$ & $\begin{array}{l}\$ 0.98 \text { (Actual) } \\
\$ 0.36 \text { (successful } \\
\text { efforts) }\end{array}$ & $\$ 0.50$ \\
\hline $\begin{array}{l}\text { Stark-Summit/ } \\
\text { Chippewa }\end{array}$ & Liquid $\mathrm{CO}_{2}$ & $\begin{array}{l}\text { Advanced hydraulic } \\
\text { fracturing }\end{array}$ & $\begin{array}{l}\text { No improvement } \\
\text { observed in test wells }\end{array}$ & $\$ 0.08$ \\
\hline Donegal & EOB & Reperforating & $\$ 4.28$ & $\$ 37.71$ \\
\hline Oakford & EOB & $\begin{array}{l}\text { Coiled tubing cleanout, } \\
\text { xylene wash }\end{array}$ & $\begin{array}{l}\text { Not operationally } \\
\text { successful }\end{array}$ & $\$ 0.12$ \\
\hline Cooks Mills & EOB & Reperforating & $\begin{array}{l}\text { Not operationally } \\
\text { successful }\end{array}$ & No improvement \\
\hline Six Lakes & Propellant & $\begin{array}{l}\text { Coiled tubing } \\
\text { wash,reperforating }\end{array}$ & $\$ 2.03$ & $\begin{array}{l}\text { No improvement } \\
\text { observed in control } \\
\text { well }\end{array}$ \\
\hline
\end{tabular}

KAO99330.PPT (19) 


\subsection{Guidelines for the Practical Application of New and Novel Fracture Stimulation Technologies}

Through the course of this project, certain general guidelines have been developed for the selection and application of the various new and novel fracture stimulation technologies investigated for gas storage wells. While neither rigorous nor comprehensive, these guidelines, which have proven useful in this project, could also be of interest and value to operators who might be considering the utility of some of the techniques studied.

\subsection{Fracturing as a Stimulation Option}

First and foremost is whether fracturing should even be considered as a stimulation option for a given field. The historical concern with fracturing, namely fracture height growth, has largely been reduced in this project as a reason to categorically eliminate the fracture stimulation option for gas storage wells. Primarily synonymous with hydraulic fracturing, this concern was directly addressed at the Huntsman test site, where hydraulic fracturing was successfully demonstrated as a safe and highly effective deliverability enhancement method in a setting where fracture height growth was of critical importance. In other areas, such as the Stark-Summit and Overisel fields, fracture height was not a significant concern and hydraulic fracturing was successfully implemented. Beyond this approach, however, pulse fracturing methods may ultimately provide additional low-risk options for fracturing where fracture height growth is a concern. With the fracture height growth concerns somewhat (but not entirely) alleviated, the most compelling reason to consider fracture stimulation is for the deliverability enhancement potential, which is much greater than can be achieved with traditional wellbore cleanout or matrix-stimulation methods. As such, if current deliverability enhancement techniques do not provide significant well stimulation (i.e., negative skins), then fracturing should be considered as a stimulation option. Furthermore, even in cases where non-fracturing techniques appear to be successful, fracturing may prove to be a more economical means of deliverability enhancement in terms of life-cycle benefits gained per investment dollar. Careful pressure transient analysis, as demonstrated in this project, can provide the information needed to make this assessment.

\subsection{Selection of Candidate Wells}

One important finding from this project was that the methods used to select stimulation candidates are frequently inadequate and can even be misleading. Commonly, short-term single-point deliverability tests are used for candidate selection, either by selecting a well with a lesser indicated deliverability than the offset wells, or by selecting a well with a historical trend of implied declining deliverability. However, as aptly demonstrated at the Stark-Summit test site, the utility of this short-term single-point data may not be appropriate with respect to the selection of stimulation candidates, and does not provide the information needed to better evaluate the stimulation needs of a particular well. For example, at the Stark-Summit test site, despite indications of declining deliverabilities, most wells appeared to possess negative true skins, and any positive skins were primarily a 
result of non-Darcy flow effects. This was identified through a multi-point deliverability and pressure transient testing procedure, and indicated that highly conductive fractures were required for effective stimulation. Therefore, TSO fracturing was performed. Hence some level of sophisticated testing is warranted to improve both the candidate selection and treatment selection process.

\subsection{Selection of Stimulation Technology}

Through the course of this project, a wide variety of gas storage fields were reviewed and assessments made as to which, if any, of the fracture stimulation technologies had application. Final technology selection (and candidate selection) for each test site was usually made only after the pre-stimulation deliverability and pressure transient testing was complete. The experiences from the tests have provided a few guidelines with respect to selecting the appropriate technology for a site with certain characteristics.

\subsubsection{Tip-Screenout Fracturing}

While not a new revelation, it has been concluded that in high permeability wells (e.g., hundreds of millidarcies) TSO fracturing seems particularly well suited and should be an immediate consideration for two reasons. Firstly, on a theoretical basis ultra-high fracture conductivities are required for effective well stimulation in high permeability wells, to a degree that can only reasonably be created via TSO fracturing. Secondly, and equally important as the experience at both the Huntsman and the Stark-Summit sites indicated, is the need to mitigate non-Darcy turbulent flow restrictions with a high conductivity fracture. This problem arises only in moderate to high permeability environments where formation flow capacities are very high. The mitigation of non-Darcy skin effects can, for gas storage wells, be used as a design criteria in and of itself where the problem exists. While these conditions represent valid reasons for utilizing TSO fracturing, there is at least one equally valid reason not to, namely fracture height growth. Despite the relatively small treatment volumes involved, based on the results from this project some fracture height growth is still likely to occur. Certain minimum treatment volumes are required to establish the fracture length desired, and the width to accept proppant, before a tip-screenout can be implemented. If the bounding layers are so thin so as only a few tens of feet of fracture height growth are unacceptable, a likely occurrence within the minimum volume requirements, then TSO fracturing may not be a good technique. Note that this was the very consideration at the Huntsman site, and a go/no-go decision point was incorporated into the design such that if the tip-screenout did not occur by a certain point, the treatment would be terminated to avoid further height growth.

\subsubsection{Liquid $\mathrm{CO}_{2}$ with Proppant Fracturing}

There are a number of important considerations for what is believed to be the proper application of liquid $\mathrm{CO}_{2}$ with proppant fracturing. First and foremost is the susceptibility of the formation in question to be adversely impacted by the introduction of liquids. As described in an earlier section of this report, this was the primary reason for considering the technique. However, as also discovered in this project there are also some other criteria that should be considered. First, if it is assumed that liquid $\mathrm{CO}_{2}$ inherently possesses both a low 
fluid viscosity and efficiency, then pump rate becomes the primary control over proppant transport and fluid loss, and must be maximized. As experienced at the Galbraith test site, a combination of both high treating pressures and high permeability created a situation where the pump rate could not be maintained at a sufficient rate to fully execute the treatments. Therefore an ability to pump at the desired rate, practically 50 to 60 barrels per minute, and a permeability "not too high" such that fluid leakoff becomes unmanageable with injection rate, should be utilized as a selection criteria for liquid $\mathrm{CO}_{2}$ with proppant fracturing.

This last criteria, that the permeability not be "too high," can be further developed from another angle. Due to the low fracturing efficiency of the liquid $\mathrm{CO}_{2}$, neither long nor highly conductive fractures are likely to be created with the technique. Hence their application in high permeability settings (where high fracture conductivities are required) and in ultra low permeability settings such as tight sands (where long fracture lengths are required) is questionable. Since gas storage fields generally have higher permeabilities than production fields, ultra low permeability environments that require massive hydraulic fracturing are rare. Hence, the application of liquid $\mathrm{CO}_{2}$ with proppant fracturing is in the lower permeability end of the spectrum for gas storage wells. This also makes intuitive sense since, very generally speaking, it is the lower permeability reservoirs that exhibit the greatest sensitivity to fluid damage due to capillary pressure and relative permeability effects.

\subsubsection{Extreme Overbalance Fracturing}

The experiences with this fracturing technique were under two circumstances; where hydraulic fracturing was proven to be of limited effectiveness due to a unique stress regime (Donegal), and where there was a desire to minimize fluid contact (Oakford). In both cases, several clear trends emerged. First, the apparent effectiveness of the treatments, as measured by the observation of expected events such as a clear breakdown as well as from EOB treatment modeling studies, was highly sensitive to the design and implementation of the treatment. More specifically, it became evident that effective treatments required a combination of tubulars configuration, fluid types, volumes and column heights, and working pressures, that were sometimes difficult to achieve within the practical limits of a given wellbore. Even if these conditions were met, the creation of a radial fracture pattern (as opposed to a short bi-winged frac) was unlikely. Secondly, to properly configure a well for an effective treatment, particularly if avoiding a well-kill was desired, is costly. Finally, even the small fluid volumes involved seemed to induce a noticeable level of fluid damage. The end result of these findings is that the EOB technique may not be a cost-effective fracturing approach.

The question becomes under what conditions could the EOB technique become a favorable option. Important to this discussion is the relative application of the HEGF technique. The HEGF method can cost-effectively provide the radial fracture pattern desired in an operationally simplistic manner. Why then would one select an EOB treatment over an HEGF? The reason is that, with the more recent developments in EOB technology, it may be possible to more cost-effectively create an even more favorable fracture pattern than with HEGF. Specifically, EOB treatments can now incorporate small volumes of proppants to retain some fracture conductivity after the treatment whereas HEGF treatments 
cannot. Further, small volumes of propellants can now be used with EOB treatments to boost the downhole pressures created and hence the effectiveness of the final fracture pattern. With these two improvements, it is believed that the EOB approach can be a viable stimulation approach for gas storage wells. Again, as alluded to earlier, the practical domain of application would include those settings where almost no fracture height growth can be allowed.

\subsubsection{High-Energy Gas Fracturing}

While the HEGF method did not provide the deliverability enhancement results desired at the Six Lakes site, there appear to be logical reasons for this. Although poststimulation video logging clearly showed the creation of multiple fractures, the techniques may not be an effective approach where salt deposition was the damage mechanism. Also, the storage horizon imbibed small volumes of $10.0 \mathrm{ppg}$ brine during treatment execution, which may have had negative consequences for deliverability. The obvious question is in what environments might HEGF be appropriate. This might first be answered by saying it could be a consideration where fracture height growth is a concern and hydraulic fracturing cannot be performed. Secondly, since it is operationally more simple and less costly than EOB fracturing, and potentially more effective (due to the higher downhole pressures that can be achieved), it should be considered any time EOB fracturing is being contemplated.

Perhaps most importantly is under what formation damage scenario would it be most effective. Obviously, due to the short fracture lengths achieved, the damage must be near the wellbore. Hence, it could be considered as an alternative to matrix or other near-well treatments such as acidizing or reperforating. However, since the created fractures are unpropped, they are susceptible to rapid replugging (e.g., salt deposition). Therefore, the bypassing of one-time, near-well damage, such as mud damage left behind from a workover, may be the best application of an HEGF treatment. 


\subsection{Technology Transfer and Fracturing Activity Surveys}

\subsection{Technology Transfer}

As important as meeting the technical performance goals and objectives of the project was the transference of those findings to the industry at large. There were two primary methods by which this was accomplished, first via direct working partnerships with industry in performing the field tests, and secondly through the publication of various written materials that described the project and its results. In the first case, a conscientious effort was made to work with those operators that control a large fraction of the nation's storage facilities. In this manner, the technologies jointly developed with them, by virtue of the close working arrangement, were effectively transferred.

To assist in this process, an analysis of the gas storage assets of the U.S. was performed on a company by company basis. Figures 6-1 and 6-2 illustrate the results; of the 85 storage organizations (consolidated) on record as of $1993^{10}$, the 17 largest (top 20\%) controlled almost $70 \%$ of the total working gas and almost $80 \%$ of the total number of gas storage wells. Cross-referencing the two populations provided a list of ten companies that were in the top $20 \%$ of both working gas and total wells, and a second list of 14 additional companies that appeared on at least one list. Those two lists are provided in Tables 6-1 and 6-2. As can be seen by these two tables, six of the eight companies that were cooperative research partners in this project appear on the first list, with the remaining two on the second list. Hence the project has directly involved and impacted a large proportion of the U.S. gas storage community.

The second method of technology transfer employed for the project, with the objective of reaching a larger audience, was via the publication of various materials that describe the project and its results. These materials include technical reports and articles that have been presented and published in various forms. The project reports, including individual technology reports, are being distributed in CD format. A list of selected project publications is presented in Table 6-3.

\subsection{Fracturing Activity Surveys}

To gauge the impact this project (at least in part) may have had on the level of fracturing activity in the gas storage community, surveys were performed at the beginning (1994) and end (1999) of the project. In 1994, of the major companies represented in Tables 6-1 and 6-2, only four were actively implementing or experimenting with fracturing for deliverability enhancement. In 1999, the number of companies increased to eight, suggesting heightened interest, albeit cautious, in the application of "New and Novel Fracture Stimulation Technologies for the Revitalization of Existing Gas Storage Wells." 
Figure 6-1: Distribution of Working Gas

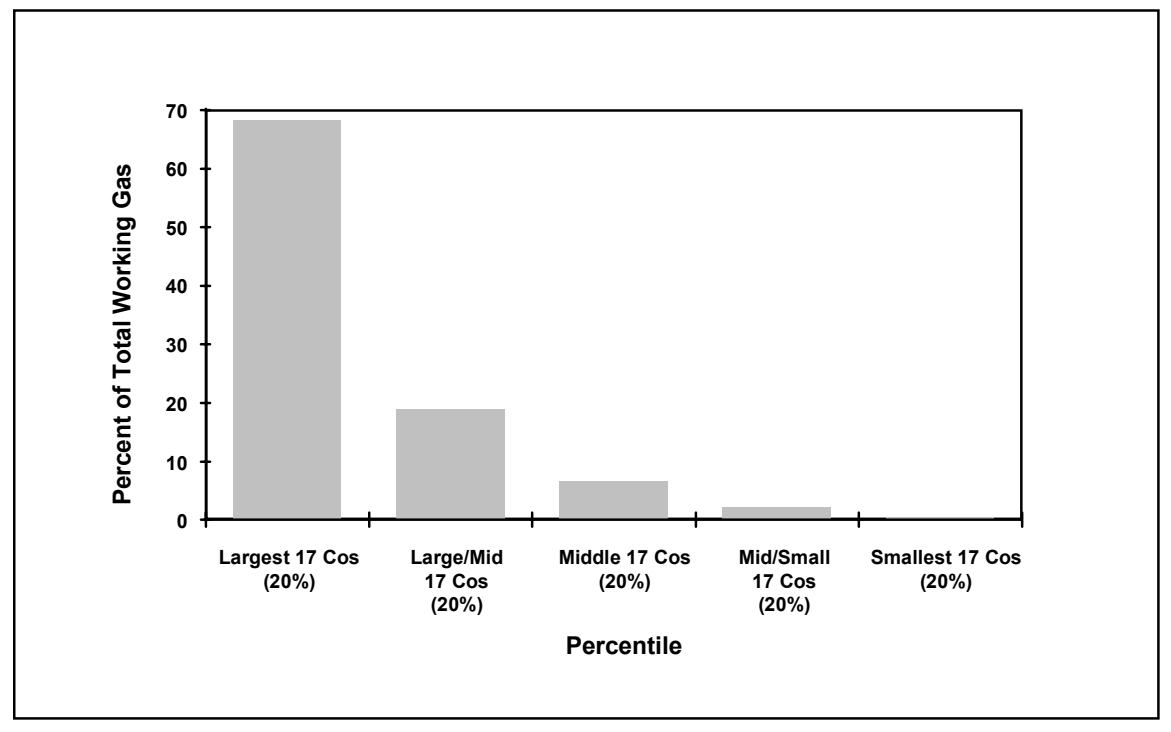

JAF00470.PPT

Figure 6-2: Distribution of Total Wells

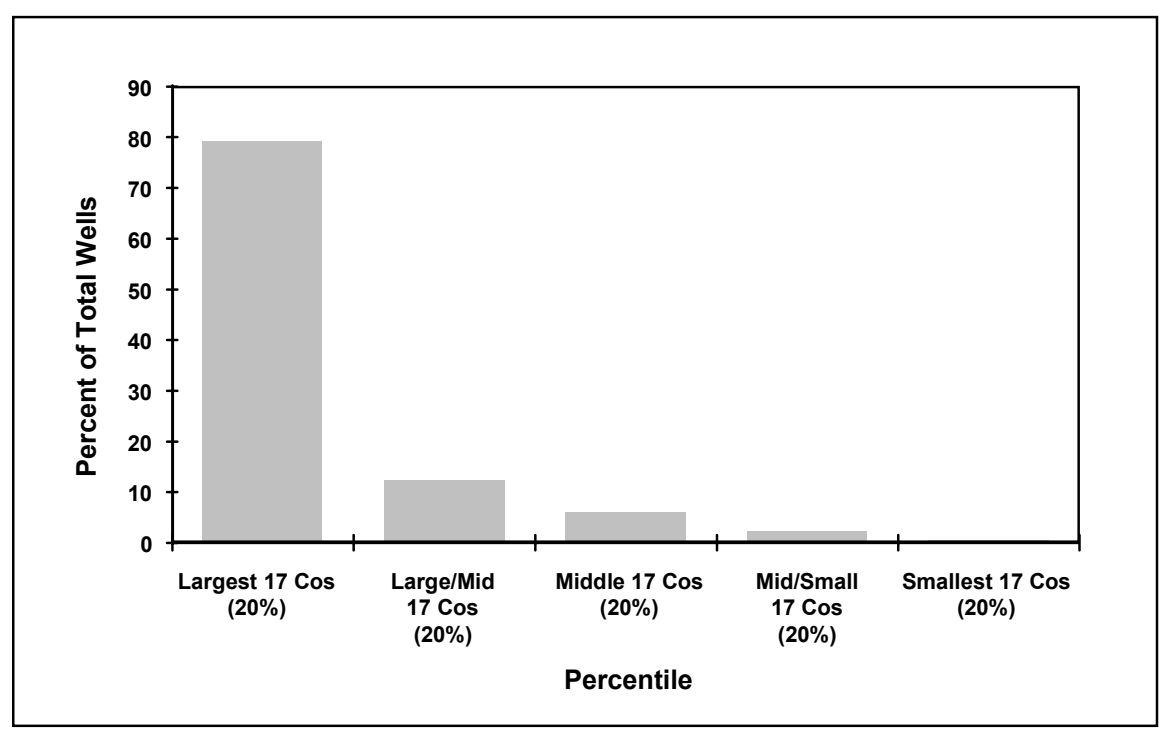

JAF00470.PPT 
Table 6-1: Storage Operators that Possess Assets in the Top 20\% of Both Working Gas and Total Wells

\begin{tabular}{|l|l|}
\hline ANR Pipeline Co. & National Fuel Gas Supply Co. \\
\hline CNG Transmission Corp. & Natural Gas P/L Co. of America \\
\hline Columbia Gas Trans. Corp. & Northern Illinois Gas Co. \\
\hline Consumers Energy Co. & Southern California Gas Co. \\
\hline Michigan Consolidated Gas Co. & Texas Gas Transmission Corp. \\
\hline $\begin{array}{l}\text { NOTE: Ten companies appearing on both “top 20\%” lists represent 50\% of total working gas } \\
\text { and 60\% of total I/W wells. Shaded companies are cooperative research partners. }\end{array}$ \\
\hline
\end{tabular}

Table 6-2: Storage Operators that Possess Assets in the Top 20\% of Either Working Gas or Total Wells

\begin{tabular}{|l|l|}
\hline ANR Storage Co. & Louisville Gas \& Electric Co. \\
\hline East Ohio Gas Co. & Michigan Gas Storage Co. \\
\hline Equitrans & Pacific Gas \& Electric \\
\hline Illinois Power Co. & The Peoples Gas Light \& Coke Co. \\
\hline Indiana Gas Company, Inc. & Transcontinental Gas P/L Corp. \\
\hline KN Energy, Inc. & Williams Natural Gas Co. \\
\hline Lone Star Gas Co. & Williston Basin Interstate P/L Co. \\
\hline $\begin{array}{l}\text { NOTE: Fourteen additional companies appearing on at least one “top 20\%” list (but not both) } \\
\text { represent an additional 24\% of total working gas and 24\% of total I/W wells. Shaded } \\
\text { companies are cooperative research partners. }\end{array}$ \\
\hline
\end{tabular}


Table 6-3: Summary of Project Technical Articles, Reports and Presentations

\begin{tabular}{|c|c|c|}
\hline$\overline{\text { Venue }}$ & $\overline{\text { Date }}$ & Title \\
\hline Topical Report & April 1995 & $\begin{array}{l}\text { Application of New and Novel Fracture Stimulation Technologies to } \\
\text { Enhance the Deliverability of Gas Storage Wells }\end{array}$ \\
\hline $\begin{array}{l}\text { Natural Gas R\&D Contractor Review Meeting, } \\
\text { Baton Rouge }\end{array}$ & April 1995 & $\begin{array}{l}\text { Field Verification of New and Novel Fracture Stimulation Technologies } \\
\text { for the Revitalization of Existing Underground Gas Storage Wells; } \\
\text { Project Description and Status }\end{array}$ \\
\hline SPE Eastern Regional Conference, Columbus & October 1996 & $\begin{array}{l}\text { Liquid } \mathrm{CO}_{2} \text { and Tip-Screenout Fracturing as Techniques for } \\
\text { Restimulating Gas Storage Wells (SPE \#37343) }\end{array}$ \\
\hline US DOE Natural Gas Conference, Houston & March 1997 & Fracture Stimulation Field Demonstration Projects \\
\hline $\begin{array}{l}\text { SPE Technology Today Series, (Journal of } \\
\text { Petroleum Technology) }\end{array}$ & February 1998 & Fracture Stimulation Technology for Gas Storage Wells (SPE \#39417) \\
\hline SPE Eastern Regional Conference, Pittsburgh & November 1998 & $\begin{array}{l}\text { Liquid Carbon Dioxide Fracturing for Increasing Gas Storage } \\
\text { Deliverability (SPE \#51066) }\end{array}$ \\
\hline $\begin{array}{l}\text { International Gas Research Conference, San } \\
\text { Diego }\end{array}$ & November 1998 & $\begin{array}{l}\text { Enhancing the Deliverability of Gas Storage Wells via New and Novel } \\
\text { Fracture Stimulation Technologies }\end{array}$ \\
\hline $\begin{array}{l}\text { SPE Hydrocarbon Economics and Evaluation } \\
\text { Symposium, Dallas }\end{array}$ & March 1999 & $\begin{array}{l}\text { Evaluating the Economics of Gas Storage Well Deliverability } \\
\text { Enhancement (SPE \#52962) }\end{array}$ \\
\hline $\begin{array}{l}\text { SPE Annual Technical Conference and } \\
\text { Exhibition }\end{array}$ & October 1999 & $\begin{array}{l}\text { Deliverability Enhancement via Advanced Fracturing Technology in } \\
\text { Gas Storage Wells (SPE \#56728) }\end{array}$ \\
\hline $\begin{array}{l}\text { Gas Storage Deliverability Series (Oil and Gas } \\
\text { Journal) }\end{array}$ & $\begin{array}{l}\text { November/December } \\
1999\end{array}$ & $\begin{array}{l}\text { Part 1: Novel Fracturing Enhances Deliverability } \\
\text { Part 2: Nonaqueous Fracture Fluids Clean Up Faster } \\
\text { Part 3: Pulse Fracturing Tests Show Mixed Results } \\
\text { Part 4: New Economics Approach Evaluates Gas Storage } \\
\text { Deliverability Enhancement }\end{array}$ \\
\hline
\end{tabular}




\subsection{Conclusions and Recommendations}

Based on the results derived from the project, the following conclusions have been drawn:

- $\quad$ New and novel fracture stimulation technologies can provide attractive deliverability enhancement results while at the same time addressing the special requirements of gas storage wells (e.g., fracture height growth, high permeability formations, fluid sensitivity). Even though fracture stimulation was very successful at several test sites and led to significant improvements in deliverability, not every stimulation treatment was effective. The most consistently effective stimulation technology was tip-screenout hydraulic fracturing. While TSO fracturing was a huge success at the Huntsman Storage Field and while at least one well at every test site had an increase in deliverability, the overall improvements in deliverability at Stark-Summit, Overisel and Donegal Storage Fields were small compared to the expectations for fracture stimulation (real or not). Liquid carbon dioxide with proppant stimulation was very effective at the Galbraith test site but very little improvement was seen at the Chippewa test site where there was still evidence of linear flow and slightly negative skin factors from previous fracture stimulations.

- $\quad$ The liquid carbon dioxide with proppant stimulations at the Galbraith Storage Field led to the largest increases in well deliverability, almost seven fold for two of three test wells. Those sites demonstrating extreme overbalanced stimulations experienced a reduction in post-stimulation well deliverability; high-energy gas fracturing was ineffective.

- Gas storage formations appear to be highly sensitive to even small amounts of liquids, which appear to temporarily reduce permeability to gas. Non-aqueous stimulation fluids, such as liquid $\mathrm{CO}_{2}$, seem to provide more immediate stimulation benefits without the prolonged fluid cleanup time typical of aqueous methods.

- Lack of satisfactory understanding of certain stimulation processes, most notably liquid $\mathrm{CO}_{2}$ fracturing and extreme overbalance fracturing, is likely to lead to inconsistent results with these methods in the short run. However, this should not be considered as a problem with the stimulation concept, but rather viewed as a technology need to be met.

- Methods commonly used by industry today to measure and monitor well deliverabilities can frequently be misleading and/or incorrect. More advanced (yet cost-effective) methods are needed such that storage operators can better understand well performance and the impact of various well intervention activities on deliverability and for candidate selection.

- $\quad$ Being able to distinguish between permeability, true skin and non-Darcy skin is critical for candidate selection. It is equally important for treatment selection, as the 
stimulation requirements for high/low permeability wells and the type of damage (true or non-Darcy) can each be very different.

- A new approach to analyzing the economic benefits of various stimulation technologies is required such that gas storage operators can select the most costeffective deliverability enhancement technique for a given situation.

Significant accomplishments with regard to the research objectives have been achieved, as summarized below:

- The potential application of the various new and novel fracture stimulation technologies to gas storage wells has been demonstrated, and guidelines developed for their selection and design.

- The first liquid $\mathrm{CO}_{2}$ with proppant treatments in gas storage wells were pumped, with deliverability improvements of up to seven-fold. Deliverability improvements achieved for tip-screenouts were as high as 50 MMcfd at mid-season operating conditions.

- A lack of analytical design tools has been identified for some of the fracture stimulation technologies being investigated. In response, a first-of-a-kind simulator has been developed to model the extreme overbalance fracturing process, and for the first time in the gas storage industry downhole pressure records have been collected for analysis. In addition, the first publicly available bottomhole pressure records for a liquid $\mathrm{CO}_{2}$ with proppant treatment were collected that answered long-standing technical questions about this process.

- A comprehensive dataset of multi-point deliverability and pressure transient tests, a rarity in the gas storage industry, has been assembled. This has provided a unique insight into the impact of stimulation on gas storage well deliverability, particularly with respect to the elimination of important non-Darcy flow effects, deliverability profiles, and how these change over time.

- $\quad$ Two new methods for evaluating the economics of deliverability enhancement in gas storage wells have been developed. The first method can be used to estimate the cost of deliverability maintenance, accounting for the variable deliverability profile of a well. The second can be used to evaluate the economic value added of a storage asset by upgrading it to a shorter term, higher value service (peaking vs. baseload).

The outcomes from this project represent a significant step forward in gas storage well deliverability enhancement technology. Further R\&D is still required, however, in several of the key areas outlined above. 


\section{References}

1. Order 636, final rule, Docket RM91-11-000, FERC, Washington, DC (8 April 1992).

2. "State-of-Technology Assessment and Evaluation of Gas Storage Well Productivity Enhancement Techniques", Topical Report, Contract No: GRI-93/0001, GRI, Chicago, Illinois, (December 1993).

3. Yeager, V.J., Blauch, M.E., Behenna, F.R., "Investigation of Storage Well Damage Mechanisms,” Final Report, Contract No. GRI-98/0197, GasResearch Institute, Chicago, Illinois (August 1997).

4. "Application of New and Novel Fracture Stimulation Technologies to Enhance the Deliverability of Gas Storage Wells," Topical Report, Contract No.

DE-AC21-94MC31112, U.S. Department of Energy, Washington, DC (April, 1995).

5. "Survey of Underground Storage of Natural Gas in the United States and Canada: 1998," Catalog No. XU9901, AGA Underground Storage Committee, American Gas Association, Washington, D.C. (January 1999).

6. "New and Novel Fracture Stimulation Technologies for the Revitalization of Existing Gas Storage Wells: Tip-Screenout Fracturing Topical Report," Technology Report, Contract No. DE-AC21-94MC31112, U.S. Department of Energy, Washington, DC (March 31,2000).

7. "New and Novel Fracture Stimulation Technologies for the Revitalization of Existing Gas Storage Wells: Liquid Carbon Dioxide with Proppant Fracturing Topical Report," Technology Report, Contract No. DE-AC21-94MC31112, U.S. Department of Energy, Washington, DC (March 31, 2000).

8. "New and Novel Fracture Stimulation Technologies for the Revitalization of Existing Gas Storage Wells: Extreme Overbalanced and High-Energy Gas Fracturing Topical Report," Technology Report, Contract No. DE-AC21-94MC31112, U.S. Department of Energy, Washington, DC (March 31, 2000).

9. Beckman, K.L., Determeyer, P.L., Mowrey, E.H., O’Connor, P.F., "Natural Gas Storage Utilization: Current Market Drivers and Probable Trends," U.S. DOE Natural gas Conference, Houston, Texas, March 24-27, 1997.

10. "Survey of Underground Gas Storage Facilities in the United States and Canada: 1993," Operating Section Report, Statistics Task Group, Underground Storage Committee, American Gas Association, Arlington, VA (1993) 